Multiphysical Effects on High-Speed Rotordynamics

Emre Dikmen 
The research described in this thesis has been carried out in the framework of the Design and Optimization work package of the cluster; Fundamentals, Modeling and Design of Microsystems of MicroNed. The financial support of MicroNed is greatly acknowledged.

Samenstelling van de promotiecommissie:

voorzitter en secretaris:

Prof. dr. F. Eising Universiteit Twente

promotor:

Prof. dr. ir. A. de Boer Universiteit Twente

assistent promotor:

Dr. ir. P.J.M. van der Hoogt Universiteit Twente

Dr. ir. R.G.K.M. Aarts Universiteit Twente

leden:

Prof. dr. ir. W. Desmet

Katholieke Universiteit Leuven

Prof. dr. ir. A. van Keulen

Technische Universiteit Delft

Prof. dr. ir. D. J. Schipper Universiteit Twente

Prof. dr. ir. R. Akkerman Universiteit Twente

ISBN 978-90-365-3121-4

DOI $10.3990 / 1.9789036531214$

1st printing December 2010

Keywords: Rotordynamics, Multiphysics, Modal Analysis, Micro Machinery

This thesis was prepared with $\mathrm{LT}_{\mathrm{E}} \mathrm{X}$ by the author and printed by Ipskamp Drukkers, Enschede, from an electronic document.

Copyright (c) 2010 by E.Dikmen, Enschede, The Netherlands

All rights reserved. No part of this publication may be reproduced, stored in a retrieval system, or transmitted in any form or by any means, electronic, mechanical, photocopying, recording or otherwise, without prior written permission of the copyright holder. 


\section{MULTIPHYSICAL EFFECTS ON HIGH-SPEED ROTORDYNAMICS}

\section{PROEFSCHRIFT}

ter verkrijging van

de graad van doctor aan de Universiteit Twente, op gezag van de rector magnificus,

prof.dr. H. Brinksma,

volgens besluit van het College voor Promoties

in het openbaar te verdedigen

op woensdag 22 december 2010 om 15.00 uur

door

Emre Dikmen

geboren op 4 september 1981

te Çankırı, Turkije 
Dit proefschrift is goedgekeurd door de promotor:

Prof. dr. ir. A. de Boer

en de assistent promotor:

Dr. ir. P.J.M. van der Hoogt

Dr. ir. R.G.K.M. Aarts 


\section{Summary}

A growing number of research projects focus on the development of rotating machinery on a small scale. These machines generally operate at high speeds and as a result multiphysical effects such as interaction with the surrounding air and thermal effects become significant for the dynamics. Therefore, the multiphysical effects should be modeled and coupled with the structural models in order to perform rotordynamic analysis accurately. This thesis describes modeling approaches for flow-induced forces in moderate flow confinements such as a casing and for temperature increase of fluid in the confinement. Furthermore, a method to couple the flow force model and thermal model with the structural model has been proposed. An experimental setup has been designed and constructed in order to verify the simulations with experimental data.

The gap ratio (air gap/rotor radius) in the moderate flow confinement is two orders of magnitude greater than the ones in small air gap geometries such as bearings and seals (0.1 to 0.001). Due to high rotation speeds, the inertia effects become significant as well as the viscous effects. A theoretical model for flow-induced forces in terms of added mass, damping and stiffness was available in the literature for turbulent flow. This model is extended for laminar flow and transition by using the suitable empirical and analytical friction coefficients to model the shear stress.

Then a method to implement the flow forces to the rotor finite element model as a spring damper and added mass at each node is proposed. Finite element modeling of the rotor is based on Timoshenko beams (including the flexibility of the rotor shaft) and each element has four degrees of freedom at each node.

As the rotation speed increases, the heat loss due to air friction and the temperature increase in the air gap between rotor and stator become more significant. Consequently, the change of air properties due to temperature change in the air gap should be considered when calculating the flow-induced forces. Therefore, a thermal model is established in order to calculate the heat dissipation and as a result, the temperature increase of the air. In this model, the rotor, stator and the gap in between is modeled as lumped thermal networks. The required convective heat transfer coefficients and heat dissipation are calculated by empirical correlations. Afterwards, the new air gap temperature is used to calculate the flow-induced forces with updated air properties. In this way, thermal and fluid effects in medium gap confinements are coupled with the rotordynamic models and their effects on critical speeds and 
stability are investigated. An experimental setup has been designed to verify the developed models for multiphysical effects on a small scale. The design criteria have been determined such that the rotor size is large enough to make multiphysical effects measurable in the operation range. Flexible supports with changing stiffness are designed to examine the effect of support stiffness. Experiments are performed as spectrum measurements and modal analysis at different support stiffness with and without casing. The developed modeling approach is verified by experimental results.

Finally, a simple way to overcome experimentally and theoretically observed instability problems has been presented. Stationary damping is increased by mounting viscoelastic inserts on the support disk. The spectrum and modal analysis experiments are repeated for different viscoelastic materials and significant improvement has been observed.

In summary, a method has been developed to couple flow induced forces with structural FE model including the thermal effects. This method can be used for the rotordynamic analysis of high-speed mini rotating machinery with medium gap for both laminar and turbulent flow regimes. In addition, the usage of viscoelastic materials to avoid theoretically and experimentally observed instability is demonstrated. 


\section{Samenvatting}

Een groeiend aantal onderzoeksprojecten richt zich op de ontwikkeling van kleine roterende machines. Deze machines functioneren over het algemeen bij hoge snelheden met als gevolg dat multifysische effecten op het dynamisch gedrag, zoals de interactie met de omringende lucht en thermische effecten, significant worden. Om een accurate rotordynamische analyse uit te kunnen voeren, moeten deze effecten gemodelleerd worden en worden gekoppeld met de structurele rotormodelen. Dit proefschrift beschrijft modelmatige benaderingen voor de stromingsgeïnduceerde krachten in rotor-stator behuizingen en voor de temperatuurstijging van het medium in deze behuizingen. Verder wordt een methode voorgesteld om het stromingsmodel en het thermische model met het structurele model te koppelen. Er is een opstelling ontworpen en gebouwd om de resultaten van de simulaties met experimentele data te verifiëren.

De spleet verhouding (luchtspleet/rotorstraal) in de rotorbehuizingen is twee ordes van grootte hoger dan die van kleine luchtspleetgeometrieën, zoals van lagers en van afdichtingen $(0,1$ tot 0,001$)$. Vanwege de hoge rotatiesnelheden worden de traagheidseffecten significant, evenals de viskeuze effecten. In de literatuur is een theoretisch model beschikbaar voor de krachten op de rotor ten gevolge van de turbulente stroming, beschreven in termen van toegevoegde massa, demping en stijfheid. Dit model is uitgebreid voor laminaire stroming. Bij de overgang tussen beide gebieden worden geschikte empirische en analytische wrijvingscoëfficiënten gebruikt om de schuifspanning te modelleren.

Vervolgens is een methode voorgesteld om de stromingskrachten als een massa-veerdemper systeem op elk knooppunt in het eindige element model van de rotor te implementeren. De eindige elementen modellering van de rotor is gebaseerd op Timoshenko balkentheorie (met inbegrip van de flexibiliteit van de rotoras) en elk element heeft vier vrijheidsgraden op elk knooppunt.

Als de rotatiesnelheid toeneemt, wordt het warmteverlies door wrijving met de lucht en de temperatuurverhoging in de luchtspleet tussen de rotor en de stator significanter. Daarom dient bij de berekening van de stromingsgë̈nduceerde krachten de verandering van de luchteigenschappen als gevolg van de temperatuurstijging in de luchtspleet in acht te worden genomen. Hiervoor is een thermisch model opgesteld dat de warmteafvoer berekent en hiermee de temperatuurverhoging van de lucht. In dit 
model wordt de rotor, de stator en de ruimte hiertussen (de luchtspleet) gemodelleerd met thermische netwerken om door middel van empirische correlaties de benodigde convectieve warmteoverdrachtcoëfficiënten en de warmteafvoer te berekenen. Daarna wordt de nieuwe luchtspleettemperatuur gebruikt om de stromingsgeïnduceerde krachten met de bijgewerkte luchteigenschappen te berekenen. Op deze manier zijn de thermische en de stromingseffecten op de luchtspleet, samen met de rotordynamica modellen en hun effecten op de kritische snelheden en de stabiliteit onderzocht.

Een experimentele opstelling is ontworpen om de ontwikkelde modellen te verifiëren, juist wat betreft de multifysische effecten die in kleine snel roterende machines optreden. Om beter te kunnen meten zijn de afmetingen wat groter gekozen maar zijn ontwerp criteria geformuleerd zodat in het geschaalde system vergelijkbare effecten optreden. Flexibele ondersteuningen met veranderende stijfheid zijn ontworpen om hun effect op de stabiliteit van de rotor te onderzoeken. Diverse experimenten bij verschillende stijfheden zijn uitgevoerd, zoals spectrum metingen en modale analyse voor zowel met als zonder behuizing. De ontwikkelde modellen zijn geverifieerd met resultaten van deze experimenten.

Tenslotte is een eenvoudige manier gepresenteerd om optredende instabiliteit uit te stellen tot hogere toerentallen: de stationaire demping wordt verhoogd door het monteren van visco-elastische inzetstukken. De modale analyse experimenten zijn herhaald met verschillende soorten visco-elastisch materiaal, waarbij zoals verwacht een significante verbetering werd waargenomen. 


\section{Contents}

Summary

Samenvatting vii

1 Introduction $\quad 1$

1.1 Background .......................... 1

1.2 About this Thesis . . . . . . . . . . . . . . 2

1.3 Outline of the Thesis . . . . . . . . . . . . . . . 2

2 Literature Survey on High-Speed Micro Rotors 5

2.1 Introduction . . . . . . . . . . . . . . . . 5

2.2 Applications . . . . . . . . . . . . . . . 6

2.2.1 Microturbine .................. 6

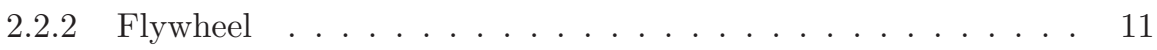

2.2.3 High-Speed Generators . . . . . . . . . . . . . . . . 13

2.3 Summary and Conclusions . . . . . . . . . . . . . . . 15

3 Structural Rotordynamics Model $\quad 17$

3.1 Introduction . . . . . . . . . . . . . . . . 17

3.2 Finite Elements in Rotordynamics . . . . . . . . . . . . . . . . . . 18

3.3 Campbell Diagram and Decay Rates . . . . . . . . . . . . . 20

3.4 Computation of the Unbalance Response . . . . . . . . . . . . . 23

3.5 Conclusions . . . . . . . . . . . . . . . . . . . . 24 
4 Modeling the Flow-Induced Forces 25

4.1 Introduction . . . . . . . . . . . . . . . . . . . . 25

4.2 Flow Force Model . . . . . . . . . . . . . . . . . . . . . . . . . . . . 28

4.3 Conclusions . . . . . . . . . . . . . . . . . . . 32

5 Thermal Model 33

5.1 Introduction . . . . . . . . . . . . . . . . . . 33

5.2 Air Friction and Heat Generation . . . . . . . . . . . . . . . . 34

5.3 Thermal Networks . . . . . . . . . . . . . . . . . . . . 35

5.4 Conclusions . . . . . . . . . . . . . . . . . . . . . 38

6 Coupling the Physical Models $\quad 41$

6.1 Introduction . . . . . . . . . . . . . . . . . . 41

6.2 Coupling Procedure . . . . . . . . . . . . . . . . 42

6.3 Analysis of the Coupled System . . . . . . . . . . . . . . . . . . 43

6.4 Discussion and Conclusion . . . . . . . . . . . . . . . . . 47

7 Design of the Experimental Setup $\quad 49$

7.1 Introduction . . . . . . . . . . . . . . . . . . 49

7.2 Analysis of the Rotor Parameters . . . . . . . . . . . . . . . . . 49

7.2 .1 Rotation Speed . . . . . . . . . . . . . . 5 50

7.2 .2 Clearance ......................... 51

7.2 .3 Disk Diameter . . . . . . . . . . . . . . . . . 51

7.2 .4 Disk Width . . . . . . . . . . . . . . . . 52

7.2 .5 Support Stiffness . . . . . . . . . . . . . . . 53

7.3 Temperature Increase and Friction Torque . . . . . . . . . . . . . . 54

7.4 Design Process . . . . . . . . . . . . . . . . . . . 54

7.4.1 Requirements .................... 54

7.4.2 Component Design . . . . . . . . . . . . . . 55

7.5 Evaluation of the Design . . . . . . . . . . . . . . 60

7.5.1 Comparison with Applications from the Literature . . . . . . . 60

7.6 Conclusions . . . . . . . . . . . . . . . . . . . 60 
8 Validation of the Developed Modeling Approach 63

8.1 Introduction . . . . . . . . . . . . . . . 63

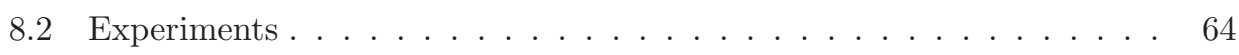

8.2 .1 Instrumentation . . . . . . . . . . . . . . 64

8.2.2 Experimental Procedure . . . . . . . . . . . . . 65

8.3 Results. . . . . . . . . . . . . . . . . 66

8.3.1 Modal Analysis of the Free Rotor . . . . . . . . . . . . 66

8.3.2 Modal Analysis of the Isolated Support . . . . . . . . . . . . 67

8.3.3 Modal Analysis of the Total System at Standstill . . . . . . . . 67

8.3.4 Modeling the rotor and flexible supports . . . . . . . . 70

8.4 Analyzing Multiphysical Effects . . . . . . . . . . . . . . . 75

8.5 Validation of the Thermal Model . . . . . . . . . . . . . . 80

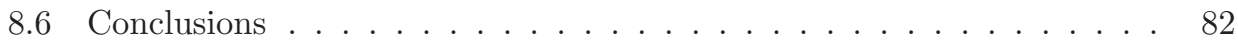

9 Implementation of Viscoelastic Supports $\quad 85$

9.1 Introduction . . . . . . . . . . . . . . . . . 85

9.2 Viscoelastic Support Structure . . . . . . . . . . . . . . . 86

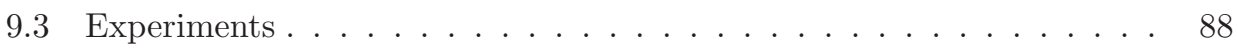

9.3.1 Modal Analysis of the Isolated Support . . . . . . . . . . 88

9.3.2 Modal Analysis of the Complete Setup . . . . . . . . . . . . . . 90

9.3.3 Spectrum Maps of the Setup . . . . . . . . . . . . . . . . 91

9.4 Discussion and Conclusion . . . . . . . . . . . . . . . . . . 95

10 Conclusions and Recommendations $\quad 97$

10.1 Conclusions . . . . . . . . . . . . . . . . . . . 97

10.2 Recommendations . . . . . . . . . . . . . . . . . 99

$\begin{array}{ll}\text { Nomenclature } & 101\end{array}$

$\begin{array}{ll}\text { A Element Matrices for Structural Model } & 105\end{array}$

$\begin{array}{ll}\text { B Thermal Network } & 107\end{array}$

$\begin{array}{lr}\text { C Dimensions of the Extra Bracket } & 111\end{array}$

$\begin{array}{ll}\text { Research Deliverables } & 113\end{array}$ 



\section{Chapter 1}

\section{Introduction}

\section{$1.1 \quad$ Background}

In our daily life we frequently unconsciously experience rotordynamics; in the engines of aircraft jets, automobiles, the pumps used in home appliances, the drum of the washing machine, computer hard disk drives, spindles of machine tools, etc. Rotordynamics can be defined as a specialized branch of applied mechanics dealing with the dynamics and stability of rotating machinery. By the ISO definition, a rotor is a body suspended through a set of cylindrical hinges or bearings that allow it to rotate freely about an axis fixed in space [32]. The non-rotating supporting structure is defined as stator.

As the rotation speed increases, the amplitude of vibration often passes through a maximum that is called a critical speed. This frequency is generally excited by the unbalance of the rotating structure. In this case the rotation speeds coincide with the natural frequency. If the amplitude of vibration at a critical speed is excessive catastrophic failure can occur. Moreover, another phenomenon occurs quite often in rotating machinery: instability. Rotors may develop unstable behavior in certain velocity ranges. The centrifugal field causes, in some cases, an unbounded growth of amplitude of vibrations in time. The ranges of rotation speeds in which self-excitation occurs are called the instability fields [32]. These so-called self-excited vibrations can result in catastrophic failure.

This is why accurate modeling of the rotordynamic behavior is crucial in the design of rotating machinery in order to improve product reliability, to increase process efficiency, to prolong machinery life, to enable safe operation, and such like.

Rotordynamic analysis dates back to the second half of the nineteenth century because of the necessity of including the rotation speed into dynamic analysis as the rotational speed of many machine elements started to increase. Many scientists tried to provide a theoretical explanation of the rotordynamic behavior. In 1919, Jeffcott introduced 
his paper about the dynamic analysis of rotors and presented a simple rotor model that consists of a point mass attached to a massless shaft [42].

Even though the Jeffcott rotor is much simpler than the real-life rotors, it still provides insight into important phenomena in rotordynamics. But for precise analysis of complex machines such as gas steam turbines, compressors, pumps, etc., more advanced models are required.

Developments in computer technology and numerical methods such as the finite element method (FEM) have made more accurate, detailed rotordynamic analysis possible. In addition, due to the more complex, multi-scale design needs and demands for miniaturization and high-speed safe operation, the effect of the surrounding medium on the dynamics of the rotor started to be investigated. Nowadays, extensive studies are available in the literature about the modeling and testing of the effect of different physical phenomena on rotordynamics $[23,55,56,69,70,86]$.

\subsection{About this Thesis}

Recently there have been a great number of research projects for designing rotating machinery on a small scale such as: micro turbines, micro electric motors, micro milling machines, etc. In order to satisfy efficiency requirements, these kinds of machinery should generally operate at high speeds, with lightweight rotors and unconventional bearings. Besides multiphysical effects such as excitations from the surrounding air, thermal effects and the influence of unconventional bearings should be taken into account while examining the rotor dynamic behavior. In order to predict the rotor dynamic behavior correctly, these effects should be modeled and the developed models should be coupled with the structural rotordynamic model.

The main objectives of this thesis are to investigate and model physical phenomena that are important for the dynamics of rotors on a small scale and at high speed. The developed modeling approach is then tested using a specially designed experimental setup. In brief, the research contributes to the area of rotordynamics by introducing a multiphysical (flow-induced forces and thermal effects) modeling approach for rotating machinery on a small scale with medium gaps.

\subsection{Outline of the Thesis}

Chapter 2 firstly explains the physical effects that become important in small scale systems. Then an overview of the recent projects on the design and development of micro-rotating machinery is presented. Finally, modeling issues that are lacking in the literature are outlined.

Chapter 3 starts with a brief description of rotordynamics theory. Then the numerical model used for structural dynamic analysis of the rotor is described. The structure will be analyzed by using finite elements based on Timoshenko beam theory. The 
axial and torsional vibrations are ignored, only flexural behavior of the rotor is taken into account. By using this model, unbalance response and critical speeds of the rotor can be predicted and the mode shapes and the Campbell diagrams can be plotted.

Chapter 4 gives an insight into the flow-induced effects that influence rotating machinery. Moreover, the flow model used in the current analysis covering both laminar and turbulent regime is discussed and the flow-induced forces on the rotor are described.

Chapter 5 deals with the thermal modeling of air between the rotor and stator. A model based on thermal networks and empirical air friction is constructed in order to compute the power dissipation and the temperature of the air in the gap between rotor and stator.

In Chapter 6 the coupling of the structural, flow and thermal models is described. The thermal model is used to update the air properties (density and viscosity) in order to compute flow forces at each rotation speed. The flow forces are implemented in the structural model for multiphysical rotordynamic analysis.

Chapter 7 describes the design of an experimental setup which is used to validate the developed modeling approach. At first, the effect of different parameters of the rotor such as the diameter, length, maximum rotation speed etc. will be examined for the dynamic behavior. This is followed by a detailed explanation of the selection of each component, the design requirements and the design process.

Chapter 8 presents the experimental and simulation results for the validation of the developed modeling approach. Equivalent models of the supports are derived and implemented in the finite element based multiphysical model which predicts the dynamic behavior of the rotor. The modal analysis and the spectrum measurements are done in order to determine the natural frequencies and threshold of instability. The experimental results are compared with the theoretical ones.

Chapter 9 discusses the usage of viscoelastic supports to overcome stability problems. Characterization of different materials and implementation of support properties into the developed multiphysical model are explained in detail. Experiments with viscoelastic supports are performed and compared with the theoretical results.

Finally, conclusions and recommendations are presented in Chapter 10. 



\section{Chapter 2}

\section{Literature Survey on High-Speed Micro Rotors}

\subsection{Introduction}

Recently, microfabrication techniques have been developed to realize the production of complex geometries, which in turn has enabled the development of micro scale systems.

A large number of researchers have been working on the development of such devices as micro electric motors, micro turbines, micro pumps, micro reaction wheels, micro gyroscopic sensors and micro milling machines which include high-speed rotation parts. However, classical rotor dynamic modeling approaches cannot be applied directly due to the effects becoming crucial at micro level.

Epstein et al. [24] state that the thermodynamic considerations are not different at micro than at macroscale. But the physics and mechanics influencing the design of the components do change with scale, so that the optimal detailed designs can be quite different. Examples of these differences include the viscous forces in the fluid (larger at microscale), usable strength of materials (larger at microscale), surface area-to-volume ratios (larger at microscale), realizable electric field strength (higher at microscale), and manufacturing constraints (limited mainly to two-dimensional, planar geometries given current microfabrication technology). The viscous forces are more important at small scale. Heat transfer is another aspect of fluid mechanics in which micro devices operate in a different design space than large-scale machines. The fluid temperatures and velocities are the same but the viscous forces are larger, so the fluid film heat transfer coefficients are higher by a factor of about three. Not only is there more heat transfer to or from the structure but thermal conductance within the structure is higher due to the short length scale. Thus, temperature gradients within the structure are reduced [24]. Similarly, Lin et al. [51] state that the air surrounding 
an oscillating microstructure has a profound effect on its dynamic behavior.

Over the last decade MEMS modeling techniques have been developed quite well, Senturia [71] identifies that of the many challenges that remain, two appear most significant. The first is the critical step of connecting the behavior of the continuum, as expressed in highly meshed simulations, to equivalent lumped models that can be used efficiently for system-level design and modeling. The second is the incorporation of non-steady-state dissipative behavior into this modeling environment, without having to make unacceptably inaccurate simplifications [71]. The high angular speeds $\left(10^{5}-10^{6} \mathrm{rpm}\right)$ also require special bearing and support systems of the rotating parts balancing the low weight systems, providing damping and minimizing the friction (power loss). This chapter discusses previous work on the development of high-speed micro devices, related equipment and modeling techniques for the physical phenomena that are important in each application. Even though the devices are called micro, length and diameter are mostly on a mm scale.

\subsection{Applications}

\subsubsection{Microturbine}

With the increasing energy demand for portable devices and the development in the design and fabrication of MEMS, power systems on a micro scale have been thought to be a feasible alternative to batteries. The energy density of the best performing batteries is about 100 times less than that of fuel-based systems. Charging times also pose problems, however, a fuel reservoir can easily be refilled. Therefore, several groups are working on the development of micro power systems. The realization of power MEMS presents new challenges to both micromachining and the traditional mechanical and electrical engineering disciplines of fluid dynamics, structural mechanics, bearings and rotor dynamics, combustion, and electric machinery design. Achieving power density similar to conventional systems requires combustor exit temperatures of $1200-1600 \mathrm{~K}$; rotor peripheral speeds of $300-600 \mathrm{~m} / \mathrm{s}$ and thus rotating structures centrifugally stressed to several hundred MPa (the power density of both turbomachinery and electrical machines scale with the square of the speed, as does the rotor material centrifugal stress). Low friction bearings, tight geometric tolerances and clearances between rotating and static parts to inhibit fluid leakage are also necessary for these systems [75].

\section{MIT Power MEMS Project}

In this study, a high-speed rotor with a diameter of $4.2 \mathrm{~mm}$ is etched from a bulk silicon substrate, taking advantage of the high strength-to-density ratio of singlecrystal silicon and the low flaw density of commercial semiconductor wafers. This material choice provides unique capabilities to withstand the stress levels induced by the centrifugal forces at high tip speeds. In order to minimize the resistance to 
rotation and prevent wear that would result from solid contact, the rotor is supported by gas-lubricated, fluid-film bearings [29]. The microturbine assembly and produced rotor are shown in Fig. 2.1 and Fig. 2.2 .

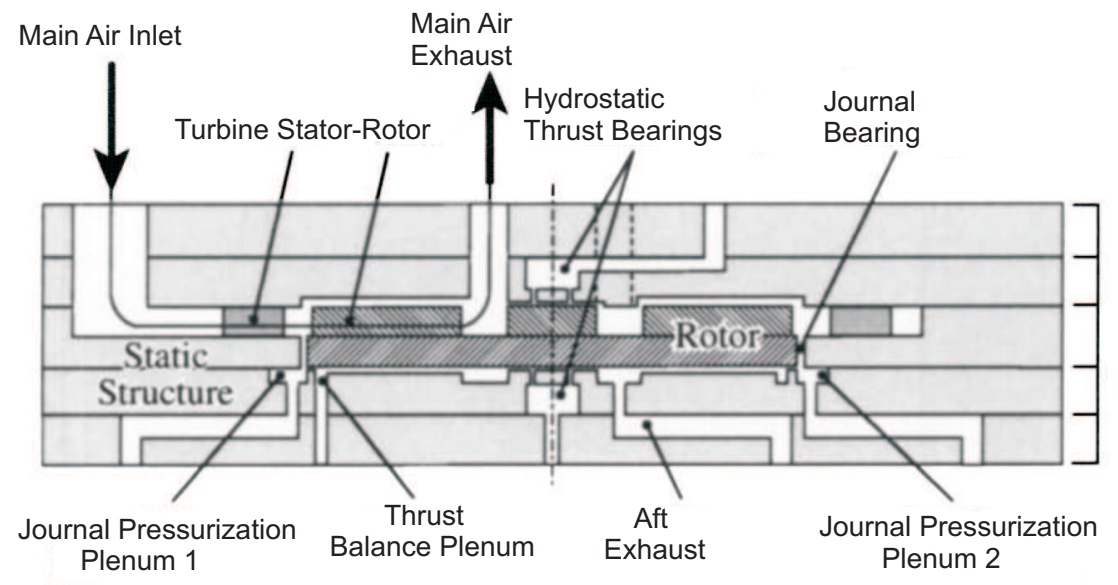

Figure 2.1: Schematic of a cross section of the microturbine-driven bearing rig. For scale reference, the rotor is $4.2 \mathrm{~mm}$ in diameter [29]

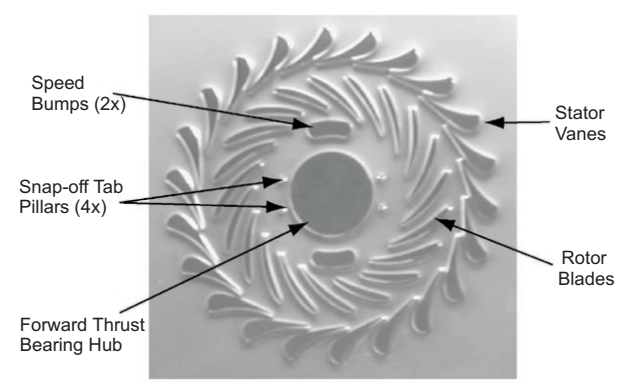

Figure 2.2: Optical photograph of the 4.2-mm diameter microturbine showing the stator and rotor blades [29]

Magnetic bearings had two challenges for this project: 1) Magnetic materials are not compatible with most microfabrication technologies 2) Curie point considerations limit the temperatures at which magnetic designs can operate (permanent magnets demagnetize). Then, electric fields are thought to be suitable for levitation but calculated forces were too low compared to the bearing loads expected. Also, since electromagnetic bearings are unstable, feedback stabilization is needed, adding to system complexity [24]. For microturbines, gas bearings have intrinsic advantages over electromagnetic approaches, including no temperature limits, high load-bearing 
capability, and relative manufacturing simplicity. Gas bearings ensure compactness, lightweight and extreme temperature operation. Gas bearings with large stiffness and damping, and preferably of low cost, will enable successful commercial applications. Current applications encompass micro power generators, air cycle machines, and turbo expanders. Gas film bearings offer advantages of low friction and less heat generation. These advantages enable their successful applications in air cycle units for airplanes, high-precision instruments, auxiliary power units, and high-speed microturbomachinery. In addition, gas bearing systems do not require costly, complex sealing and lubricant circulation systems. Besides, these types of bearings eliminate process fluid contamination and are environmentally friendly [69]. In the end, a plane cylindrical hydrostatic journal bearing is used due to its ease of manufacturing. Some other more complex variations like foil bearings and wave bearings are used in large-size machines increasing the load carrying capacity and stability. However, microfabrication of these systems is quite difficult at present.

Epstein et al. [25] presented a new analytical model for axially fed gas journal bearings and the test results of micro gas bearings to characterize the rotordynamic behavior. The model consists of two parts, a fluid dynamic model for axially fed gas journal bearings and a rotordynamic model for micro-devices. The model was used to predict the natural frequency, damping ratio and the instability boundary for the test devices. Experiments were conducted using a high-resolution fiber optic sensor to measure rotor speed. Both hydrodynamic and hydrostatic approaches are used and tested for thrust bearings. Hydrodynamic thrust bearings use viscous drag, often enhanced with shallow spiral grooves to generate a pressure gradient in the bearing, which increases toward the rotor center. It also adds an additional design consideration: rotor lift off, i.e. the minimum rotational speed needed to develop sufficient pressure to eliminate rubbing between the stationary and rotating parts. Design charts for self-pressurizing, hydrodynamic gas thrust bearings were given by Wong et al. [88] using information adapted from macroscale gas bearing literature. Compared to existing hydrostatic thrust bearings, a hydrodynamic approach offers significantly simplified fabrication and elimination of the need for a source of pressurized gas external to the bearing. However, such bearings exhibit a design trade-off between load bearing capability and maximum operating speed (as limited by instabilities). They designed a $700 \mu \mathrm{m}-$ diameter bearing using these techniques to fit an existing device, a $4.2 \mathrm{~mm}$-diameter MEMS radial inflow turbine, which was fabricated and tested achieving $450000 \mathrm{rpm}$ rotation speed. This test device demonstrated the load bearing capability predicted by the macroscale gas bearing theory in the literature [88]. Two different devices were tested for higher speeds. Device 1 was brought up to a tip speed of $260 \mathrm{~m} / \mathrm{s}\left(1.2 \times 10^{6}\right.$ $\mathrm{rpm}$ ) and was held there for $20 \mathrm{~min}$ (a pressure leak resulted in a slight deceleration). The rotor was then rapidly decelerated to stop. Device 2 reached a tip speed of 303 $\mathrm{m} / \mathrm{s}\left(1.4 \times 10^{6} \mathrm{rpm}\right)$ prior to going unstable, crashing, and fracturing into many pieces. The main failure mechanism is thought to be the inability of the journal bearing to withstand loads induced by rotor imbalance. Even for rotors with small imbalance, a slight offset of the rotor produces circumferential pumping of fluid, and causes the development of hydrodynamic forces in the journal bearing gap. These hydrodynamic 
forces tend to be destabilizing and increase with the square of speed [26].

\section{Belgian Power MEMS Project}

The aim of the project is to design and fabricate a micro gas turbine in cm range with an output of $100 \mathrm{~W}$. Both photolithographic micro manufacturing techniques and traditional micromechanical manufacturing are intended to be used for fabrication of the microturbine. The design of the micro gas turbine is shown in Fig. 2.3. Rotation

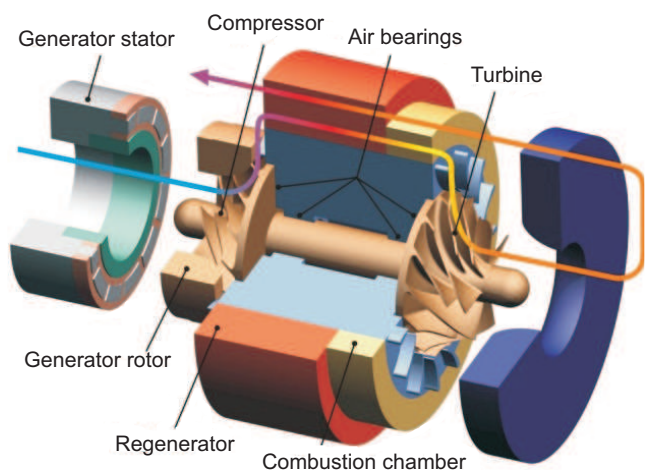

Figure 2.3: Initial Design of the microturbine in Belgian Power MEMS Project [60]

speeds of $500000 \mathrm{rpm}$ and above with rotor diameters of $10-20 \mathrm{~mm}$ are intended to be reached. Conventional ball bearings are thought to be unusable for this application due to high speed and high temperature. High temperature $\left(100-1000^{\circ} \mathrm{C}\right)$ also prevents the usage of permanent magnets as they could demagnetize. Another choice, electromagnetic bearings, would consume some of the energy produced. Therefore hydrodynamic gas bearings without the need of external pressure were thought to be the most suitable bearing system. However, self-excited instabilities (half-speed whirl) in hydrodynamic bearings limit the maximum attainable speed. The application of bearings with conformable surfaces (foil bearings) are thought to be a promising stabilization technique [60]. A stability analysis of foil bearings using dynamic stiffness and damping coefficients was carried out by Waumans et al. [86]. Foil bearings are a type of hydrodynamic gas bearing that are characterized by a flexible bearing surface that can accommodate large variation in displacement. They are becoming more popular in turbine/compressor applications. Even without additional damping, a foil bearing was observed to be more stable than a rigid surface aerodynamic journal bearing with similar geometry but not as stable as was previously believed. However, it is claimed that due to its flexible nature, it is possible to improve the stability by simple means [86].

To gather initial experience, a simple turbine driven by compressed air was built first. The rotor diameter is $10 \mathrm{~mm}$ and the rotor is supported by two ball bearings. The sub assembly of nozzle disk, rotor and bearings are shown in Fig. 2.4. The turbine is 


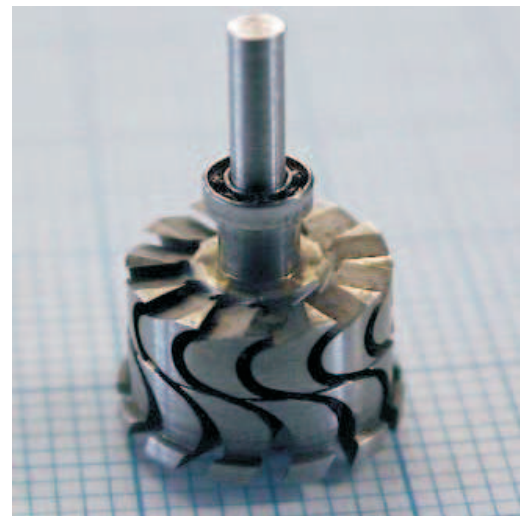

Figure 2.4: $10 \mathrm{~mm}$ diameter air turbine in Belgian Power MEMS Project [61]

a single-stage axial impulse turbine (Laval turbine) with a rotor diameter of $10 \mathrm{~mm}$, made of stainless steel using die-sinking electro-discharge machining [63]. The first tests were performed up to a speed of $160000 \mathrm{rpm}$, generating a maximum mechanical power of $28 \mathrm{~W}$ with an efficiency of $18 \%$ [62, 63]. Further tests reported $50 \mathrm{~W}$ power generation at $130000 \mathrm{rpm}$ with an efficiency of $24 \%$. Power and efficiency is expected to increase further with speed [61, 62].

\section{Development of Micromachine Gas Turbine in Tohoku University}

A micromachine gas turbine with centrifugal impellers of $10 \mathrm{~mm}$ diameter fabricated by 5 axis micro milling is under development in Tohoku University. A compressor of $10 \mathrm{~mm}$ diameter has been developed as a micromachine turbocharger. In the performance test the turbocharger ran up to $566000 \mathrm{rpm}$. To achieve a pressure ratio of 3 , the design speed was determined to be $870000 \mathrm{rpm}$ with an impeller diameter of $10 \mathrm{~mm}$. Hydrodynamic air bearings are planned to be used due to contactless operation and no need for extra air supply. However, the hydrodynamic air journal bearings are immune to whirl instability. But it is observed that the hydrodynamic bearings with so-called herringbone grooves on the rotating surface have significantly longer stable operation ranges. Therefore the hydrodynamic bearings with so-called herringbone grooves on the rotating side are set as the baseline configuration for the journal bearings. The rotor (Fig. 2.5) is made of titanium alloy (Ti-6Al-4V) and the rotor assembly uses a conventional tie-bolt construction to connect the impellers to the shaft. It was designed to run above the first and second rigid mode frequencies, but below the first bending mode resonance frequency, at the design speed. The rotor has herringbone grooves on the shaft for the journal bearings and a thrust disk with spiral grooves for the thrust bearings. The herringbone grooves and spiral grooves are formed by photolithography and wet etching. In the tests both pressure ratio and the mass flow rate are smaller than the expected value but the shape of the curves are similar [41]. 
The research was extended in order to reach higher speeds [40]. Hydro-inertia gas bearings were studied for this application. The hydro-inertia gas bearing is a type of static air bearing with wider bearing clearance. It has larger load capacity and lower viscous loss in comparison to other types of gas bearings. A test rig was constructed and the shaft speed of $770000 \mathrm{rpm}$ has been achieved by using these bearings [40].

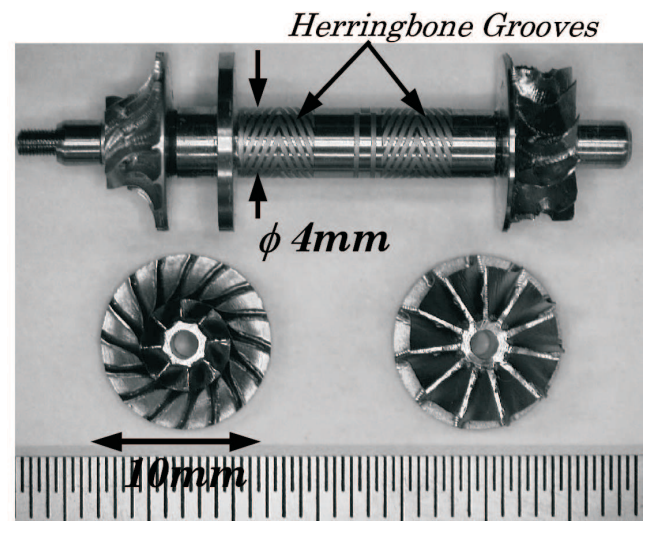

Figure 2.5: Rotor of the turbocharger [41]

\subsubsection{Flywheel}

Flywheels have been used to achieve smooth operation of machines for a long time. Nowadays flywheels are complex constructions where energy is stored mechanically and transferred to and from the flywheel by an integrated motor/generator. Today flywheels are used as supplementary UPS storage in several industries. The progress in power electronics, makes it possible to operate flywheels at high power, with a power electronics unit comparable in size to the flywheel itself or smaller. The use of composite materials enables high rotational velocity with power density greater than that of chemical batteries. Future applications may be intermediate storage systems for renewable energy generation and energy storage/attitude control systems for microsatellites [13]. Flywheels have the following advantages over other storage systems:

- High power density

- High energy density

- Lifetime of the flywheel is almost independent of the depth of the charge/discharge cycle

- The state of charge can easily be measured

- No periodic maintenance is required 
- Short recharge time

- Environmentally friendly materials, low environmental impact

Lee $[48,49]$ proposed an energy storage and attitude control system for microelectromechanical systems in spacecraft using a high-temperature superconductor (HTS) magnet bearing system. The system consists of an HTS magnet flywheel energy storage system and a brushless motor/generator. Dimensions of the system are given in Table 2.1 .

The micro high-temperature superconductor flywheel for nano/pico satellites has an angular momentum capacity of $0.083 \mathrm{Js}$ and stores $2.32 \mathrm{~kJ}$ at $530000 \mathrm{rpm}$. The energy storage capacity is approximately $45 \mathrm{Wh} / \mathrm{kg}$ with an energy density of around $370 \mathrm{~kJ} / \mathrm{L}$. The HTS systems can perform the dual function of a power/attitude control system and are ideally suited for low earth orbit energy storage, power generation, and attitude control of spacecraft [49]. HTS is able to operate at low temperatures, radiation, and vacuum environments in space, enhancing system stability passively without power consumption. This system also offers an attractive power supply and energy storage system for use during solar nights or in Geosynchronous Orbit (GEO) and deep space where the environments are cryogenic temperatures [48].

Table 2.1: Dimensions of the HTS System

\begin{tabular}{|c|c|}
\hline Quantity & Dimension \\
\hline Diameter (Rotor) & $30 \mathrm{~mm}$ \\
\hline Diameter (HTS) & $10 \mathrm{~mm}$ \\
\hline Diameter (Magnet) & $13 \mathrm{~mm}$ \\
\hline Height (Rotor) & $4 \mathrm{~mm}$ \\
\hline Height (HTS) & $1.15 \mathrm{~mm}$ \\
\hline Height (Magnet) & $3 \mathrm{~mm}$ \\
\hline Height (Levitation) & $0.95 \mathrm{~mm}$ \\
\hline Width (Coil) & $20 \mu \mathrm{m}$ \\
\hline Depth (Coil) & $700 \mu \mathrm{m}$ \\
\hline
\end{tabular}

When a superconductor is placed in a magnetic field, it tries to minimize the magnetic flux density, and thus expels the magnetic flux from its body. If a permanent magnet is placed above a superconductor, the induced superconducting currents in the superconductor act to exclude the total flux from it. These currents act as repelling magnets and levitate the permanent magnet. A superconductor also tries to keep the magnetic flux within itself constant when it experiences a magnetic field change. If the permanent magnet levitated on top of a disk of HTS is pulled away from its center of rotation, the HTS brings the permanent magnet back to its original position to keep the magnetic flux constant, and thus provides inherent stability. This property is known as a flux pinning effect. Superconductor-magnet bearing systems are based on passive magnetic levitation and the flux pinning effect [49]. Sung et al. manufactured 
a horizontal axle-type flywheel energy storage system with HTS Bearings. The system consists of a composite flywheel rotor, superconductor bearings, a motor/generator and its controller. The present system was designed to have an energy storage capacity of $440 \mathrm{Wh}$ at its operating speed of $40000 \mathrm{rpm}$. Superconductor bearings were assumed to be isotropic and their stiffness and damping values are found by a static loading test and impact test. Two critical speeds corresponding to the rigid body modes were found to be below $1000 \mathrm{rpm}$. The horizontal axle flywheel is shown in Fig. $2.6[75]$. High- $\mathrm{T}_{c}$ superconductors are arranged circumferentially inside the

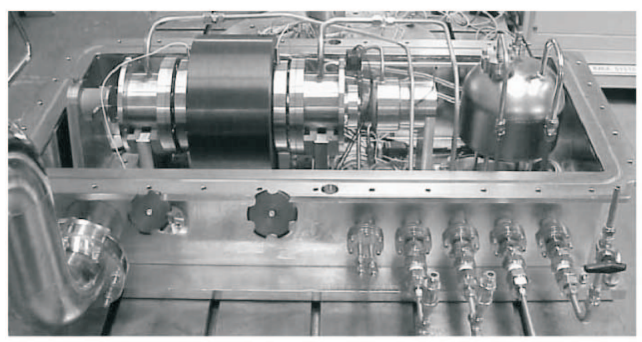

Figure 2.6: Horizontal axle type flywheel [75]

bearings. The journals have outer diameter of $79 \mathrm{~mm}$, and the bearings have inner diameter of $88 \mathrm{~mm}$ and length of $111 \mathrm{~mm}$. The radial clearance between the journal and the bearing is set to be $4.5 \mathrm{~mm}$ [75]. In an another study Varanthajoo et al. [80] presented an initial investigation of useful models that allow for a systematic analysis of combined energy attitude control systems independent of satellite types. The concept discussed was based on a double counter rotating flywheel assembly in the pitch axis. The capabilities of energy storage and attitude control were demonstrated. The critical limitations were analyzed and the simulation results were presented [80].

\subsubsection{High-Speed Generators}

Recently, there have been many studies on the design of Micro Power devices, but these studies generally focus on the design of the turbine. However, all power supply systems based on a gas turbine require an electrical system consisting of a high-speed generator/starter, power electronics, a control platform and a form of energy storage to power the starting of the turbine. Zywssig et al. studied the design of a $100 \mathrm{~W}, 500$ $000 \mathrm{rpm}$ generator suitable for use with a gas turbine. The losses caused by the high frequency operation were minimized by optimizing the winding and the stator core material. The final design was a permanent-magnet generator with a volume of $3 \mathrm{~cm}^{3}$ and experimental measurements from a test bench were presented [91]. Ball bearings were selected for a first test bench setup. Bending modes of the rotor are determined with finite element simulations. The length of the shaft was adjusted such that the operation speed is between the second and third bending mode [93]. At the rated speed of $500000 \mathrm{rpm}$ a mechanical coupling between motor and generator was not feasible. Therefore, the rotor is mechanically designed as common shaft for the two 
machines. The rotor consists of a titanium sleeve that includes two samarium-cobalt permanent magnets, one for each machine. The titanium sleeve, which also acts as shaft, was shrink-fitted onto the magnets in order to limit the stresses and guarantee torque transfer without gluing the magnets to the shaft. The rotor diameter is $6 \mathrm{~mm}$ and the length is $55 \mathrm{~mm}$. Stator core, stator winding and air friction losses were determined analytically. With the normal deceleration test the total losses in open loop operation were determined, which include copper, core, air friction and bearing friction losses. The experimental results were observed to match the calculations well [92]. The experimental setup and components are shown in Fig. 2.7.

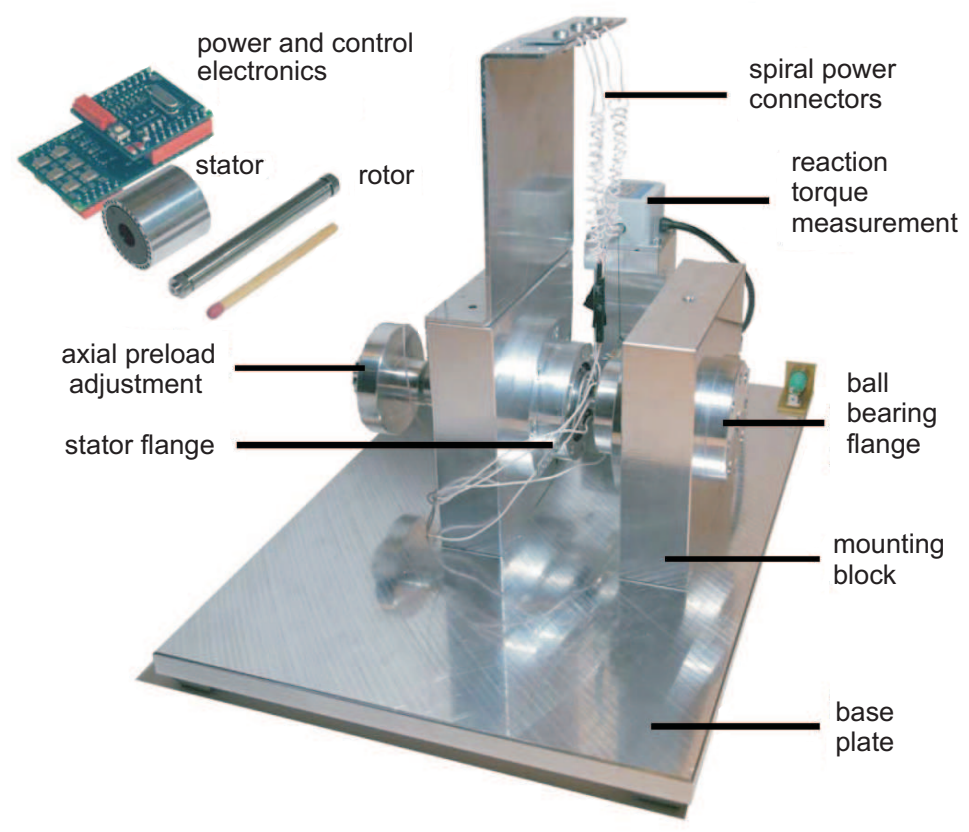

Figure 2.7: Ultra-high-speed test bench with motor in the right flange and generator in the left flange [92]

In other studies the thermal behavior of the high-speed mini generators was investigated. For instance, Aglen et al. [1] described a thermal model to analyze the temperature distribution in the high-speed generator using loss calculation and calorimetric measurements. For the generator, a critical point is to ensure that the rotor never reaches the temperature that would demagnetize the magnets. In this study, the losses were determined calorimetrically, the input and output temperature and flow were measured in the stator cooling water, the rotor cooling air and the bearing oil. A thermal resistance network was used for the calculation of temperature distribution in the machine. The model is made according to a method where temperatures and internal power (losses) are considered to exist in points or nodes. In a similar study Chun et al. [17] analyzed the thermal stability of high-speed permanent 
magnetic generator through a simplified model employing an air-cooling system. As the losses and air flux are known, it is easy to estimate the heat rate taken away by the cooling air, and easy to obtain the temperature distribution of the stator at a steadystate. They performed simulation of this problem using the FLOTRAN computational fluid dynamics (CFD) software package embedded in Ansys software. The simulation results are found to be in good agreement with real operation circumstance.

\subsection{Summary and Conclusions}

As explained above, most of the studies involve the construction of micro rotating machinery. Modeling efforts mostly focus on the bearings. Different gas, foil and magnetic bearing types have been analyzed. In some other analysis only the thermal behavior has been studied. However multiphysical effects on rotordynamics such as interaction with the surrounding air and the thermal effects become important in small scale [55]. Besides in most cases for different applications there is a casing around the rotor for protection and for good operation conditions. The interaction with the air in the confinement formed by the casing and rotor plays an important role on the dynamics of the structure due to the high rotation speeds. Therefore in our study the flow induced effects on the rotordynamics in small scale for medium gap systems such as a casing have been investigated. The flow induced forces change the critical speeds and also result in instability of the rotor.

In conclusion, the current literature lacks coupled thermal, fluid and structural analysis for dynamics of rotating machinery in small scale. The study described in this thesis developed a coupled multiphysical approach and presents experimental validation. The theory on separate effects will be discussed in the following chapters and put in the multiphysical framework. 



\section{Chapter 3}

\section{Structural Rotordynamics Model}

\subsection{Introduction}

There has been a lot of research about the dynamics of rotating machinery throughout the last century. Simple models such as the Jeffcott rotor were developed to analyze rotor dynamic problems. These models provide an understanding of the dynamics of the rotating machinery. However, they are unable to give accurate predictions for the complex geometries experienced in practice. Flexible rotors can be modeled as continuous systems and dynamic characteristics can be investigated by the related differential equations which describe the behavior of linear elastic continua. However, only a few simple cases can be solved analytically and therefore discretization methods are necessary to study more practical problems. The finite element method (FEM) is a widely used discretization technique in rotordynamics. Many different element formulations have been developed, with different shapes and characteristics like beam elements, shell elements, plate elements, solid elements, etc. However, the elements commonly used in elementary rotor dynamics are just beam, mass and spring elements [32]. In order to determine the dynamic behavior of rotating shafts, this research has developed a structural model capable of calculating unbalance response, critical speeds, mode shapes and of plotting Campbell diagrams. Finite elements based on Timoshenko beam formulation $[6,31]$ are often used for modeling the rotor.

In this chapter, first the finite elements which are widely used in rotor dynamics (Sec. 3.2) will be explained. Next the Campbell diagram and decay rate plot will be explained and the formulation to calculate the decay rates and the natural frequencies will be given (Sec. 3.3). Finally, unbalance and response calculations will be discussed (Sec. 3.4). 


\subsection{Finite Elements in Rotordynamics}

The Timoshenko beam element is widely used in rotor dynamic analysis. It has two nodes at the ends of the beam and six degrees of freedom (three translational, three rotational) per node with uncoupled axial, torsional and flexural behavior. Torsional excitations are related to the operation of e.g. the rotors in reciprocating machines that are driven by belt or chain drives. These torsional excitations are essential to study faults and transients during the operation of such rotating machines [56], but they can be omitted in cases where this behavior is not important. Furthermore, the natural frequencies of axial modes are usually much higher than of other modes and mostly little excitation acts on axial modes [32]. Therefore, in our study axial and torsional vibrations are ignored, so only flexural behavior of the rotor is taken into account, reducing the number of degrees of freedom (DOF) to four at each node (Fig. 3.1). The vector of nodal displacements of the element using complex notation is given as below:

$$
\mathbf{q}=\left[u_{x_{1}}+i u_{y_{1}}, \phi_{y_{1}}-i \phi_{x_{1}}, u_{x_{2}}+i u_{y_{2}}, \phi_{y_{2}}-i \phi_{x_{2}}\right]^{T}
$$

The complex notation is applicable for an isotropic rotor which has axisymmetric parts and isotropic supports having the same stiffness and damping properties in $\mathrm{x}$ and $\mathrm{y}$ directions. The complex notation reduces the number of DOF by half as compared to real coordinates. As a result the size of the matrices and the computational time for rotordynamic analysis decreases radically.

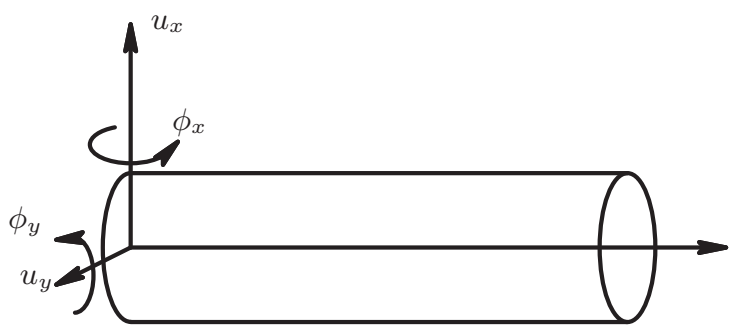

Figure 3.1: Beam element

With the use of shape functions consistent stiffness $\mathbf{K}$, mass $\mathbf{M}$ and gyroscopic matrices $\mathbf{G}$ for a beam element were already derived by Genta [6, 31]. These matrices are given in App. A.

Furthermore, mass and spring elements are used to model the interaction between the rotating and non-rotating parts. Then these elements are assembled into the related nodes of the stiffness $\mathbf{K}$ and mass matrices $\mathbf{M}$. The mass element $\mathbf{M}_{e}$ for an added mass on the $i$ th node of the rotor can be described as a $2 \times 2$ matrix in case complex coordinates are used. It involves the added mass $m$ and the inertia $J$ as:

$$
\mathbf{M}_{e}=\left[\begin{array}{ll}
m & 0 \\
0 & J
\end{array}\right]
$$


This matrix should be assembled into the corresponding node of the mass matrix $\mathbf{M}$. The spring element is used to model the stiffness between the rotating elements such as the flexible coupling between the rotor and the motor, also the stiffness between the rotating and non-rotating parts such as the bearings. The matrix for the spring element between two nodes has the dimensions $4 \times 4$ using the complex notation. The stiffness matrix for the spring element is [32].

$$
\mathbf{K}_{e}=\left[\begin{array}{llll}
k & 0 & -k & 0 \\
0 & \kappa & 0 & -\kappa \\
-k & 0 & k & 0 \\
0 & -\kappa & 0 & \kappa
\end{array}\right]
$$

where $k$ is the stiffness for translational DOF and $\kappa$ is the stiffness for the rotational DOF. If the spring element is intended to be used between the rotor and non-rotating parts (stator) and the stator is not included in the analysis, the spring element matrix in Eq. 3.2 is replaced by a $2 \times 2$ matrix similar to the mass element. In this case the spring element matrix becomes:

$$
\mathbf{K}_{e}=\left[\begin{array}{ll}
k & 0 \\
0 & \kappa
\end{array}\right]
$$

All spring elements used for the bearing, support structures or the flexible coupling are assembled into the related nodes of the stiffness matrix $\mathbf{K}$.

Finally, the damping should be taken into account for the dynamic analysis of the rotating systems. The damping can be classified as rotating damping $\mathbf{C}_{r}$ and nonrotating damping $\mathbf{C}_{n}$. The non-rotating damping $\mathbf{C}_{n}$ is related with the non-rotating parts whereas the rotating damping $\mathbf{C}_{r}$ is related with the rotating components of a machine. The size of these matrices are the same as the stiffness matrix. Similar to the spring element, the damper element can be used to model the damping between different nodes. These elements should be added into the related nodes of these matrices. The gyroscopic matrix $\mathbf{G}$ includes the effects of moment of inertia and is given in App. A.

Then the governing equation of motion for an axisymmetric rotor is defined as [32]:

$$
\mathbf{M} \ddot{\mathbf{q}}+\left(\mathbf{C}_{r}+\mathbf{C}_{n}-i \Omega \mathbf{G}\right) \dot{\mathbf{q}}+\left(\mathbf{K}-i \Omega \mathbf{C}_{r}\right) \mathbf{q}=\Omega^{2} \mathbf{f}_{r} e^{i \Omega t}+\mathbf{f}_{n}(t)
$$

In our study a MATLAB based code is developed to form and assemble element matrices. The unbalance response at a certain node is calculated considering the unbalance force vector $\mathbf{f}_{r}$ and omitting the non-rotating force vector $\mathbf{f}_{n}(t)$. The complex eigenvalues in the absence of $\mathbf{f}_{r}$ and $\mathbf{f}_{n}(t)$ are obtained at different speeds. Then these results are used to plot the Campbell diagram and decay rates which finally reveal the critical speeds and the onset of instability. The details of calculations are given in the following sections. 


\subsection{Campbell Diagram and Decay Rates}

Since the rotation speed is included in the equation of motion of a rotor (Eq. 3.4), the calculated natural frequencies are functions of the rotation speed. This dependency is shown generally in a plot of natural frequencies of the system $\omega_{i}$ versus the rotation speed $\Omega$, which is called the Campbell diagram. In many cases the frequency of excitation also depends on the rotation speed (see next section). Hence the Campbell diagram is very useful to study the effect of different excitation forces on the system. The rotation speeds, at which the frequency of forcing functions coincides with one of the natural frequencies, are called the critical speeds. The operation in the neighborhood of critical speeds may result in excessive vibrations and catastrophic failure. The critical speeds can be observed in the Campbell diagram by intersecting the natural frequency and forcing function curves. In most cases the excitation is caused by the unbalance, then the frequency of the forcing function can be plotted with the straight line $\omega=\Omega(1 \mathrm{x}$ line)(see sec. 3.4) in the Campbell diagram and the excitation is defined as synchronous. Fig. 3.2 depicts the Campbell diagram and critical speeds and mode shapes for synchronous excitation of a flexible rotor with flexible supports. In the figure the first three natural frequencies are plotted as a function of rotation speed and the corresponding mode shapes (one rigid body and two bending modes) are presented. The critical speeds are determined by intersecting the $(1 \mathrm{x}$ line) with the natural frequencies.

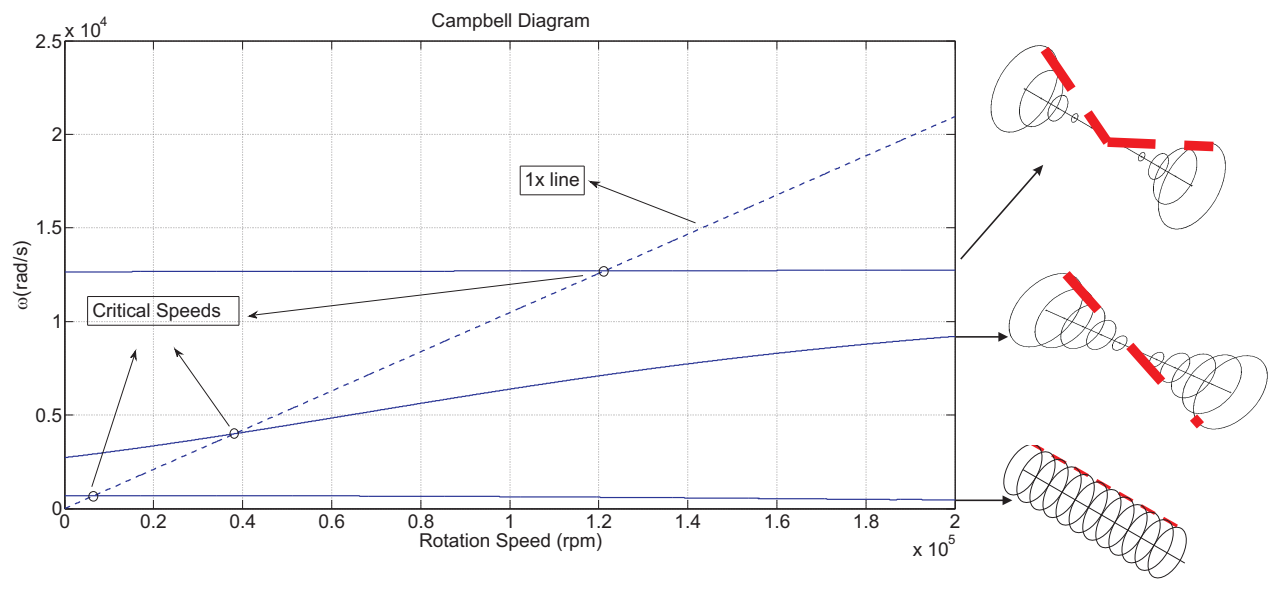

Figure 3.2: The Campbell diagram

Another important phenomenon in rotordynamics is instability. Rotors may develop unstable behavior at certain rotation speeds depending on the support stiffness and more on the non-rotating/rotating damping ratio. Normally the amplitude of free vibration of a linear system decays exponentially. However, in the case of rotors selfexcitations may occur and cause unbounded growth of the amplitude of vibrations in time. The speed at which this self-excitation happens is called the threshold of 
instability. This may occur due to the enclosed surrounding fluid, cracks in the shaft, coupling and internal friction etc. The main difference between the instability and critical speeds is that critical speeds are a sort of resonance between the forcing function and natural frequency leading to large but bounded amplitudes. On the other hand, in unstable operation self-excited vibrations occur and grow unbounded by the rotation of the shaft. Genta [32] explains the main features of the critical speeds and instability:

Critical speeds:

- They occur at well-defined values of the rotation speed.

- The amplitude of vibration grows linearly in time if no damping is present.

It can be maintained with reasonable limits and a critical speed can be passed. In that case safe operation can be performed.

- The value of the critical speed does not depend on the amplitude of excitation; however, the maximum amplitude of vibration depends on the amplitude of the perturbation causing it.

Fields of Instability:

- The speeds higher than the onset of instability are often unstable.

- The threshold of instability is generally in the supercritical (higher operation speeds than the critical speed) range.

- The amplitude grows exponentially in time. It grows in an uncontrollable way and consequently working above the threshold of instability is impossible.

As explained above, the natural frequencies of the system should be computed as a function of rotation speed in order to plot the Campbell diagram. For the stability analysis rotating and non-rotating damping should be taken into account and the decay rates should be calculated. This makes the computation time longer. In the case of viscous damping, the basic equation is the homogeneous equation associated with Eq. 3.4 [32]. Non-rotating damping stabilizes the system; on the other hand rotating damping causes self-excitations resulting in instability. The material damping of the rotor, friction between rotating components such as coupling-rotor, flow in the bearings, seals, casing, contributes to the rotating damping.

$$
\mathbf{M} \ddot{\mathbf{q}}+\left(\mathbf{C}_{r}+\mathbf{C}_{n}-i \Omega \mathbf{G}\right) \dot{\mathbf{q}}+\left(\mathbf{K}-i \Omega \mathbf{C}_{r}\right) \mathbf{q}=0
$$

The Campbell diagram and decay rates are computed using a solution of type $\mathbf{q}=$ $\mathbf{q}_{0} e^{i \lambda t}$. Where $\lambda=\omega+i \sigma$ is the complex frequency (eigenvalue). The real part of the complex frequency $(\omega)$ is the natural frequency and the imaginary part $(\sigma)$ is the decay rate. State space representation makes the calculations of eigenvalues easier. At first $\ddot{\mathbf{q}}$ can be formulated as:

$$
\ddot{\mathbf{q}}=\mathbf{M}^{-1}\left(i \Omega \mathbf{G}-\mathbf{C}_{n}\right) \dot{\mathbf{q}}+\mathbf{M}^{-1}\left(-\mathbf{K}+i \Omega \mathbf{C}_{r}\right) \mathbf{q}
$$


Then the Eq. 3.5 can be transformed into:

$$
\left[\begin{array}{cc}
\mathbf{M}^{-1}\left(i \Omega \mathbf{G}-\mathbf{C}_{n}\right) & \mathbf{M}^{-1}\left(-\mathbf{K}+i \Omega \mathbf{C}_{r}\right) \\
\mathbf{I} & 0
\end{array}\right]\left\{\begin{array}{c}
\dot{\mathbf{q}} \\
\mathbf{q}
\end{array}\right\}-\left[\begin{array}{cc}
\mathbf{I} & 0 \\
0 & \mathbf{I}
\end{array}\right]\left\{\begin{array}{c}
\ddot{\mathbf{q}} \\
\dot{\mathbf{q}}
\end{array}\right\}=\left\{\begin{array}{l}
0 \\
0
\end{array}\right\}
$$

The onset of instability can be determined from the decay rate $(\sigma)$ plots. If the decay rate becomes negative the vibrations are not damped out and self-excitation occurs. It can be difficult to evaluate the decay rate with a sufficient degree of precision, since it is influenced by many factors that are difficult to measure or model accurately, such as damping. Therefore theoretical studies may be used to make initial predictions which should be later validated. The decay rates are plotted as a function of rotation speed similar to the Campbell diagram for the prediction of the onset of instability. Fig. 3.3 illustrates the decay rates belonging to the first three natural frequencies of a rotor which is surrounded by a casing. The air between the casing and rotor causes instability as observed in the figure.

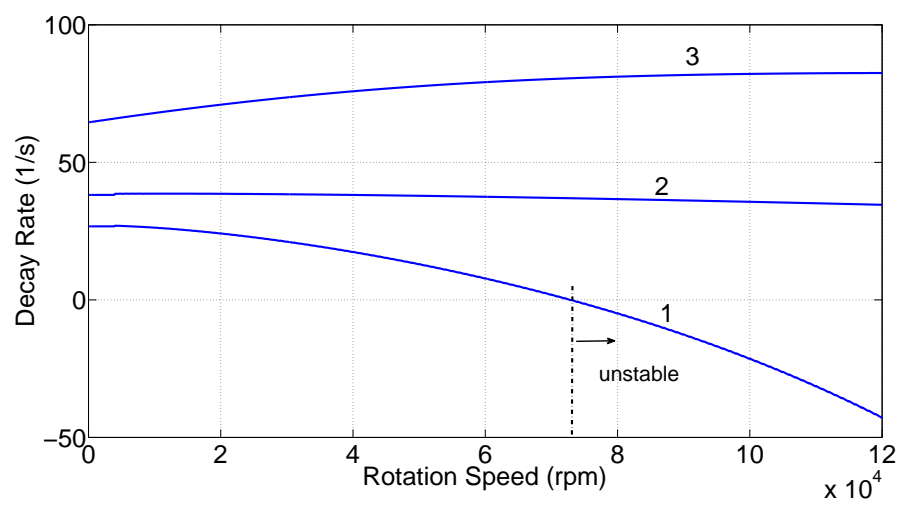

Figure 3.3: Decay rate

With the state space representation, $\mathbf{z}=\left\{\begin{array}{l}\dot{\mathbf{q}} \\ \mathbf{q}\end{array}\right\}$ Eq. 3.7 may be transformed into the eigenvalue problem, $\mathbf{A z}=\lambda \mathbf{z}$.

Then the eigenvalues, in this case the complex frequencies $\lambda$ can be calculated revealing the natural frequencies $(\omega)$ and decay rates $(\sigma)$. In order to plot the Campbell diagram for $m$ values of the rotation speed $\Omega$, an eigen problem of order $2 n$, where $n$ is the number of complex degrees of freedom, must be solved $m$ times [32]. The damping has generally little effect on the values of the natural frequencies. On the other hand it affects the decay rate drastically. As a result, the rotating and stationary damping should be considered for stability analysis.

In the current study a finite element based structural model is developed in MATLAB, the element matrices are formed and assembled by using this code. The damping can be added by viscous dampers between the corresponding nodes into the related damping matrix, $\mathbf{C}_{n}$ or $\mathbf{C}_{r}$. The bearings and the support structure are added 
into the stiffness and mass matrices using the mass and spring elements. Then the eigenvalues are calculated from the Eq. 3.7 and the "eig" eigenvalue solver function of MATLAB [53]. In this way the natural frequencies and the decay rates are calculated and plotted.

\subsection{Computation of the Unbalance Response}

In general the center of mass is not located exactly in the center of the cross section of the rotor. Then the eccentricity $\epsilon$ causes a static unbalance $m \epsilon$ which has a significant effect on the dynamic behavior. Fig. 3.4 depicts the center of cross section C, center of mass $\mathrm{P}$, origin of the fixed system $\mathrm{O}$ and the eccentricity $\epsilon$.
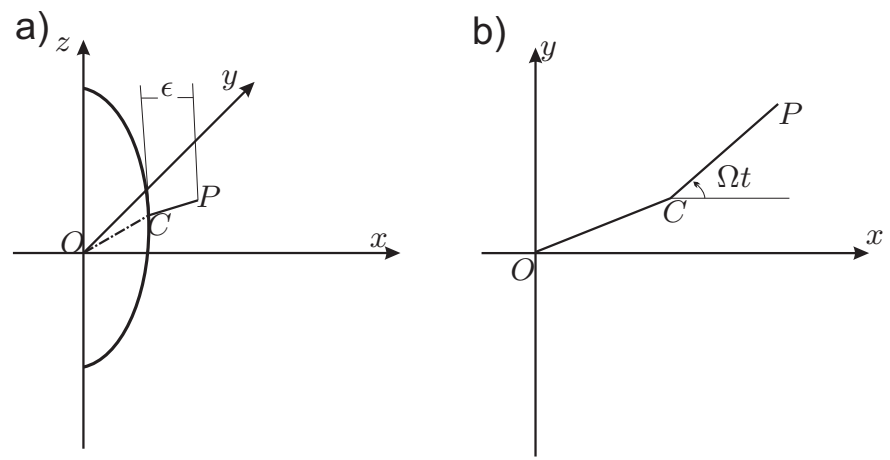

Figure 3.4: Unbalanced rotor a) sketch of the deflected system b) situation in the xy plane [32]

Unbalance can be a result of rotor material non-homogeneity (voids, porosity, etc.) or specific types of imperfection in design, fabrication and assembly. Unbalance may also occur during machine operation due to erosion or building up of deposits, missing or loose rotor parts and thermal distortion of the rotor. In addition crack formation can be another reason for unbalance [56].

The amplitude of unbalance response is important in the computation of the induced stress on the rotor and transmitted vibration on the non-rotating parts. Furthermore rotors mostly have bearings, seals or housings having small clearances. The amplitude of the unbalance should be known to balance the rotor or to design the surrounding non-rotating parts accordingly. In this way the rub-impact of the rotor can be prevented.

Unbalance produces a forward synchronous excitation, that is, an excitation that rotates at the same speed $\Omega$ as the rotor. It generates a centrifugal force perpendicular to the axis of rotation. By introducing the force caused by unbalance into the equation of motion, it is possible to obtain the response of the system in terms of the displacement vector $\mathbf{q}$. The response of the structure due to an unbalance at a 
certain point is calculated from Eq. 3.4 by assuming a solution of $\mathbf{q}=\mathbf{q}_{0} e^{i \Omega t}$, where $\mathbf{q}_{0}$ is the vector of amplitude of response. Then the following algebraic equation is obtained for a system with only non-rotating damping [32] and static unbalance caused by an eccentricity $\left(\epsilon_{i}\right)$ at the $i^{\text {th }}$ node:

$$
\left(-\Omega^{2}(\mathbf{M}-\mathbf{G})+i \Omega \mathbf{C}_{n}+\mathbf{K}\right) \mathbf{q}_{0}=\Omega^{2} m \epsilon_{i}
$$

The computation of the response to an arbitrary unbalance distribution is similar to the computation of the response of a vibrating system excited by a harmonic forcing function, where the excitation frequency equal to the rotational speed $\Omega$ is used in the equation, the amplitude of the excitation is proportional to $\Omega^{2}$, and the mass matrix of the system is $\mathbf{M}-\mathbf{G}$ [32]. The unbalance response is usually reported in graphical form as a plot of the amplitude of the circular orbit at a selected location as a function of the rotation speed (see Fig. 3.5). The peaks correspond to the critical speeds and are followed by antiresonances.

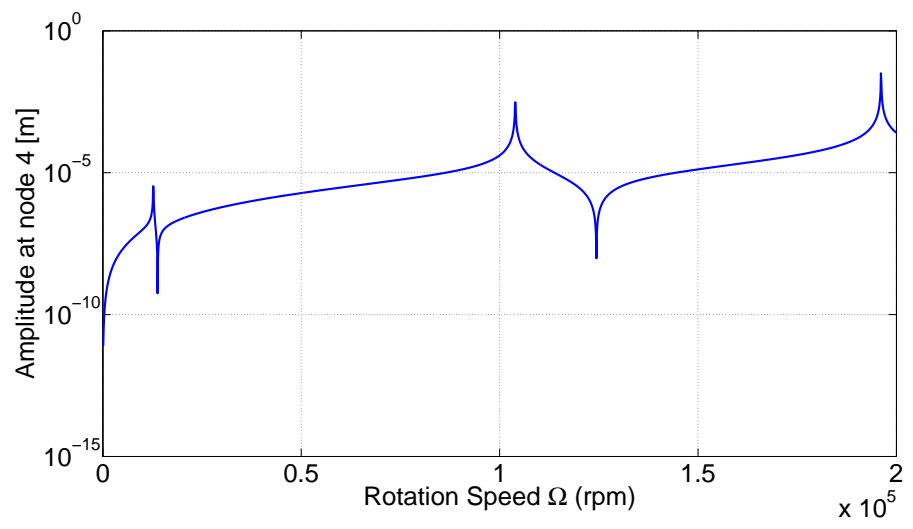

Figure 3.5: Unbalance response

\subsection{Conclusions}

FE is a widely used method to examine the dynamic behaviour of the rotor. The structural model using finite elements based on Timoshenko beam formulation enables computation of unbalance response, plotting Campbell diagrams, decay rates. The Campbell diagram reveals the critical speeds of the rotor. On the other hand the decay rate plot shows the onset of instability. The multiphysical effects can be implemented into the structural model (see following chapters) and rotordynamic analysis can be performed to determine critical speeds and onset of instability. 


\section{Chapter 4}

\section{Modeling the Flow-Induced Forces}

\subsection{Introduction}

As stated in Sec. 2.3, there has been much research on microrotating machinery. In most applications there is a casing around the rotor. Due to the high rotation speeds, the air in the confinement formed by the casing and the rotor plays an important role on the dynamics of the structure. The surrounding flow alters the natural frequencies and results in rotating damping. The rotating/stationary damping ratio determines the stable operation ranges. The behavior of the flow in a gap between a rotating cylinder and non-rotating casing depends on the Couette-Reynolds number $\left(R e_{\delta}\right)$ and Taylor number $(T a)$ which are defined as:

$$
\operatorname{Re}_{\delta}=\frac{\rho \Omega r H}{\mu} \quad \text { and } \quad T a=\operatorname{Re}_{\delta}^{2} \frac{H}{r}=\frac{\rho^{2} \Omega^{2} r H^{3}}{\mu^{2}}
$$

where $\rho$ is the density of the fluid, $\Omega$ is the rotation speed, $H$ is the nominal clearance, $\mu$ is the dynamic viscosity and $r$ is the rotor radius. If $R e_{\delta}<2000$ and $T a<1700$, the laminar two-dimensional Couette flow theory is valid; when $R e_{\delta}<2000$ and $T a>1700$, the flow is still laminar, but three-dimensional Taylor vortices are present; if $R e_{\delta}>2000$, the flow is turbulent but less-organized vortices still exist up to higher values of $\operatorname{Re}_{\delta}$ [3]. In laminar flow the fluid particles move in smooth layers, on the other hand in turbulent flow the fluid particles move with random three-dimensional velocity fluctuations [28]. If there is no axial flow, linear velocity profiles are observed in laminar flow between the rotor and stator. The fluid velocity close to the rotor is the same as the surface speed of the rotor. The velocity of the fluid particles near to the stator is zero. In the turbulent flow a linear velocity profile is not observed. The flow in the gap between the rotor and stator can be separated into three layers: 
two viscous layers near the walls and one turbulent layer in the middle of the flow. The motion of fluid particles in the turbulent layer is independent from viscosity. The highest velocity gradients are in the viscous layers [67]. Fig. 4.1 illustrates the laminar and turbulent flow in the gap between the rotor and the stator when the curvature of the air gap is neglected. Taylor vortices are periodic secondary flows

\section{Laminar flow}

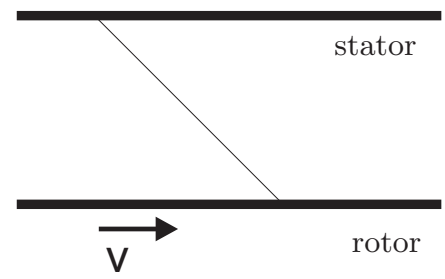

\section{Turbulent flow}

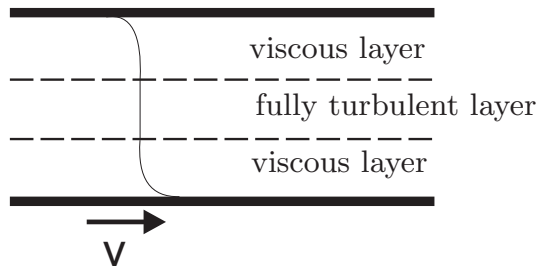

Figure 4.1: Tangential velocity profiles of laminar and turbulent air gap flows [67]

that are developed due to the centrifugal force affecting the fluid particles that are confined between two cylinders. At lower speeds the flow is laminar and the formation of the Taylor vortices is prevented by frictional forces [67]. Fig. 4.2 depicts the Taylor vortices in the gap between the rotor and the stator.

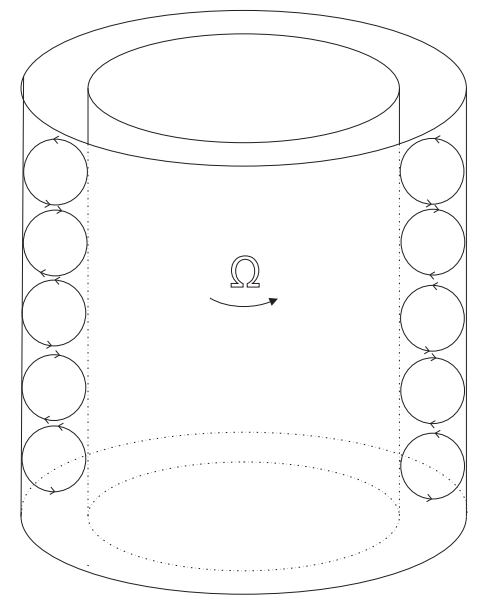

Figure 4.2: Taylor vortices [67]

Most of the existing research about the flow effects on rotors concerns the bearings and seals. The gap ratio, $\delta=H / r$ (nominal clearence/rotor radius) in these geometries is around 1/1000. For these applications the inertia effects are ignored and the flow properties are governed by the Reynolds equation. Derivation of the Reynolds equation, the solution procedure and rotordynamic coefficients are provided in various textbooks $[2,15,56]$. However, fluid inertia effects become significant at high rotation 
speeds and large gap ratios. This condition occurs when $R e^{*} / \widetilde{K}_{z} \geq 1$ where $\widetilde{K}_{z}$ (shear stress factor) is 12 for laminar flow and $0.066\left(\frac{R e_{\delta}}{2}\right)^{0.75}$ for turbulent flow(i.e. $R e_{\delta}>2000$ ) [2] and the modified Reynolds number is given as $R e^{*}=R e_{\delta} H / r$. Table 4.1 illustrates the Couette-Reynolds number $\left(R e_{\delta}\right)$ at which the fluid inertia effects start to be effective for different gap ratios.

Table 4.1: For different gap ratios $(\mathrm{H} / \mathrm{r})$ the Couette-Reynolds number $\left(R e_{\delta}\right)$ at which fluid inertia effects become significant

\begin{tabular}{|c|c|}
\hline $\mathbf{H} / \mathbf{r}$ & $R e_{\delta}$ \\
\hline $1 / 10$ & 120 \\
\hline $1 / 50$ & 600 \\
\hline $1 / 100$ & 1200 \\
\hline $1 / 200$ & 3827 \\
\hline $1 / 500$ & 149394 \\
\hline
\end{tabular}

The mini rotor casings typically have medium gaps (reduced gap size of $1 / 10$ to $1 / 100)$. In addition, the high rotation speeds make inertia effects significant and a turbulent flow regime can be present in microrotating machinery. As a result modeling approaches for flow-induced forces have to be adapted which cover both laminar and turbulent flow regimes including the inertia effects. These flow forces should then be used for rotordynamic analysis of these systems.

Detailed numerical studies are available in the literature in order to calculate the rotordynamic coefficients (added mass, stiffness and damping terms) including the inertia effects $[7,8,38,73]$. Coupling this approach to a structural model is cumbersome. The fluid numerical model has to be run for each different geometry and fluid properties in order to obtain fluid forces and as a result the rotordynamic coefficients.

In other studies the momentum and continuity equations are used and linearized fluid forces are obtained analytically as a function of speed, fluid properties and geometry. Fritz [30] modeled flow with inertia effects by using an extension of a lubrication theory in which he included fluid inertia and fluid frictional effects for flow in the annulus. Antunes et al. [3] extended this work by including rotor eccentricity and experimentally verified the developed modeling approach for concentric and eccentric configurations [37]. Both studies use semi-empirical friction coefficients and 2-D flow assumption in order to derive added mass, damping, stiffness. However these studies do not include the laminar flow regime. Brennen [14] states that these forces could be used also for laminar regime including necessary friction coefficients for shear stress.

Our study uses the force model given by Fritz [30] and Antunes et al. [3] for a concentric configuration. These forces are implemented into a structural finite element model (FEM) as added mass, stiffness and damping. The next section describes the main assumptions and outcome of the used flow force model. 


\subsection{Flow Force Model}

The aim of the current study is to implement flow-induced forces into the structural model and perform rotordynamic analysis under the effect of surrounding fluid. As we are dealing with high speeds it is important to include the turbulent regime and inertia effects. For this case a detailed model of the flow is quite complex. Therefore the following assumptions are commonly made for simplifying the governing equations: (a) the flow is assumed to be incompressible and two dimensional; (b) the shear stresses are modeled using semi-empirical friction coefficients [3]. The two dimensional flow field is illustrated in Fig. 4.3. Antunes et al. [3] obtained linearized flow-induced

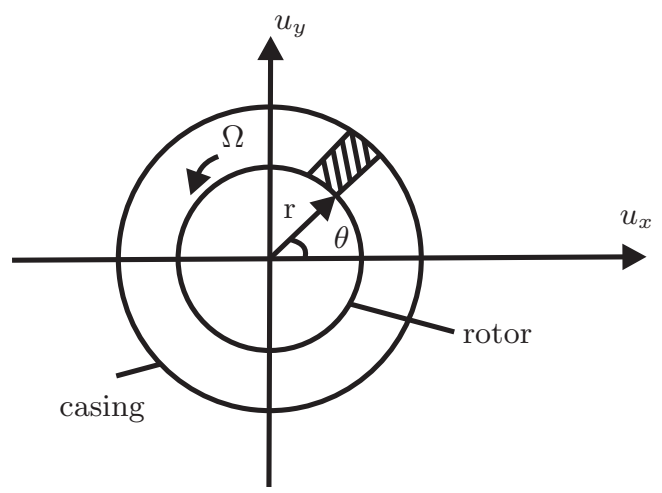

Figure 4.3: Two dimensional annular flow

forces per unit length for a fluid annulus with medium gap using perturbation methods with the above assumptions incorporating the inertia terms. The obtained forces were added to a simple rotordynamic model with a rigid rotor and flexible supports. Then simulations were performed and verified experimentally [37]. The complex turbulent flow features are represented by the empirical friction coefficient. This friction coefficient is available in the literature by numerous studies $[12,39,87]$. A bulk-flow approach has been used. Consequently, the presence of the Taylor vortices has been ignored. As a result the validity of the theoretical model is expected to decrease as the reduced gap increases due to the formation of Taylor vortices. But the numerical computation of the Taylor vortices and complex turbulent flow could be difficult and time consuming when coupled to a structural analysis. Furthermore, some experimental studies reveal that simple assumptions may lead to reasonably accurate estimations in moderate gap systems and analytically obtained force models could be feasible $[5,9,37]$. Then the governing continuity and momentum equations for these geometries are given as [3]:

$$
\begin{array}{ll}
\text { Continuity: } & \frac{\partial h_{g}}{\partial t}+\frac{1}{r} \frac{\partial}{\partial \theta}\left(h_{g} u\right)=0 \\
\text { Momentum: } & \rho\left[\frac{\partial}{\partial t}\left(h_{g} u\right)+\frac{1}{r} \frac{\partial}{\partial \theta}\left(h_{g} u^{2}\right)\right]+\frac{h_{g}}{r} \frac{\partial p}{\partial \theta}+\tau_{s}+\tau_{r}=0
\end{array}
$$


where $\tau_{r}$ is the shear stress on the rotor and $\tau_{s}$ is the shear stress on the stator. They are given by:

$$
\tau_{s}=\frac{1}{2} \rho(\Omega R-u)^{2} c_{f r} \quad \tau_{r}=\frac{1}{2} \rho u^{2} c_{f s}
$$

where $u$ is the mean flow velocity in the gap and assumed to be as $\frac{\Omega r}{2}$ in our study. This assumption is made in other previous studies $[12,68]$. The velocity profile along the gap depth is plotted from experiments by Piteau [3] and the velocities at different locations of the fluid apart from the rotor and stator surfaces are observed be very close to $\frac{\Omega r}{2}$. Besides, in our study the empirical friction coefficients on the rotor and stator are assumed to be identical and are given as $c_{f}$. Then the shear stress on the rotor and the stator are the same $\left(\tau_{s}=\tau_{r}\right)$ as a result of these assumptions and expressed as the shear stress $\tau$. The relation between the friction coefficient $c_{f}$ which depends on the surface roughness and Reynolds number and the shear stress $\tau$ is formulated as:

$$
c_{f}=\frac{\tau}{\frac{1}{2} \rho u^{2}}
$$

Antunes et al. [3] solved the equations 4.1 and 4.2 by using a classical perturbation analysis and obtained linearized equations which apply to small vibratory motions about the static position. By integrating the fluctuating pressure, the linearized flow-induced forces are expressed by means of mass-stiffness-damping matrices. The solutions are only available for the frictionless eccentric rotor or concentric rotor with friction.

The linearized fluid forces per unit length are given as:

$\left\{\begin{array}{l}f_{x} \\ f_{y}\end{array}\right\}=-\left[\begin{array}{ll}m_{x x} & m_{x y} \\ m_{y x} & m_{y y}\end{array}\right]\left\{\begin{array}{l}\ddot{u}_{x} \\ \ddot{u}_{y}\end{array}\right\}-\left[\begin{array}{ll}c_{x x} & c_{x y} \\ c_{y x} & c_{y y}\end{array}\right]\left\{\begin{array}{l}\dot{u}_{x} \\ \dot{u}_{y}\end{array}\right\}-\left[\begin{array}{ll}k_{x x} & k_{x y} \\ k_{y x} & k_{y y}\end{array}\right]\left\{\begin{array}{l}u_{x} \\ u_{y}\end{array}\right\}$

The elements of the above matrices take the following form for the eccentric rotor ignoring friction [3]:

Mass elements:

$$
m_{x x}=m_{y y}=\frac{2\left[1-\left(1-\epsilon^{2}\right)^{1 / 2}\right]}{\epsilon^{2}} m_{a} \quad m_{x y}=m_{y x}=0
$$

Damping elements:

$$
c_{x x}=c_{y y}=0 \quad c_{x y}=-c_{y x}=\Omega m_{a}
$$

Stiffness elements:

$$
k_{x x}=-\frac{\Omega^{2} m_{a}}{4\left(1-\epsilon^{2}\right)^{1 / 2}} \quad k_{y y}=-\frac{\Omega^{2}\left(1-\epsilon^{2}\right)^{1 / 2} m_{a}}{4} \quad k_{x y}=-k_{y x}=0
$$


where

$$
m_{a}=\frac{c_{3 d} \pi r^{2} \rho}{\delta}
$$

These elements take the following form for a concentric configuration $[3,30]$ :

Mass elements:

$$
m_{x x}=m_{y y}=m_{a} \quad m_{x y}=m_{y x}=0
$$

Damping elements:

$$
c_{x x}=c_{y y}=\frac{\Omega m_{a} c_{f}}{\delta} \quad c_{x y}=-c_{y x}=\Omega m_{a}
$$

Stiffness elements:

$$
k_{x x}=k_{y y}=-\frac{\Omega^{2} m_{a}}{4} \quad k_{x y}=-k_{y x}=\frac{\Omega^{2} m_{a} c_{f}}{2 \delta}
$$

All the elements in both cases are proportional to $m_{a}$. Therefore inertia effects are present in all elements affecting the stability and natural frequencies of the rotor. In our study the eccentricity is ignored and the casing and rotor is assumed to be concentric, therefore only the forces for the concentric configuration are coupled with the thermal and structural model (see chapter 6).

In these equations $c_{3 d}$ is the correction factor for three-dimensional flow effects and given as $c_{3 d}=M_{a 3 d} / M_{a 2 d}$, where $M_{a 2 d}$ is the added mass for 2-D flow given as:

$$
M_{a 2 d}=\frac{L \pi r^{2} \rho}{\delta}
$$

This added mass is formulated for two-dimensional flow that happens in infinitely long rotors. However as the $\mathrm{L} / \mathrm{D}$ ratio decreases the axial flow along the rotor (z-axis) can be present. The added mass for three-dimensional flow $\left(M_{a 3 d}\right)$ for a confined rotor has been formulated including the boundary conditions on the sides. For a rotor-casing which has one open side and one closed side the added mass is given as [35]:

$$
M_{a 3 d}=\int_{0}^{L} \frac{L \pi r^{2} \rho}{\delta}\left(1-\frac{\cosh (z / r)}{\cosh (L / r)}\right) d z .
$$

If both sides are open $M_{a 3 d}$ takes the form as:

$$
M_{a 3 d}=\int_{0}^{L} \frac{L \pi r^{2} \rho}{\delta}(\tanh (L / 2 r)-\tanh (z / 2 r)) \sinh (z / r) d z .
$$

The $c_{3 d}$ for both cases is provided in Table 4.2 as a function of length/diameter [35]. The flow forces per unit length given in Eq. 4.5 are multiplied by the element length and lumped into the nodes of each element in the confinement. 
Table 4.2: Correction factor for three-dimensional flow effects [35]

\begin{tabular}{|c|c|c|c|c|c|c|c|c|}
\hline L/2r & $\mathbf{0 . 1}$ & $\mathbf{0 . 2 5}$ & $\mathbf{0 . 5}$ & $\mathbf{1}$ & $\mathbf{2}$ & $\mathbf{4}$ & $\mathbf{1 0}$ & $\infty$ \\
\hline \multicolumn{8}{|c|}{ One Side Closed } \\
\hline$c_{3 d}$ & 0.01 & 0.08 & 0.23 & 0.51 & 0.75 & 0.87 & 0.95 & 1 \\
\hline \multicolumn{8}{|c|}{ Both Sides Open } \\
\hline$c_{3 d}$ & 0.01 & 0.02 & 0.08 & 0.23 & 0.51 & 0.75 & 0.90 & 1 \\
\hline
\end{tabular}

The above formulations are used for friction coefficients in the turbulent regime $[3,30]$. Brennen [14] states that this modeling approach could be extended by using the analytical laminar friction coefficient for the calculation of flow forces in laminar flow in which the inertia effects are significant. The analytical friction coefficient is given by Brennen [14] for laminar flow:

$$
c_{f}=\frac{12 \mu}{H \Omega r \rho}
$$

Alternatively, there are some studies in the literature where friction is expressed as a function of Reynolds number and geometrical properties using experimental data. Bilgen et al. [12] have investigated friction coefficients for rotating cylinders having different gap sizes. The results from different studies and their own results are fitted into correlations covering four different regimes in laminar and turbulent flow:

$$
\begin{array}{ll}
c_{f}=20 \frac{\left(\frac{H}{r}\right)^{0.3}}{R e_{\delta}} \quad & \left(R e_{\delta}<64\right) \\
c_{f}=4 \frac{\left(\frac{H}{r}\right)^{0.3}}{R e_{\delta}^{0.6}} & \left(64<R e_{\delta}<500\right) \\
c_{f}=2.06 \frac{\left(\frac{H}{r}\right)^{0.3}}{R e_{\delta}^{0.5}} & \left(500<R e_{\delta}<10000\right) \\
c_{f}=0.135 \frac{\left(\frac{H}{r}\right)^{0.3}}{R e_{\delta}^{0.2}} & \left(10000<R e_{\delta}\right)
\end{array}
$$

Both friction factors, analytical (Eq. 4.15) and empirical (Eqns. 4.16, 4.17, 4.18) are plotted for laminar flow for a gap ratio(H/r) of 1/50 in Fig. 4.4 as a function of Couette-Reynolds number. For low Couette-Reynolds number the friction coefficients are equal. However as the Couette-Reynolds number increases the empirical friction coefficient becomes higher. This can be due to the complex flow effects which result in considerable differences between the experimentally determined coefficients and the analytical model. In this study both analytical and experimental friction coefficients are used to determine the flow forces in laminar flow and to evaluate the suitability of each friction modeling approach by comparing the expected stability bounds with experimental data (see Chapter 7). For turbulent flow only the empirical friction 


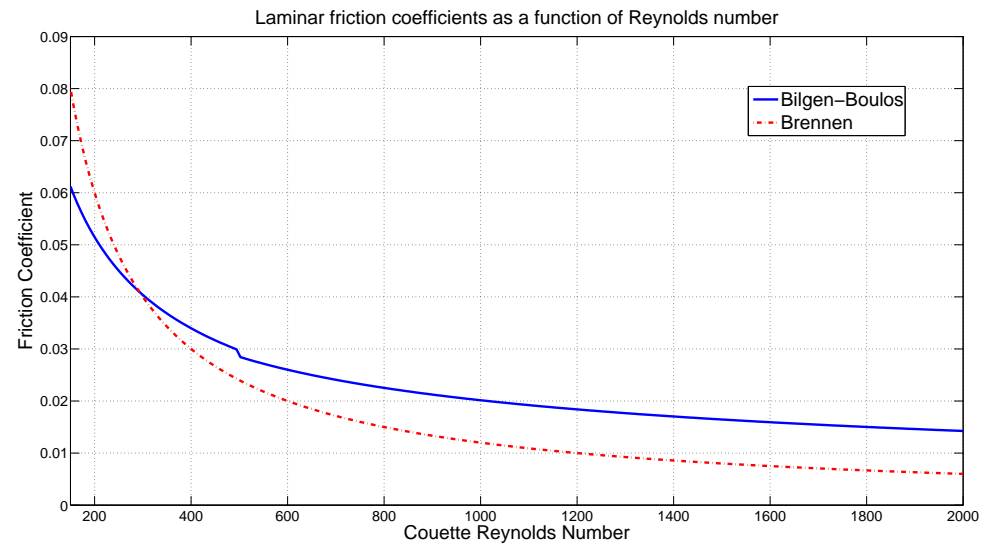

Figure 4.4: Laminar friction coefficients

coefficients given in equations 4.18 and 4.19 are available and they are used for the calculation of the flow-induced forces.

\subsection{Conclusions}

In this chapter the flow characteristics apparent in the casings of small scale rotating machinery are outlined. The requirements for a flow force model to perform rotordynamic analysis are explained. Due to high rotation speeds and high gap/radius ratios, the inertia effects must be taken into account and both laminar and turbulent flow must be covered. Both numerical and analytical studies are available in the literature [3] for determining flow induced forces. A linearized fluid force model derived analytically can be more easily implemented into the structural model and would have less computational cost than numerical techniques (CFD, etc.). This model was originally proposed for turbulent flow; however it can be extended to include laminar flow with effective inertia by using friction coefficients for shear stress in the laminar flow regime. The coupling of the flow forces with the structure is described in Chapter 6. The experimental results and the comparison are presented in Chapter 8. 


\section{Chapter 5}

\section{Thermal Model}

\subsection{Introduction}

Microrotating machinery generally operate at high speed in order to satisfy the design considerations. However, as the rotation speed increases, the heat generation due to air friction is larger and therefore the temperature increase of air in the gap between rotor and stator becomes more significant. Friction losses in the air gap of a rotor stator system result from viscous flow. The air friction loss is determined by the velocity field and the air properties. The fluid velocity field is modeled with the Navier-Stokes and the continuity equations. These equations can be solved analytically for simple geometries in laminar flow. However turbulent flow is frequently observed in high-speed micro machinery, in which case these equations are more difficult to solve. Therefore, semi-empirical friction constants are used generally to describe the friction loss for turbulent flows (see Chapter 4 and Eq. 4.18- 4.19).

The temperature changes of the air in the gap between rotor and stator result in changing air properties and consequently changing flow-induced forces. Therefore, a thermal model is needed to determine these effects and it must be coupled with the other multiphysical models for a detailed rotordynamics analysis. In our study the thermal network method is chosen to determine the temperature change in a cylindrical rotor stator system. This thermal network model was chosen owing to the following advantages over other methods such as finite difference and finite element methods [68]:

- Less computation time is required.

- Networks describing each component can be easily constructed and assembled.

- Power loss equations can simply be implemented.

- Equations for convection heat transfer coefficients can be implemented. 
At first, the heat generation due to the air friction is calculated then the resistances describing the rotor and the stator are constructed. A MATLAB based code has been developed to solve the temperature of the air at each rotation speed. The heat dissipation due to air friction will be calculated via empirical friction coefficients which are functions of the Couette-Reynolds number and the Taylor number. Then generated heat is applied to the node representing the air in the gap between rotor and stator. In this way, the temperature of the air has been calculated at different rotation speeds. The calculation of the air temperature in the gap by using the thermal networks method is quite fast and as a result it can be coupled to multiphysical models without causing excessive computations.

\subsection{Air Friction and Heat Generation}

Due to air friction, a significant amount of power is dissipated in the air gap between the rotor and the stator at high speeds. Friction losses in the air gap of a rotor stator system are caused by the viscous flow. The friction loss in the gap is determined by the velocity field, the air properties and roughness of the confinement surfaces. The friction loss of the rotating machine due to air friction is converted into heat. It is important to estimate the air friction losses in order to determine the temperature distribution in the machine and to design the rotor for maximum efficiency. The relation between the shear stress and the friction coefficient is given in Eq. 4.4. The heat generation $P_{f}$ can be calculated by multiplying the shear force with the surface velocity. The heat generation depends on the rotor velocity, friction coefficient and the surface roughness. The surface roughness of the rotor has a crucial effect on the air friction loss. Therefore, a roughness coefficient $k_{1}$ is included in the equation for heat generation in the air gap which is given as:

$$
P_{f}=k_{1} c_{f} \pi \rho \Omega^{3} r^{4} L
$$

where $c_{f}$ is the friction coefficient, $\rho$ is the density of the fluid in the gap and $L$ is the length of the rotor immersed in the fluid. The roughness coefficient is experimentally determined and is 1.0 for smooth cylinders.

A great number of studies are available in the literature for the calculation of the friction coefficient $\left(c_{f}\right)$ of a rotating cylinder. Saari [67] made a literature review of friction losses and heat transfer between concentric cylinders in detail. One of the initial studies concerning the friction loss of a rotating cylinder in free space was made by Theodorsen and Regier [76]. In their study the relation between the friction coefficient and the Reynolds number is investigated for both rough and smooth cylinders. In other studies the friction torque between two concentric cylinders with the inner cylinder rotating was measured. High Couette-Reynolds numbers $\left(6 \times 10^{4}\right)$ were achieved and the correlations for the friction coefficient were presented $[68,89]$. Bilgen and Boulos [12] determined the correlations given in Eq. 4.16 to Eq. 4.19 as a function of Couette-Reynolds number for smooth concentric cylinders. These correlations are determined by fitting the experimental data from the previous studies 
and their measurements. The experimental data include different gap ratios. The largest deviation between the fitted friction coefficient and the experiments was observed to be $10.4 \%$ [66]. In our study the friction models developed by Bilgen and Boulos [12] have been used since they cover a large range and use the available experimental data from previous research.

In addition to the radial friction loss both ends of the rotor have also friction losses. The axial heat transfer from the rotor and shaft ends can be modeled by using correlations for friction coefficients of rotating free disks (see next section) [66]. The friction coefficients for a disk rotating in free space are given as [44]:

$$
\begin{array}{ll}
c_{f}=\frac{3.870}{R e_{r}^{0.5}} & \left(R e_{r}<3 \times 10^{5}\right) \\
c_{f}=\frac{0.146}{R e_{r}^{0.2}} & \left(R e_{r}>3 \times 10^{5}\right)
\end{array}
$$

where $R e_{r}$ is the tip Reynolds number:

$$
R e_{r}=\frac{\rho \Omega r^{2}}{\mu}
$$

In our study, the rotor and stator surfaces are assumed to be smooth ignoring the roughness effects on the friction. Eq. 4.16 to Eq. 4.19 are used to determine the heat generation in the gap due to air friction for a simple rotor-stator system. The CouetteReynolds number is calculated at each rotation speed, then the friction coefficient and heat generation in the gap due to air friction are computed. Eq. 5.2 and Eq. 5.3 are used to calculate the axial heat transfer from the rotor to the ambient which will be explained in the next section.

\subsection{Thermal Networks}

The thermal networks method is applied in this study due to its advantages over other methods. Thermal networks have been widely applied for thermal analysis of electrical machines. Perez and Kassakian [64] modeled each component of a highspeed synchronous machine in terms of a thermal node that approximates the mean temperature of the component. Mellor [54] et al. described a similar thermal model for both steady-state and transient analysis. Kylander [46] presented a thermal model for enclosed electric motors. The thermal network involves nodes describing the mean temperature of each component and resistances between them. The following assumptions are made to obtain the thermal resistances:

- The heat flow in the radial and axial directions are independent.

- A single mean temperature defines the heat flow both in the radial and axial directions. 
- There is no circumferential heat flow.

- The thermal capacity and heat generation are uniformly distributed.

All the heat generation in a component is applied to the node describing this component. Each component of the motor is modeled with independent axial and radial thermal networks with the resistances for conductive and convective heat flow. Fig. 5.1 illustrates independent axial and radial networks defined for a general cylindrical component ( outer section has the radius $r_{1}$ and inner section has $r_{2}$ ).

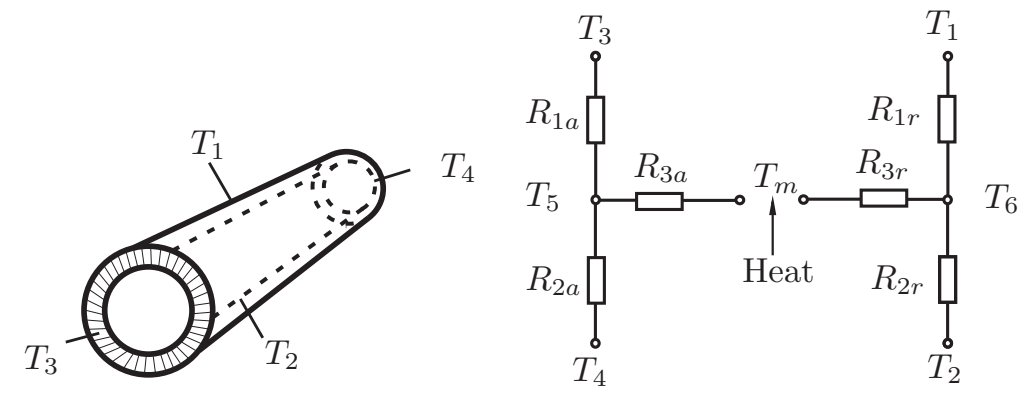

Figure 5.1: Thermal networks for a cylindrical section [54]

$T_{1}$ and $T_{2}$ are radial surface temperatures, $T_{3}$ and $T_{4}$ are axial surface temperatures, $T_{5}$ and $T_{6}$ are central nodes of each network and $T_{m}$ is the mean temperature of the component. The central node of each network will give the mean temperature of the component if there is no internal heat generation or storage [54].

The values of the thermal resistances in each network come directly from the independent solutions of the heat conduction equation in the axial and radial directions. These are given in terms of the dimensions of the cylinder and the axial and radial thermal conductivities $k_{a}$ and $k_{r}$ by the following expressions [54]:

$$
\begin{aligned}
R_{1 a} & =\frac{L}{2 \pi k_{a}\left(r_{1}^{2}-r_{2}^{2}\right)} \\
R_{2 a} & =\frac{L}{2 \pi k_{a}\left(r_{1}^{2}-r_{2}^{2}\right)} \\
R_{3 a} & =\frac{-L}{6 \pi k_{a}\left(r_{1}^{2}-r_{2}^{2}\right)} \\
R_{1 r} & =\frac{1}{4 \pi k_{r} L}\left[1-\frac{2 r_{2}^{2} \ln \left(\frac{r_{1}}{r_{2}}\right)}{\left(r_{1}^{2}-r_{2}^{2}\right)}\right] \\
R_{2 r} & =\frac{1}{4 \pi k_{r} L}\left[\frac{2 r_{1}^{2} \ln \left(\frac{r_{1}}{r_{2}}\right)}{\left(r_{1}^{2}-r_{2}^{2}\right)}-1\right] \\
R_{3 r} & =\frac{-1}{8 \pi\left(r_{1}^{2}-r_{2}^{2}\right) k_{r} L}\left[r_{1}^{2}+r_{2}^{2}-\frac{4 r_{1}^{2} r_{2}^{2} \ln \left(\frac{r_{1}}{r_{2}}\right)}{\left(r_{1}^{2}-r_{2}^{2}\right)}\right]
\end{aligned}
$$


The cylinder can be used to model a solid rod, such as the rotor shaft, by evaluating the above expressions for resistances with the radius $r_{2}=0$. If the temperatures on the sides are the same, the resistance network for a symmetrical rotor takes the form as shown in Fig. 5.2 [54].

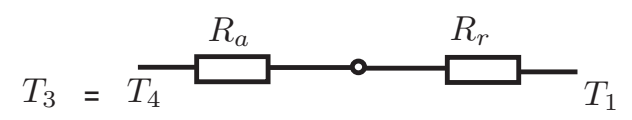

Figure 5.2: The resistance network for symmetrical solid rod

The above equations (Eq. 5.4 to Eq. 5.9) consider the conductive resistances. However, due to the interaction between the solid components (rotor, stator) and surrounding air (air gap, ambient air on the sides of the rotor) convective heat transfer also occurs. A single resistance can be used for modeling the heat transfer between the surrounding air and the solid components. The thermal resistance in that case is given as:

$$
R_{\text {conv }}=\frac{1}{h A_{c}}
$$

where $h$ is the convective heat transfer coefficient, $A_{c}$ is the surface area in contact with the air. The conductive resistances in the structure are constant, however the convective resistances between the air-rotor and air-stator surfaces change with the rotation speed due to the changes of heat transfer coefficient $h$. The convective heat transfer directions in the rotor-stator system are shown in Fig. 5.3. A literature

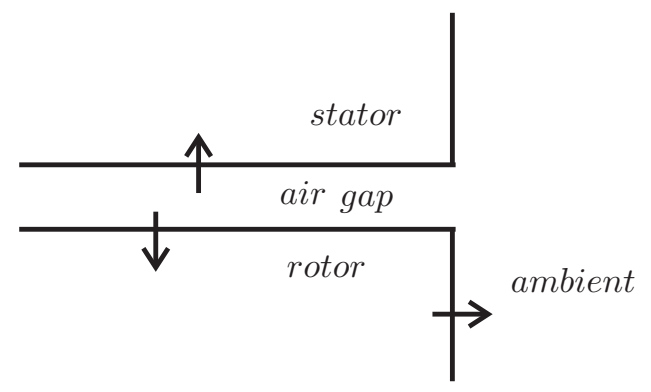

Figure 5.3: The convective heat transfer directions

review on the heat transfer characteristics of rotating cylinders has been published by Saari [66]. Suitable correlations for the calculation of the convective heat flow coefficients for the rotor-air gap, stator-air gap and rotor ends-surrounding air are reported. The convective heat transfer coefficient which is used for the calculation of convective resistances in the air gap is given as [68]:

$$
h=\frac{2 k_{\text {cond }} N u}{\delta}
$$

where $\mathrm{Nu}$ is the Nusselt number and $k_{\text {cond }}$ is the thermal conductivity of the fluid. The Nusselt number for tangential air flow between concentric cylinders is given by 
Becker and Kaye [10] as a function of the Taylor number:

$$
\begin{array}{lll}
N u=2 & & (T a<1700) \\
N u=0.128 \times T a^{0.367} & & \left(1700<T a<10^{4}\right) \\
N u=0.409 \times T a^{0.241} & & \left(10^{4}<T a<10^{7}\right)
\end{array}
$$

The axial heat transfer from the rotor ends to ambient can be modeled by the equations for rotating disks. The Reynolds analogy is widely used in modeling. This analogy assumes that the velocity and thermal boundary layers are similar to the one at disk surface [66]. The correlation between the heat transfer coefficient and Nusselt number for disks rotating in free space is given as:

$$
h=\frac{k_{\text {cond }} N u}{r}
$$

where $N u$ is given as:

$$
N u=\operatorname{Pr} R e_{r} \frac{c_{f}}{2 \pi}
$$

where $c_{f}$ is given in Eq. 5.2 and Eq. 5.3 and $\operatorname{Pr}$ is the Prandtl number given as $\operatorname{Pr}=\frac{c_{p} \mu}{k_{\text {cond }}}$. The Nusselt number is approximately $40 \%$ of that of a free disk for a gap ratio of 0.01 and $100 \%$ when it is $0.2[44,66]$.

In the current study, a MATLAB based code has been developed for the calculation of air friction and temperature increase in the gap between rotor and casing. The material properties, dimensions and rotation speed are inputs of the program. The temperature of the air in the gap and the heat generation are given as the outputs of the program. At each rotation speed the friction coefficients and heat dissipation in the gap are calculated by using the Eq. 5.1, Eq. 4.16- Eq. 4.19. The rotor and stator are modeled with the resistance networks and these networks are then assembled. The air is modeled as a node in between the networks resembling the rotor and stator. The heat dissipation due to friction is applied to this node. The complete network is explained in App. B. The conductive resistances are calculated using material and geometrical properties. The convective resistances are obtained from a convection heat transfer coefficient given by equations 5.11-5.16 and geometrical properties.

The equations are obtained for the complete system and written in matrix form as in Eq. 5.17 from which the temperature vector is solved:

$$
\mathbf{T}=\mathbf{R}^{-1} \mathbf{P}
$$

where $\mathbf{R}$ is the matrix of thermal conductances, $\mathbf{P}$ is the heat generation vector and $\mathbf{T}$ is the temperature vector.

\subsection{Conclusions}

Since the micro rotating machinery operate mostly at high rotation speeds the heat generation due to air friction is larger. Therefore the temperature increase of air in 
the gap between rotor and stator becomes significant. The changed temperature of the air in the gap due to friction must be calculated to update the air properties. The updated properties result in more accurate calculation of flow induced forces. The thermal network method can be used to calculate the temperature change. This method requires less computation time as compared to finite elements and finite difference methods and can be easily coupled with other multiphysical models. 



\section{Chapter 6}

\section{Coupling the Physical Models}

\subsection{Introduction}

In this chapter a model will be presented that takes multiphysical effects into account in the prediction of the rotordynamic behavior of high-speed minirotating machinery with a moderate flow confinement. Models for the temperature increase in the confinement and the flow-induced forces resulting from the surrounding fluid are combined with the structural finite element (FE) model for determining the rotordynamic behavior of minirotating machinery accurately. The structure has been analyzed via finite elements based on Timoshenko beam theory (Chapter 3). The FE model has been developed for predicting the rotordynamic behavior of the flexible rotor on flexible supports. Linearized flow-induced forces for a concentric rotor (Chapter 4) are implemented to the structure as added mass-stiffness-damping at each node representing the structure in the fluid confinement. As the rotation speed increases the following become more important: the heat loss because of friction and the subsequent temperature increase in the gap between rotor and casing. Consequently, the change of air properties due to temperature increase in the gap should be considered when calculating the flow-induced forces. A thermal model based on thermal networks in steady state has been developed (Chapter 5). This model is used to calculate the heat dissipation resulting from air friction and the temperature increase in the air gap as a function of rotation speed. At each rotation speed the temperature in the air gap between the rotor and the stationary casing is computed and air properties (density and coefficient of friction), which are used for the computation of flow-induced forces, are updated. In this way, the flow-induced forces and the thermal effects in medium gap confinements are coupled with the rotordynamic model (see Fig. 6.1) and their effects on stability, critical speeds and vibration response are investigated. 


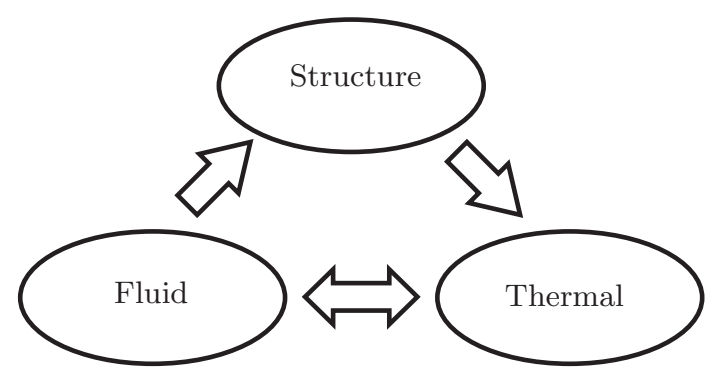

Figure 6.1: Interaction between physical domains

\subsection{Coupling Procedure}

The fluid forces given in Eq. 4.5 per unit length for the concentric configuration can be written in the following form:

$$
\begin{aligned}
& m_{x x} \ddot{u}_{x}+c_{x x} \dot{u}_{x}+c_{x y} \dot{u}_{y}+k_{x x} u_{x}+k_{x y} u_{y}=0 \\
& m_{x x} \ddot{u}_{y}+c_{x x} \dot{u}_{y}-c_{x y} \dot{u}_{x}-k_{x y} u_{x}+k_{x x} u_{y}=0
\end{aligned}
$$

By multiplying Eq. 6.2 with the imaginary number $i$ and summing up Eq. 6.1 and 6.2 we obtain:

$$
m_{x x}\left(\ddot{u}_{x}+i \ddot{u}_{y}\right)+c_{x x}\left(\dot{u}_{x}+i \dot{u}_{y}\right)-i c_{x y}\left(\dot{u}_{x}+i \dot{u}_{y}\right)+k_{x x}\left(u_{x}+i u_{y}\right)-k_{x y}\left(u_{x}+i u_{y}\right)=0
$$

In this way equations for flow-induced forces can easily be converted to complex coordinates and added to the structural formulation of Eq. 3.4. The flow forces per unit length are multiplied with element length $\mathrm{L}$ and lumped to the nodes of each element in the confinement as illustrated in Fig. 6.2. Eq. 6.3 only considers the translational degrees of freedom as $q=\left[u_{x_{1}}+i u_{y_{1}}, 0\right]$. Therefore flow-induced forces are implemented into the elements of the mass, damping, stiffness and gyroscopic matrices which correspond to the translational DOF. The mass $m_{x x}$ is added to the mass matrix $\mathbf{M}$, the damping $c_{x x}$ to the damping matrix $\mathbf{C}=\mathbf{C}_{r}+\mathbf{C}_{n}$ and the stiffness $k_{x x}$ to the stiffness matrix $\mathbf{K}$, the damping $c_{x y}$ is assembled to the gyroscopic matrix $\mathbf{G}$ and the stiffness $k_{x y}$ to the rotating damping matrix $\mathbf{C}_{r}$.

By using the developed thermal model the heat generation and air temperature in the gap are obtained at each rotation speed. Rotor, stator and air properties (density, viscosity, thermal conductivity, specific heat) at room temperature are used to calculate the heat generation and the air gap temperature. This temperature is used to update the friction coefficient and the air properties (density and viscosity) which are required for the calculation of the flow-induced forces.

Finally, the flow-induced forces are implemented into the structural model. In this way a coupled analysis of three physical domains is performed. The procedure for the coupling of these domains is given in Fig. 6.3. Note that in this way some of the relations between the physical domains as illustrated in Fig. 6.1 are ignored. It 


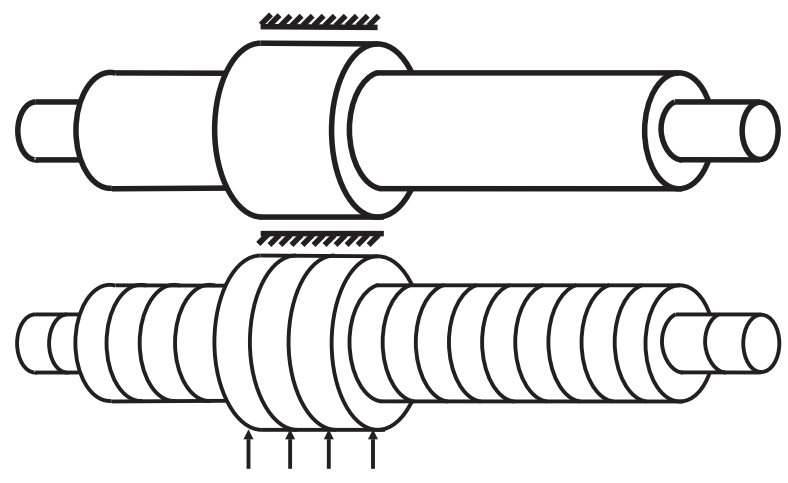

Flow Forces

Figure 6.2: Flow forces applied to structure model (up: rotor and casing, down: meshed rotor with finite elements)

is assumed that the update of the friction coefficient does not affect the computed temperatures significantly. Consequently, an iterative approach for this analysis is avoided.

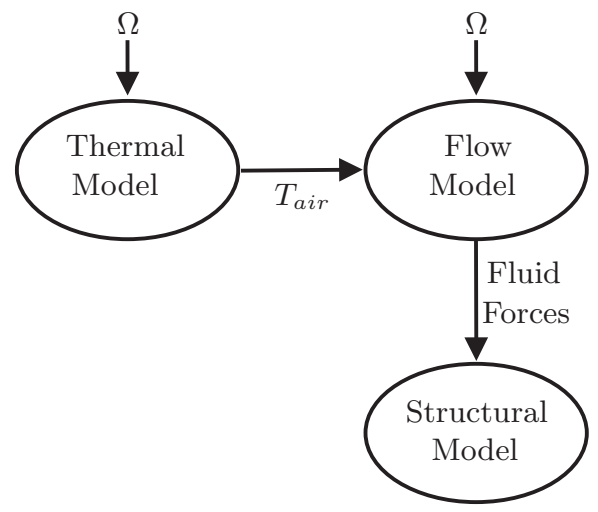

Figure 6.3: Coupling procedure

\subsection{Analysis of the Coupled System}

After coupling the influence of the multiphysical effects as described in the previous section, the dynamic behavior of the system has been investigated. A parametrical analysis has been carried out in order to find out the effect of fluid mass/rotor mass ratio, damping, friction coefficient, etc. In Fig. 6.4 the change of the natural frequencies and decay rates with speed is outlined for the first three eigenvalues of the rotor with the specifications given in Table 6.1. The reduced natural frequencies 
$\left(\bar{\omega}=\omega / \omega_{1}\right)$ and the decay rate, $\left(\bar{\sigma}=\sigma / \sigma_{1}\right)$ are plotted as a function of reduced rotation speed $\left(\bar{\Omega}=\Omega / \omega_{1}\right)$, where $\omega_{1}$ is the first rigid body mode natural frequency at standstill and $\sigma_{1}$ is the corresponding decay rate.

Table 6.1: System Specifications

\begin{tabular}{|cc|}
\hline Geometric and Material Specifications \\
\hline \hline Rotor Length $(\mathrm{mm})$ & 200 \\
Rotor Radius (mm) & 10 \\
Modulus of Elasticity $(\mathrm{GPa})$ & 205 \\
Shear Modulus $(\mathrm{GPa})$ & 79.3 \\
Density $\left(\mathrm{kg} / \mathrm{m}^{3}\right)$ & 7800 \\
Support Stiffness $(\mathrm{N} / \mathrm{m})$ & $2 \times 10^{5}$ \\
\hline
\end{tabular}
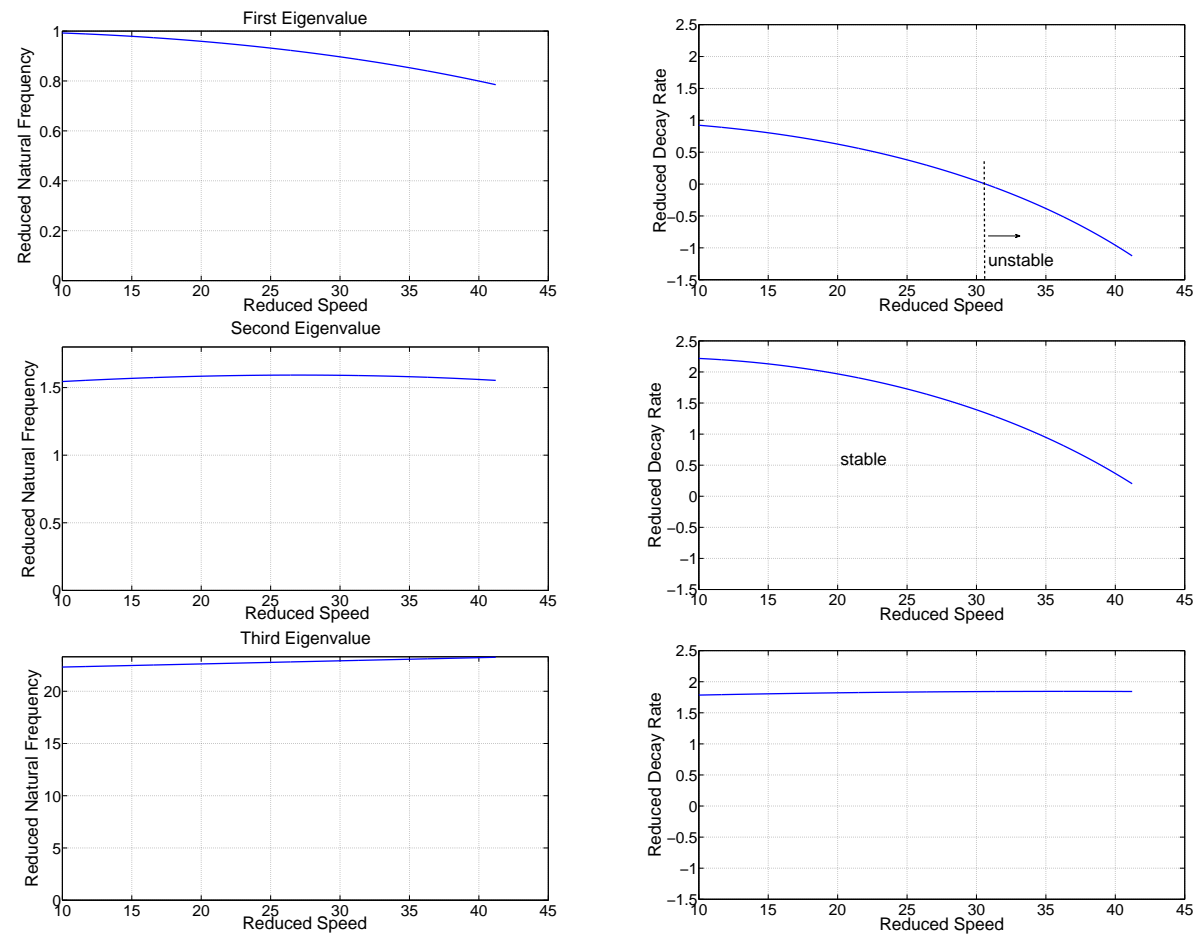

Figure 6.4: First three natural frequencies and decay rates

The first rigid body mode natural frequency resulting from the stiffness of the flexible support is affected most by multiphysical effects and the structure tends to become unstable at higher rotation speeds. Mini rotors mostly have flexible supports, 
therefore resulting in low natural frequencies. High-speed rotating mini machinery generally works at much higher rotational speeds beyond the first rigid body mode critical speed. Therefore the influence of different parameters such as support damping ratio, mass ratio (fluid mass/rotor mass) and friction coefficients are examined for a fully confined rotor running at high speeds. The influence of the mass ratio on the first natural frequency and decay rate is illustrated in Fig. 6.5. The mass ratio (fluid mass/rotor mass) has a profound effect on the natural frequency and the onset of instability. The high-speed mini rotating machinery generally operates at much higher speeds than the first rigid body critical speed. Therefore the change in first natural frequency at higher speeds is not significant since the related critical speed has already been passed. However, stable operation ranges should be accurately determined in order to prevent failures. The mass ratio has significant influence on the stability of the system as shown in Fig. 6.5.
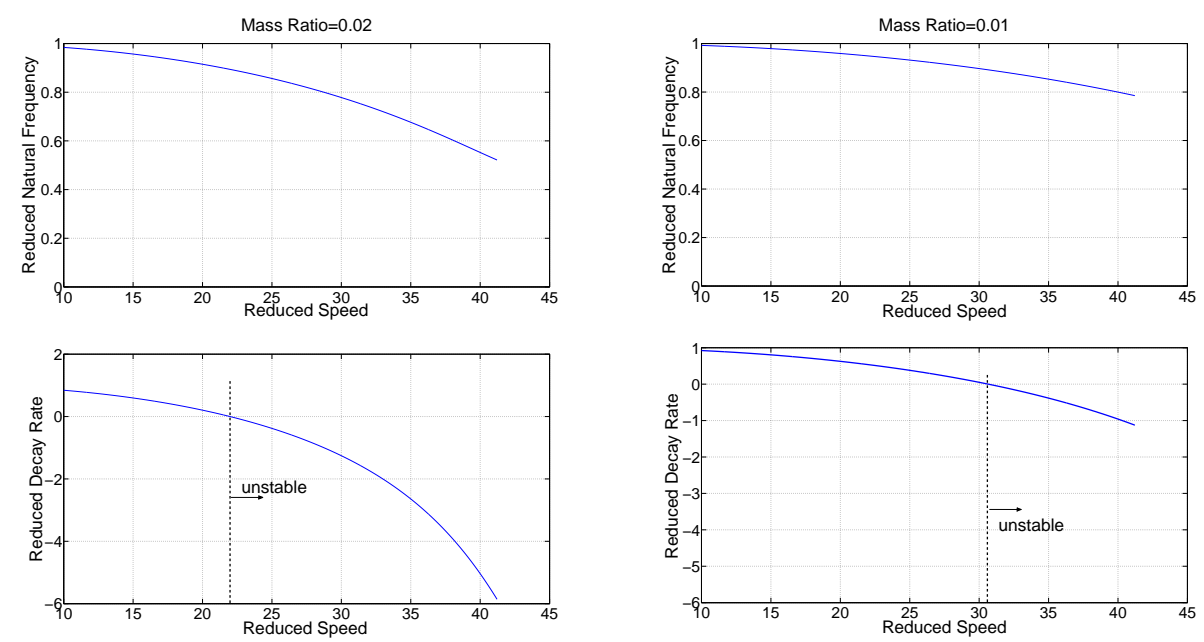

Figure 6.5: Change of first natural frequency and decay rate with different mass ratios

Another parameter affecting the dynamics of the structure is the support damping ratio. The flow in the casing leads to both rotating and non-rotating damping. The flow-induced forces have also components that contribute to the rotational damping matrix $\mathbf{C}_{r}$ as explained in the previous section, resulting in self-excited vibrations. If the support damping is not enough, the system may easily become unstable and catastrophic failure may happen. The change of the first natural frequency and the decay rate with different support damping ratios is presented in Fig. 6.6. The support damping ratio does not affect the natural frequency, however, it has large influence on the stability of the system. The onset of instability changes from a reduced speed of 16 to 22 and 31 for damping ratios of $0.02,0.04,0.1$ respectively.

Another important parameter influencing the dynamics of the system is the friction coefficient. The dynamic properties with different friction coefficients are shown in 

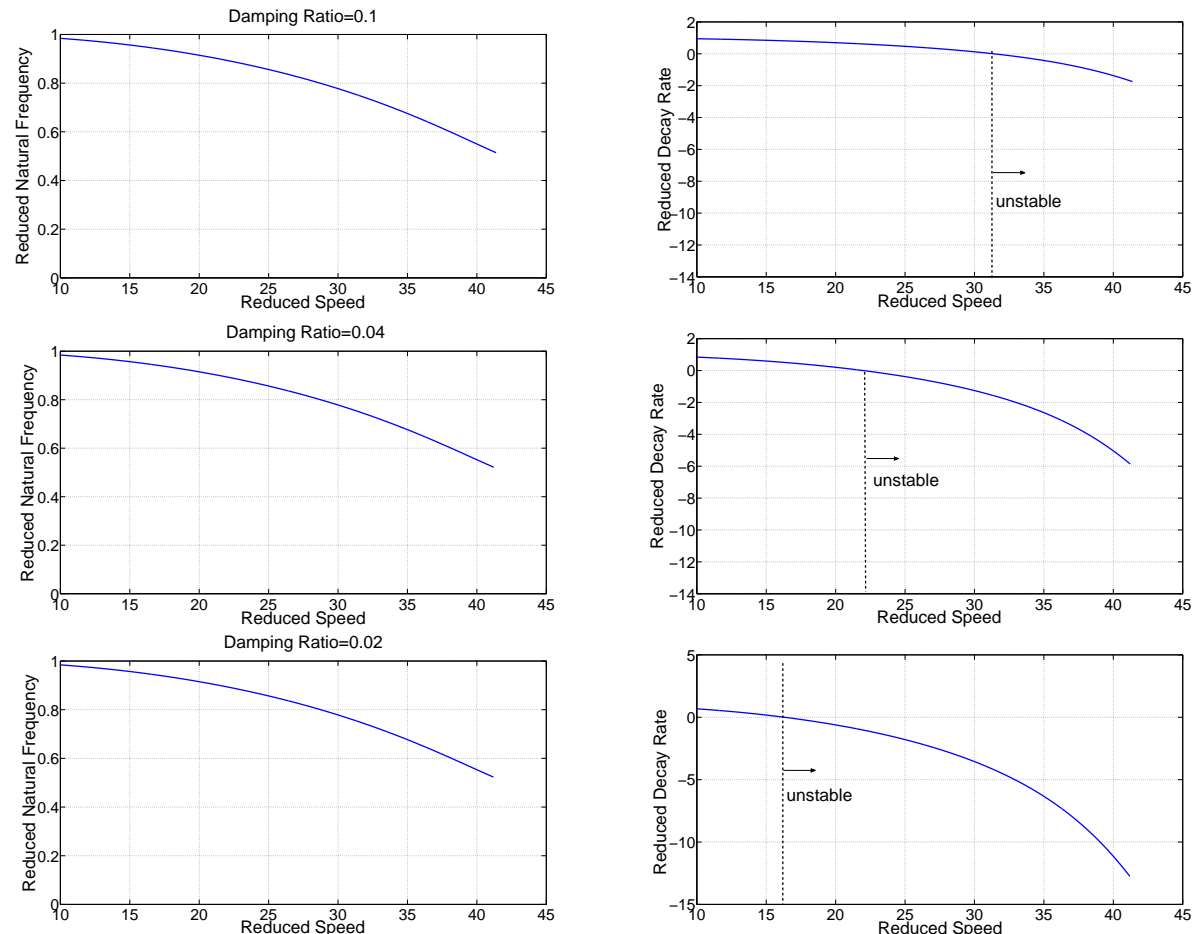

Figure 6.6: Change of first natural frequency and decay rate with damping
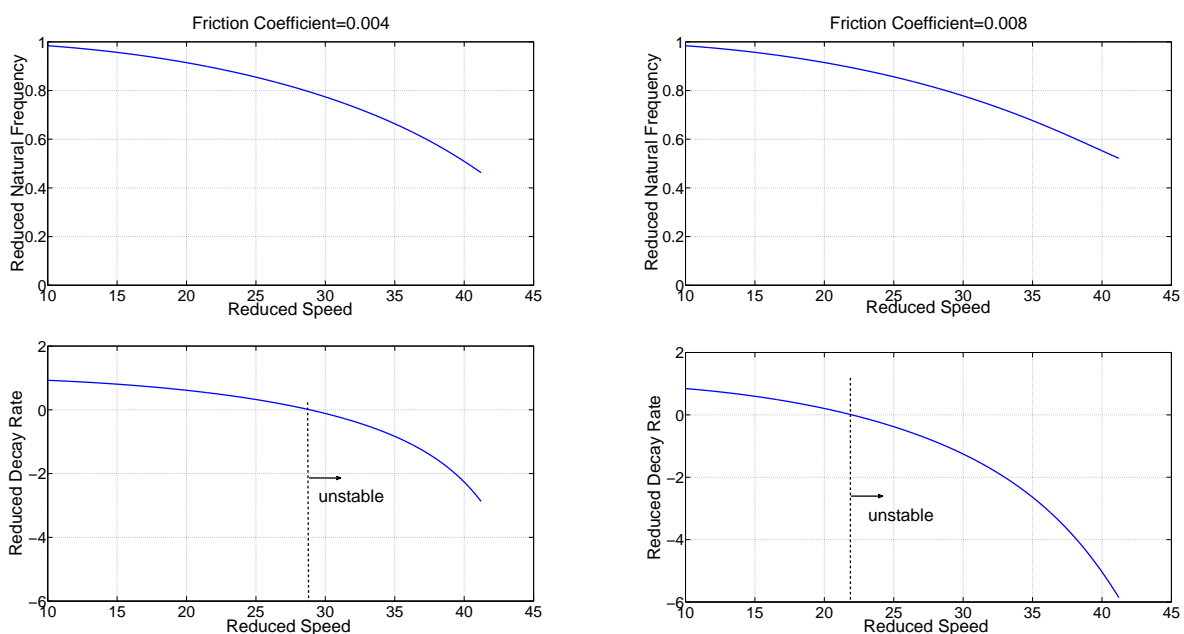

Figure 6.7: Change of first natural frequency and decay rate with friction coefficient 
Fig. 6.7. The friction coefficients are chosen as 0.004 and 0.008 since similar values are used in the literature [3] as realistic predictions. The friction coefficient also has a slight effect on the natural frequency but it has an important effect on the stability of the system. Therefore accurate friction coefficients should be estimated for predicting the stable operation speeds. The developed model enables calculation of the friction coefficients at different rotation speeds and also with changing air properties due to thermal effects. The influence of the change of temperature in the air gap on the dynamics of the structure is shown in Fig. 6.8. The natural frequencies and decay rates are calculated for temperature changes of $0^{\circ}, 20^{\circ}$ and $50^{\circ}$. The onset of instability varies around $4 \%$ between constant temperature and $50^{\circ}$ of change. Finally, the
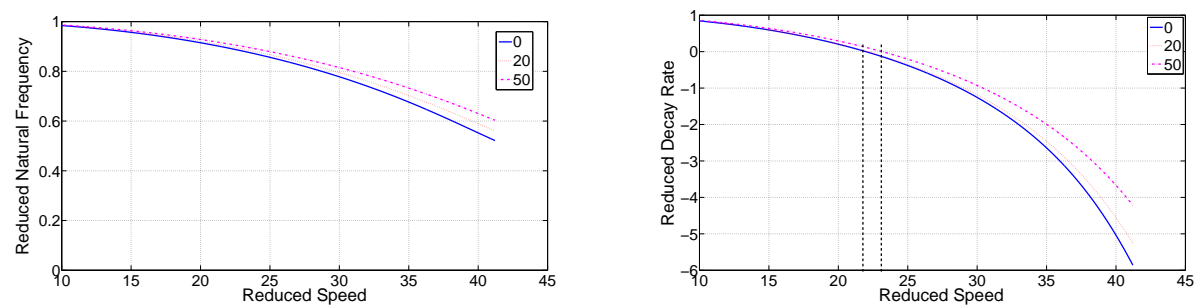

Figure 6.8: The effect of temperature change in the air gap on the dynamics of the structure

effect of the air gap length on stability has been examined as shown in Fig. 6.9. As the air gap length increases, the onset of instability changes drastically. Instability does not occur without a gap $(\delta \rightarrow \infty)$.

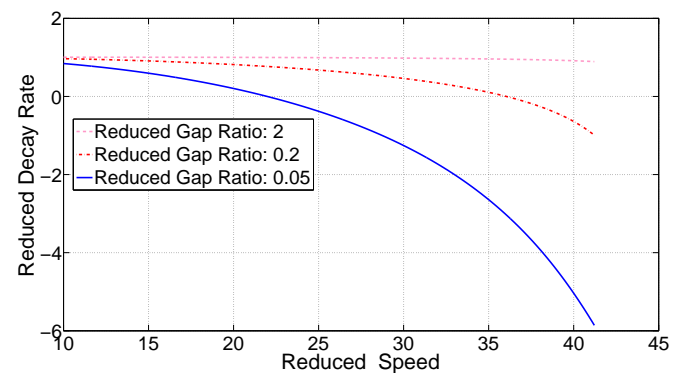

Figure 6.9: The effect of air gap on stability

\subsection{Discussion and Conclusion}

This chapter describes a method to add the flow-induced forces to the structural finite element model. In addition, a thermal model is used to include the changing flow properties due to temperature change. 
Structural, fluid and thermal models have been developed by using FEM, linearized flow forces and thermal networks, respectively. Then these models have been coupled and an analysis of the structure has been performed with dimensionless parameters such as mass ratio, support damping ratio and air friction coefficient in order to determine the parameters influencing the dynamics of high-speed rotors. The analysis has been done by assigning values to these parameters in order to find out the effect of each variable disregarding its dependency on other parameters. The results are plotted as reduced speed, reduced damping and reduced natural frequency. The mass ratio (fluid mass/ rotor mass) has been observed to greatly affect the first natural frequency as well as the onset of instability. High-speed mini rotors with flexible supports (support stiffness is much less than the stiffness of the rotor itself), generally operate at speeds much higher than the first rigid body mode critical speed, which means that stable operation at high speeds is an important issue. The flow forces incorporate both rotating and non-rotating damping which may result in stability problems depending on the amount of support damping. Different support damping ratios have been analyzed and appeared to have a strong effect on the stability of the rotor. Finally, the effect of the fluid friction coefficient on the rotordynamics has been examined. The friction coefficients are also observed to have very strong influence on the stability of the structure.

In conclusion, the analysis from the developed modeling approach reveals that the flow in moderate air gaps of minirotating machinery results in stability problems due to rotating damping. This has to be validated in an experimental setup. Design and construction of an experimental set up, experimental results and comparison with the theory will be presented in the upcoming chapters. 


\section{Chapter 7}

\section{Design of the Experimental Setup}

\subsection{Introduction}

In the previous chapters different models have been outlined for multiphysical effects that are relevant in rotating machinery on a small scale and a coupling method has been explained. In order to test the developed multiphysical rotordynamics analysis approach (see Chapter 6) an experimental setup is required. This chapter identifies the design requirements and design process of the experimental setup for the analysis of the dynamic behavior. The effect of different geometrical parameters such as the diameter, length, maximum rotation speed, etc. on the rotordynamic behavior will be examined. The design decisions based on these results as well as on the availability, simplicity and applicability of each component will be discussed in detail.

\subsection{Analysis of the Rotor Parameters}

The multiphysical effects on the dynamics of the rotor are investigated for different geometries, various gap sizes and different support stiffnesses to determine the design parameters. The design parameters should be selected such that the multiphysical effects (previous chapters) indeed play a role and hence can be measured (see also Sec. 7.4). Microrotating machinery has mostly small shaft diameters (5-10 mm) and high speeds (100 000-300 $000 \mathrm{rpm}$ ). However similar flow conditions occur at low speeds with larger rotor diameters. To demonstrate the effect of a single parameter clearly the other parameters are kept constant. Therefore an initial geometry, support stiffness, speed and clearance are used in the simulations as shown in Table 7.1 and Fig. 7.1. The geometrical parameters are determined in order to investigate whether 
the multiphysical effects are visible at lower speeds. The damping ratio is assumed to be $1 \%$ which is a reasonable value for steel components.

Table 7.1: Initial system parameters

\begin{tabular}{|c|c|c|}
\hline Rotation Speed $(\Omega)$ & 50000 & $\mathrm{rpm}$ \\
\hline Clearance $(H)$ & 0.5 & $\mathrm{~mm}$ \\
\hline Disk Diameter $\left(D_{d}\right)$ & 40 & $\mathrm{~mm}$ \\
\hline Disk Width $(L)$ & 30 & $\mathrm{~mm}$ \\
\hline Diameter-Near Disk & 15 & $\mathrm{~mm}$ \\
\hline Diameter-Shaft $\left(D_{s}\right)$ & 6 & $\mathrm{~mm}$ \\
\hline Near Disk Length & 10 & $\mathrm{~mm}$ \\
\hline Total Length $(L t)$ & 150 & $\mathrm{~mm}$ \\
\hline Support Stiffness $(k)$ & $10^{5}$ & $\mathrm{~N} / \mathrm{m}$ \\
\hline Damping $(c)$ & 1 & $\%$ \\
\hline
\end{tabular}

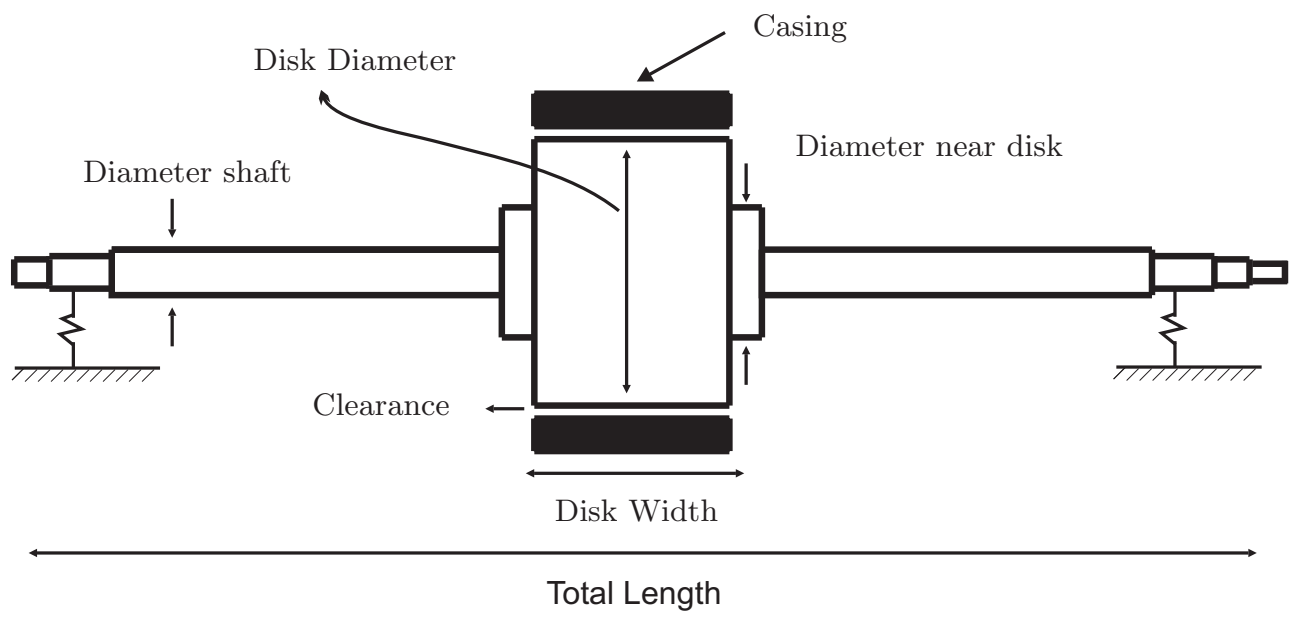

Figure 7.1: Rotor parameters

\subsubsection{Rotation Speed}

The simulation results with and without casing are compared to observe the flowinduced effects on the dynamic behavior. The simulations are performed in a range of rotation speeds, $\Omega$. It is observed that only the first natural frequency changes significantly in the case of air gap. The flow-induced effects become more important with increasing rotation speed $(\Omega)$. A summary of these results is listed in Table 7.2. 
Table 7.2: First natural frequency at different rotation speeds

\begin{tabular}{|c|c|c|c|c|c|c|c|}
\hline Rotation Speed & $\mathrm{rpm}$ & 1000 & 30000 & 50000 & 60000 & 80000 & 100000 \\
\hline without air & $\mathrm{rad} / \mathrm{s}$ & 692.1 & 692.1 & 692.1 & 692.1 & 692.1 & 692.1 \\
with air & $\mathrm{rad} / \mathrm{s}$ & 692.0 & 690.0 & 682.1 & 676.0 & 659.2 & 636.3 \\
\hline difference & $\%$ & 0.01 & 0.30 & 1.45 & 2.32 & 4.75 & 8.06 \\
\hline
\end{tabular}

\subsubsection{Clearance}

The clearance between the casing and the rotor affects the flow-induced forces. Therefore the size of the gap is significant for the rotordynamic behavior. Simulations have been performed for three different clearances. The onset of instability and the first natural frequencies are listed in Table 7.3. The difference with respect to the situation without casing is also presented.

Table 7.3: Natural frequencies at $50000 \mathrm{rpm}$ and onset of instability

\begin{tabular}{|cc|ccc|}
\hline Clearance & {$[\mathrm{mm}]$} & $\mathbf{0 . 2 5}$ & $\mathbf{0 . 5 0}$ & $\mathbf{0 . 7 5}$ \\
\hline Gap Ratio (H/r) & - & $1 / 80$ & $1 / 40$ & $3 / 80$ \\
\hline First Natural Frequency & $\mathrm{rad} / \mathrm{s}$ & 671.8 & 682.1 & 685.0 \\
\hline Difference between without casing & $\%$ & 2.93 & 1.44 & 1.02 \\
\hline Onset of Instability & $\mathrm{rpm}$ & 28800 & 62000 & 102100 \\
\hline
\end{tabular}

As the clearance decreases the flow-induced effects become more important. The natural frequencies do not change significantly. However, the onset of instability changes drastically.

\subsubsection{Disk Diameter}

The disk diameter $D_{d}$ is another important design parameter. It has a significant contribution on the disk surface velocity and thus on the flow-induced forces and the flow regime. The simulation results for different disk diameters are given in Table 7.4.

As the diameter increases the surface velocity increases linearly and the flow-induced effects become more dominant. The decay rate graphs are given in Fig. 7.2 for $D_{d}=30$ and $60 \mathrm{~mm}$, respectively. As the decay rate becomes negative self-excited vibrations occur and the system becomes unstable. 
Table 7.4: Natural frequencies at $50000 \mathrm{rpm}$ and onset of instability for different disk diameters

\begin{tabular}{|cc|cccc|}
\hline Diameter & {$[\mathrm{mm}]$} & $\mathbf{3 0}$ & $\mathbf{4 0}$ & $\mathbf{5 0}$ & $\mathbf{6 0}$ \\
\hline Gap Ratio(H/r) & - & $1 / 30$ & $1 / 40$ & $1 / 50$ & $1 / 60$ \\
\hline First Natural Frequency & $\mathrm{rad} / \mathrm{s}$ & 873.3 & 682.1 & 549.4 & 450.7 \\
\hline Difference between without casing & $\%$ & 0.55 & 1.44 & 3.21 & 6.05 \\
\hline Onset of Instability & $\mathrm{rpm}$ & 106600 & 62000 & 40300 & 28700 \\
\hline
\end{tabular}

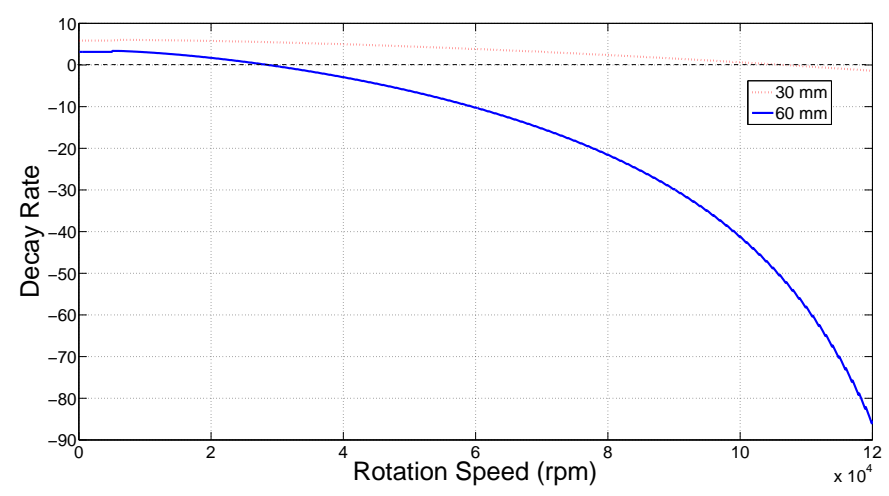

Figure 7.2: Decay rates for disk diameter of $60 \mathrm{~mm}$ and $30 \mathrm{~mm}$

\subsubsection{Disk Width}

The Disk Width, $L$ is also an important design parameter. It alters the mass of the rotor and consequently the natural frequencies. Besides, it is confined in the casing and it determines the surface area of the rotor under the influence of fluid. Simulations are performed for different lengths and the results are shown in Table 7.5.

Table 7.5: Natural frequencies at $50000 \mathrm{rpm}$ and onset of instability for different disk lengths

\begin{tabular}{|cc|cccc|}
\hline Disk Width & {$[\mathrm{mm}]$} & $\mathbf{1 0}$ & $\mathbf{2 0}$ & $\mathbf{3 0}$ & $\mathbf{4 0}$ \\
\hline First Natural Frequency & $\mathrm{rad} / \mathrm{s}$ & 1064.0 & 815.2 & 682.1 & 595.3 \\
\hline Onset of Instability & $\mathrm{rpm}$ & - & 93700 & 62000 & 48600 \\
\hline
\end{tabular}




\subsubsection{Support Stiffness}

The support stiffness determines the critical speeds and the mode shapes. In Table 7.6 the first three critical speeds till $200000 \mathrm{rpm}$ are given for different support stiffnesses. In Fig. 7.3 the mode shapes corresponding to the first natural frequency are given for different support stiffnesses. The horizontal axis shows the length of the shaft and the vertical axis shows the displacement normalized with respect to the displacement of first node.

Table 7.6: The critical speeds for different support stiffness

\begin{tabular}{|cc|ccc|}
\hline Stiffness & {$[\mathrm{N} / \mathrm{m}]$} & $10^{5}$ & $10^{6}$ & $10^{7}$ \\
\hline First Critical Speed & $\mathrm{rpm}$ & 6400 & 12700 & 14800 \\
\hline Second Critical Speed & $\mathrm{rpm}$ & 38300 & 104900 & 152400 \\
\hline Third Critical Speed & $\mathrm{rpm}$ & 121800 & 196000 & Above 200 000 \\
\hline
\end{tabular}

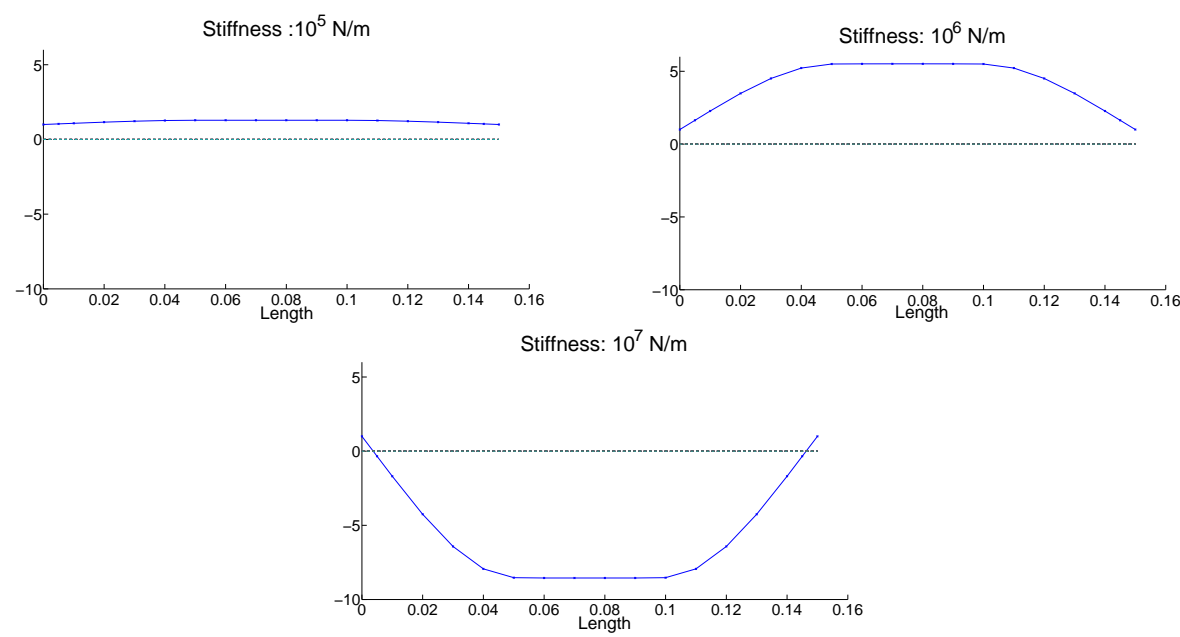

Figure 7.3: Mode shapes for the first natural frequency at different support stiffnesses

The support stiffness changes the mode shapes and the critical speeds drastically. The mode shapes show that the deformation of the shaft is considerable for support stiffnesses of $10^{6}$ and $10^{7} \mathrm{~N} / \mathrm{m}$. In addition, the second and third critical speed changes significantly (Table 7.6). 


\subsection{Temperature Increase and Friction Torque}

The air in the gap results in friction losses as explained in the previous chapters. The amount of power loss and torque due to air friction should be known in advance in order to select the motor which can reach the desired operation speeds. The air friction loss due to the shaft itself is much lower compared to the disk, since the shaft diameter is much smaller. For different disk diameters, disk widths, spin speeds and air gaps, the air gap temperature, power loss and friction torque are calculated. For an initial geometry (Table 7.1) these results are listed in Table 7.7. The maximum rotation speed and the disk diameter have the largest effect on the friction torque.

Table 7.7: System Parameters and Friction Torque

\begin{tabular}{|cc|c|c|c|c|c|c|}
\hline Disk Diameter & $\mathbf{m m}$ & $\mathbf{1 0}$ & $\mathbf{2 0}$ & $\mathbf{3 0}$ & $\mathbf{4 0}$ & $\mathbf{5 0}$ & $\mathbf{6 0}$ \\
\hline Temperature & $\mathrm{K}$ & 293.2 & 293.8 & 294.8 & 295.7 & 297.1 & 299.7 \\
Torque & $\mathrm{mNm}$ & 0.02 & 0.16 & 0.56 & 1.42 & 2.91 & 5.21 \\
\hline Disk Width & $\mathbf{m m}$ & $\mathbf{1 0}$ & $\mathbf{2 0}$ & $\mathbf{3 0}$ & $\mathbf{4 0}$ & $\mathbf{5 0}$ & $\mathbf{6 0}$ \\
\hline Temperature & $\mathrm{K}$ & 295.7 & 295.7 & 295.7 & 295.7 & 295.7 & 295.7 \\
Torque & $\mathrm{mNm}$ & 0.47 & 0.95 & 1.42 & 1.90 & 2.37 & 2.85 \\
\hline Rotation Speed & $\mathbf{K r p m}$ & $\mathbf{2 0}$ & $\mathbf{4 0}$ & $\mathbf{5 0}$ & $\mathbf{6 0}$ & $\mathbf{8 0}$ & $\mathbf{1 0 0}$ \\
\hline Temperature & $\mathrm{K}$ & 293.4 & 294.7 & 295.7 & 296.9 & 300.2 & 304.6 \\
Torque & $\mathrm{mNm}$ & 0.36 & 1.02 & 1.42 & 1.88 & 2.88 & 4.03 \\
\hline Clearance & $\mathbf{m m}$ & $\mathbf{0 . 2 0}$ & $\mathbf{0 . 2 5}$ & $\mathbf{0 . 3 0}$ & $\mathbf{0 . 4 0}$ & $\mathbf{0 . 5 0}$ & $\mathbf{0 . 6 0}$ \\
\hline Temperature & $\mathrm{K}$ & 295.7 & 295.7 & 295.7 & 295.7 & 295.7 & 295.7 \\
Torque & $\mathrm{mNm}$ & 1.71 & 1.63 & 1.58 & 1.49 & 1.42 & 1.37 \\
\hline
\end{tabular}

\subsection{Design Process}

\subsubsection{Requirements}

The aim of this study is to design an experimental setup in which the multiphysical effects on the dynamics of the microrotating machinery can be investigated. The onset of instability resulting from the surrounding fluid should be measured in the operation range. The design criteria have been determined by considering the analysis in the previous section. The requirements for each parameter are listed below:

- Rotation Speed $(\Omega)$ : Must be high enough to observe instability. Besides, the maximum rotation speed should be in the operation range of the motor.

- Gap Size $(\mathrm{H})$ : Must be determined such that the gap ratio $(\mathrm{H} / \mathrm{r})$ is different from the gap ratios present in bearings and seals. Flow-induced instability should be measurable in the operation range (Table 7.3). 
- Disk Diameter $\left(D_{d}\right)$ : Must be determined to result in similar flow conditions as the microrotating applications in the literature. Besides, the disk diameter should be selected such that the instability can be observed in the operation range (Table 7.4 ).

- Disk Width $(L)$ : The disk width must be selected such that the air friction torque is low but still the multiphysical effects are observable.

- Shaft Diameter $\left(D_{s}\right)$ : Must be small such that the flexural mode natural frequency can be measured.

- Rotor Length $(L t)$ : Must be determined such that the air friction torque is negligible but still the modeled multiphysical effects can be measurable.

- Support Stiffness $(k)$ : Most of the applications in the literature use air bearings or magnetic bearings with low support stiffness. The support structure must be designed to have similar support properties to mimic these applications and to enable the measurement of instability in the operation range.

Studying the temperature increase in the air gap is not a design criterion because from the previous analysis (Table 7.7) it can be seen that the increase in temperature cannot be easily observed with a feasible design. Besides, accurate measurements of air temperature could be quite difficult. The high rotation speeds, the complex flow and the small gap prevent locating a sensor for temperature measurement. Therefore the thermal model has been verified by comparing it with results obtained from a CFD model [18](See Chapter 8).

\subsubsection{Component Design}

\section{Motor}

There are different ways to drive the rotor. A pelton impulse turbine has been used in the preliminary design of microturbines. High rotation speeds (160 $000 \mathrm{rpm})$ and driving torques can be achieved [61]. However, the design and manufacturing of blades are complex and require a long design process.

Another option is to use a permanent magnet motor. This motor consists of magnets attached to the rotor and a stator made of windings reaching high speeds of 170 $000 \mathrm{rpm}$. Only the stator and permanent magnets are commercially available in the market, from which the complete motor should be built by the client. Furthermore, this choice results in long delivery time.

The third option is to use a brushless motor. This is a complete motor with an output shaft and makes use of windings and magnets. A disadvantage of this motor is the lower maximum speed, which is limited by the bearings in the motor. In addition a coupling is needed to connect the output shaft to the rotor. This option has been selected since it is available in the market and simple to be implemented into the 
experimental setup. A speed of $50000 \mathrm{rpm}$ is enough to observe the multiphysical effects provided the disk diameter is increased as seen in Table 7.4. This enables similar flow conditions as exist in smaller micromachinery with higher rotation speeds. In addition, in Table 7.2 it is observed that the change in natural frequency is not significant even at a speed of $100000 \mathrm{rpm}$ and the unstable operation can happen before reaching this speed. Therefore it was decided to use a motor with a maximum operation speed of $50000 \mathrm{rpm}$ and to adjust the disk diameter, $D_{d}$, the clearance and the other parameters analyzed in section 7.2 so that the onset of instability can be determined.

A Maxon EC 22 motor has been used for the current application. The EC 22 motor has three hall sensors to locate the orientation of the output shaft. The hall sensors provide information about the rotation speed. This information is sent to an amplifier. This unit also controls the speed, acceleration and direction of the motor. The motor is clamped on an aluminum block.

\section{Rotor}

The dimensions of the rotor have been determined so that the critical speeds and the unstable operation can be observed within the operation range. The final geometry is shown in Fig. 7.4 and the properties are given in Table 7.8.

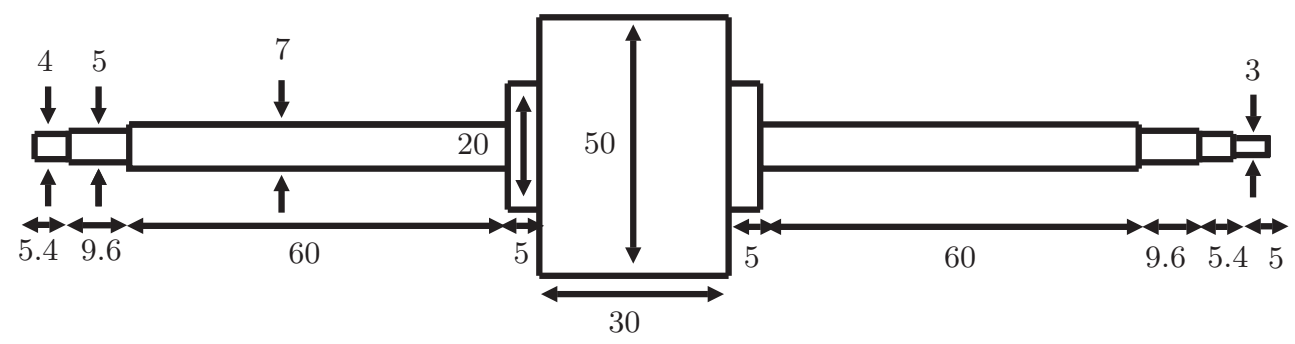

Figure 7.4: The dimensions of the rotor

Table 7.8: Specifications of the experimental setup

\begin{tabular}{|cc|}
\hline Parameter \\
\hline \hline Rotor Material & Steel (DIN 1.2510) \\
Rotor Length L (mm) & 195 \\
Maximum Rotor Radius r (mm) & 25 \\
Annular Gap H (mm) & 0.5 \\
Gap Ratio $\delta$ & $1 / 50$ \\
Modulus of Elasticity E (GPa) & 205 \\
\hline
\end{tabular}


A disk diameter of $50 \mathrm{~mm}$ results in significant flow-induced effects as can be seen in Table 7.4. A larger diameter would be even more significant, but it would increase the amount of torque required for the motor. The total length of the rotor is $195 \mathrm{~mm}$ with a nominal shaft diameter of $7 \mathrm{~mm}$. The length of the disk has been determined to be $30 \mathrm{~mm}$. In that case the multiphysical effects are significant. Making the disk width longer increases the multiphysical effects only slightly (see Table 7.5), while it results in more friction torque. Because of the large difference in diameter between the shaft and the disk, the diameter of the rotor is locally increased to $20 \mathrm{~mm}$ near the disk. This results in lower stresses in the rotor. The diameter of the shaft at the bearing locations is $5 \mathrm{~mm}$ in order to mount the bearings. An M4 nut locks the other side of the inner ring. The right side of the rotor has an additional part with a diameter of $3 \mathrm{~mm}$ to mount the coupling. The tolerances on the bearing seats are based on the information provided by the bearing company. The rotor has been manufactured with strict tolerances and from one piece in order to reduce eccentricity and unbalance. High performance steel DIN 1.2510, hardened at $50 \mathrm{HR}$ is used in order to achieve better surface quality and to increase the yield strength.

\section{Bearing}

Due to high rotation speeds and friction losses, contactless (air or magnetic) bearings $[50,86]$ or special ball bearings are used for the high-speed minirotating machinery [91]. Aerostatic, aerodynamic and air foil bearings rely on external pressure or rotor rotation. The operation is contactless and the amount of friction loss is less than the traditional levitation systems. However they are not commercially available and they require detailed, complex analysis to design and manufacture. Magnetic bearings use magnetic forces to levitate the rotor. They have the same advantages as the gas bearings, but they require sensors and control units. Besides they are not commercially available for standard solutions. High-speed ball bearings are available commercially at small size. They are robust and do not require extra equipment. More friction than contactless bearings and limited operation temperatures are the main disadvantages. However, due to robustness, availability in the market, simplicity of mounting and operating at high speed, angular contact ball bearings are selected for this experimental setup. Angular contact bearings are also capable of supporting the axial loads. In this study, the GMN S625 C TA bearings are used which enable safe operation above $100000 \mathrm{rpm}$. This bearing consists of balls made from chrome steel, an inner ring with two shoulders, an outer ring with one shoulder and a cage made from textile-reinforced phenolic resin between these two rings.

\section{Coupling}

A coupling is needed to connect the motor to the rotor. This coupling should be flexible, otherwise the vibrations will be transmitted to the motor and vice-versa then the motor could be damaged. The torque delivered by the motor has to be transferred to the rotor by using the coupling. Therefore the coupling is stiff in the 
rotating axis and flexible in the radial axes. The coupling KTR Rotex GS 5 is used to connect the motor to the rotor. The coupling consists of three parts: two metal hubs and a flexible plastic spider in between. The coupling is illustrated in Fig. 7.5.

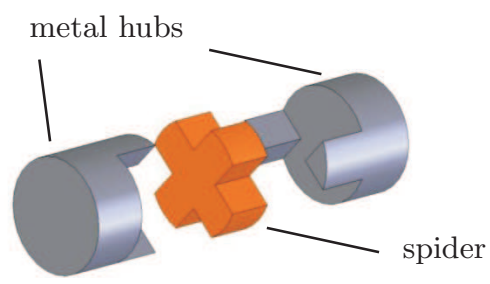

Figure 7.5: The coupling

One hub is connected to the motor and the other to the rotor. This can be done by gluing or clamping with a bolt. Gluing is a better solution, since the bolt introduces an extra unbalance. The choice of the spider is also important, because a more flexible spider can absorb more axial, angular and radial misalignment but can handle less torque. The most flexible spider can handle $300 \mathrm{mNm}$, which is much higher than the driving torque at maximum speed $(15 \mathrm{mNm})$.

\section{Flexible Support}

As explained before most of the high-speed microrotating machinery has contactless bearings which have lower support stiffness compared to conventional supports. Besides, from the previous analysis it has been observed that the support stiffness should be in the order of $10^{5} \mathrm{~N} / \mathrm{m}$ in order to observe the multiphysical effects. The radial stiffness of the ball bearings is around $10^{7}-10^{8} \mathrm{~N} / \mathrm{m}$. Therefore, an extra support system is required to decrease the support stiffness of the rotor. This is achieved with a flexible support between the bearing and the fixed frame. The support structure must be radially isotropic and axial movement must be prevented. This flexible support can be made of beams or leaf springs. The stiffness of this bearing support can be changed by elongating these beams or leaf springs. Another solution is to use flexible rings between the bearing and the bearing housing [77]. However these rings are made of plastic or rubber and are not available on the market. Besides, it is difficult to manufacture isotropic rings. Furthermore, for each new experiment these rings should be replaced by rings with a different stiffness and the whole setup should be aligned again in order to perform experiments with different support stiffnesses. A different solution to decrease the stiffness is hanging the bearings on springs. However, the springs can easily bend and the bearing housing can tilt resulting in alignment problems and extra friction.

Finally, a robust support which provides isotropic radial stiffness has been designed. The flexible support includes three support beams, a support disk in which the bearings are located and two brackets as shown in Fig. 7.6. The supporting bracket can be moved to another position thus changing the beam length. In this way the 
support stiffness, which changes the rotordynamic behavior, can be adjusted. The aligning bracket avoids alignment problems during this process. An ANSYS model has been developed to determine the stiffness and the support beam lengths are determined accordingly. The supports are modeled by structural solid elements: Solid 92. The stiffness results obtained from the finite element analysis are provided in Table 7.9. The evaluation of the support stiffness and different equivalent support models are explained in the following chapter in more detail.

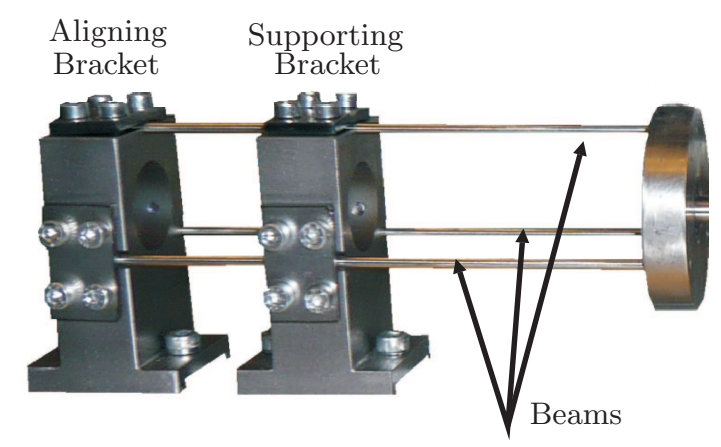

Figure 7.6: Flexible supports

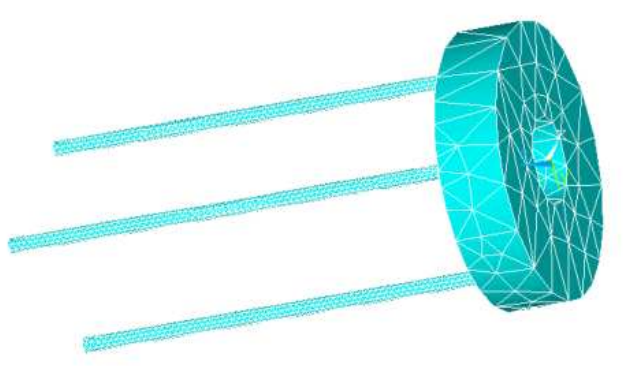

Figure 7.7: ANSYS model of the support

Table 7.9: Support stiffness for different beam lengths

\begin{tabular}{|c|c|c|c|}
\hline Beam Length $\mathbf{( m m})$ & $\mathbf{7 2} \mathbf{~ m m}$ & $\mathbf{8 0} \mathbf{~ m m}$ & $\mathbf{9 0} \mathbf{~ m m}$ \\
\hline Stiffness $\mathbf{( N / \mathbf { m } )}$ & $7.03 \times 10^{4}$ & $5.16 \times 10^{4}$ & $3.36 \times 10^{4}$ \\
\hline
\end{tabular}




\subsection{Evaluation of the Design}

\subsubsection{Comparison with Applications from the Literature}

The final design of the setup is shown in Fig. 7.8 [19]. The maximum operation speed is $50000 \mathrm{rpm}$. The reduced natural frequency and reduced decay rate are calculated for the experimental setup. They are compared with the ones from a microgenerator [91] from the literature. The microgenerator has a length of $55 \mathrm{~mm}$, diameter of $6 \mathrm{~mm}$ and maximum operation speed of $500000 \mathrm{rpm}$ [91]. Since the support stiffness of the microgenerator is unknown, different support stiffnesses are assumed in the simulations. For the experimental setup the beam length of $90 \mathrm{~mm}$ has been chosen in the simulations. In all simulations the same damping ratio of $1 \%$ is used.

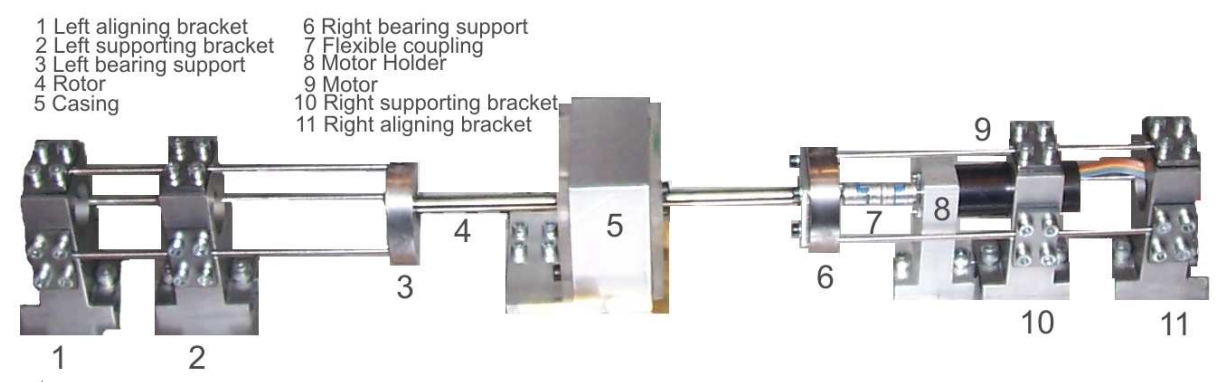

Figure 7.8: The complete experimental setup

The reduced natural frequency $\left(\bar{\omega}=\omega / \omega_{1}\right)$ and the reduced decay rate $\left(\bar{\sigma}=\sigma / \sigma_{1}\right)$ are plotted in Fig. 7.9 and Fig. 7.10 as functions of the reduced rotation speed $\left(\bar{\Omega}=\Omega / \omega_{1}\right)$, where $\omega_{1}$ is the first rigid body mode natural frequency at standstill and $\sigma_{1}$ is the corresponding decay rate.

As can be seen from Fig. 7.9 and Fig. 7.10, the support has significant effect on the first natural frequency and the stability of the rotor. Depending on these values similar reduced velocities and dynamic behavior (reduced natural frequency and decay rate) can be observed in both the designed setup and the microgenerator which is an example of microrotating machinery with high rotation speeds and low shaft diameters.

\subsection{Conclusions}

An experimental setup has been designed to validate the developed modeling approach for investigating multiphysical effects on the dynamics of mini rotors. 

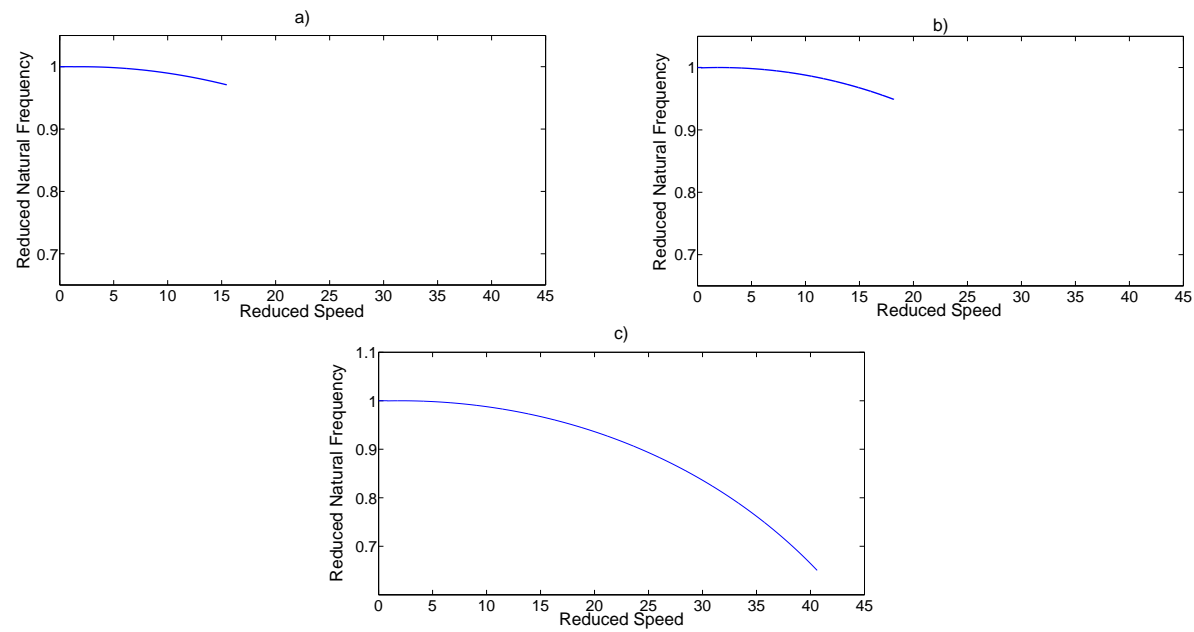

Figure 7.9: The reduced natural frequencies for different applications: a) The experimental setup b) Microgenerator, support stiffness: $5 \times 10^{4}$ c) Microgenerator support stiffness: $1 \times 10^{4}$

a)
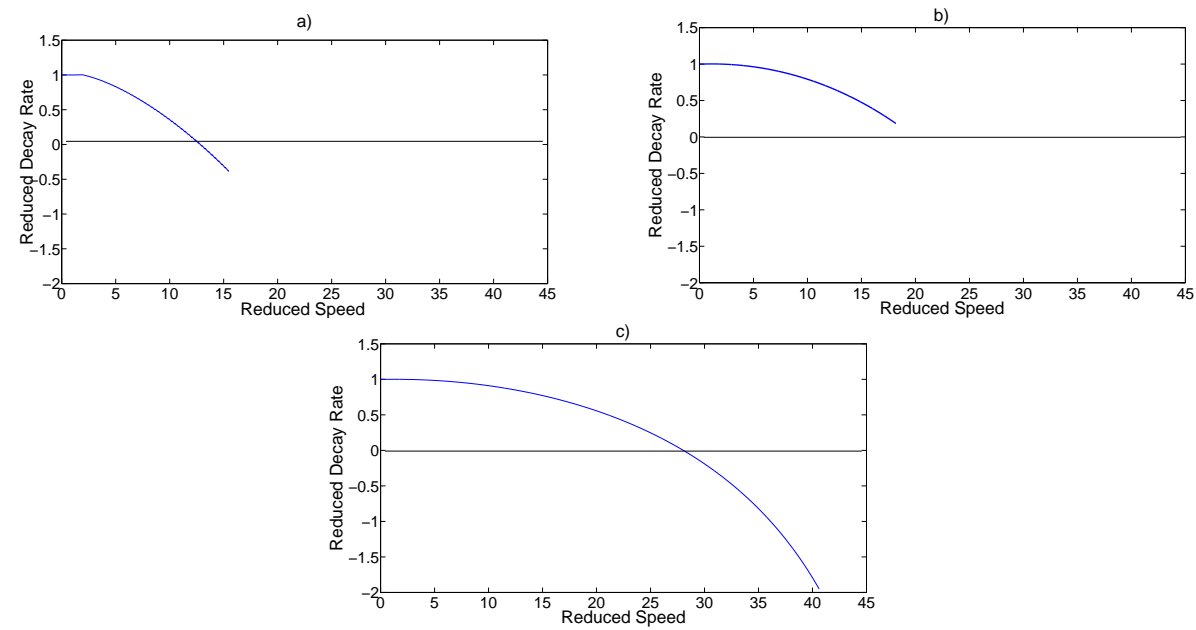

Figure 7.10: The reduced decay rate for different applications: a) The experimental setup b) Microgenerator, support stiffness: $5 \times 10^{4} \mathrm{~N} / \mathrm{m} \mathrm{c}$ ) Microgenerator support stiffness: $1 \times 10^{4} \mathrm{~N} / \mathrm{m}$

The multiphysical effects should be present in the operation range and the designed setup should represent similar operating conditions (surface velocity, flow type) as the other minirotating machinery. The design criteria have been determined and the construction of the experimental setup has been realized. Simulations revealed 
that the experimental setup is capable of imitating the dynamic behavior in other applications with higher rotation speed and smaller diameter. The results of the experiments conducted on the designed setup are explained in the next chapter. 


\section{Chapter 8}

\section{Validation of the Developed Modeling Approach}

\subsection{Introduction}

In the previous chapter, the design process of an experimental setup for testing the developed physical models was explained. In the foregoing analysis the surrounding air between the rotor and the casing appeared to affect the dynamic behavior of the high-speed mini rotors significantly. Especially unstable operation at high speeds may happen, which results in catastrophic failure (Chapter 6). Therefore the rotordynamic behavior should be tested in order to investigate the multiphysical effects and the applicability of the developed models. This chapter covers the validation of the structural model and flow-force model via experiments with and without confined rotor.

There are scarce results in the literature for testing the dynamic behavior of highspeed mini rotors under the influence of other physical phenomena. However, some experimental studies are available for larger systems. Antunes et al. [4] presented experimental results for systems with a medium air gap thickness between rotor and casing on a test model at low spinning velocities, for various values of the immersed shaft length. Grunenwald et al. [36] performed similar experiments using different fluids with a large range of fluid viscosity. In another study concentric and eccentric configurations were studied [37]. Experiments are done to determine the natural frequencies and the onset of instability. The experimental and theoretical results agree fairly well. These studies report rigid rotor formulation, highly viscous fluids as compared to air and relatively low rotation speeds (2000 rpm).

Rotating machines on a small scale operate at much higher velocities than the rigid body mode critical speed and generally also beyond the first flexural mode critical speed. These speeds result in stability problems even with low viscous fluids. 
Therefore, in the current study, the dynamic properties and stable operation regimes of a mini rotor confined in air are tested at different support stiffnesses and compared with the theoretical results obtained using the developed modeling approach (Chapters 3-6).

At first a modal analysis of the rotor is done in free-free conditions in order to test the capability of the rotordynamic model without the supports and multiphysical effects. Then modal analysis of the whole structure is done at standstill and during operation in the absence of the casing. In this way, multiphysical effects are eliminated and only support effects on the dynamics of the structure are observed. The supports appear to have a significant effect on the natural frequencies of the flexural modes of the system. Different support modeling techniques are studied and adequate equivalent models are obtained. Simple support models consisting of mass-spring systems are extracted from a modal analysis of the isolated support and by applying static loads to the finite element model of the supports. These models are then implemented into the structural model of the rotor. An experimental modal analysis of the rotor is performed with different support beam lengths. The experimental and theoretical results have been compared and an adequate support modeling approach has been examined.

Finally, multiphysical effects are tested at different speeds with different support stiffness. Experiments are performed with and without the casing to determine the change of the natural frequencies and onset of instability.

Different support damping has been observed with and without the shaker. Instability has been experimentally observed for both laminar and turbulent flow regime. For turbulent flow only empirical friction coefficients are available. For laminar flow, both empirical and analytical friction coefficients can be used (see chapter 4). By comparing the experiments with the theoretical models, the applicability of the different friction models in laminar flow has also been examined.

As was seen in sections 7.3 and 7.4 the thermal model cannot be validated by experiments on a feasible design. Therefore more complicated modeling techniques are used and compared with thermal networks. The rotor, the stator and the air gap are also modeled by using computational fluid dynamics (CFD) and FEM with CFX and ANSYS respectively. The results have been compared and the capability of the thermal networks method to calculate the temperature of the air between the rotor and stator of a high-speed mini rotor has been discussed.

\subsection{Experiments}

\subsubsection{Instrumentation}

The measurement setup is illustrated in Fig. 8.1. Two B\&K 4374 accelerometers and a Polytec OFV 505 Laser Doppler Vibrometer (LDV) are used to measure the vibration of the rotor and the supports. The accelerometers are mounted on the non-rotating 
support disks in which the bearings have been mounted. The LDV is directed to the rotor surface. Random noise excitation is provided by a B\&K 4810 electromechanical shaker. The excitation forces of both impact hammer and shaker are measured by using a B\&K 8203 force transducer. A B\&K Nexus conditioning amplifier and a B\&K 2706 power amplifier are used to amplify the analogue signal from the transducers. A Siglab 4-channel 2042 digital signal processor is used for acquisition of the data and to generate the shaker signal. Postprocessing of the data is performed by modal analysis software: Siglab 3.28 and Matlab 6.5.

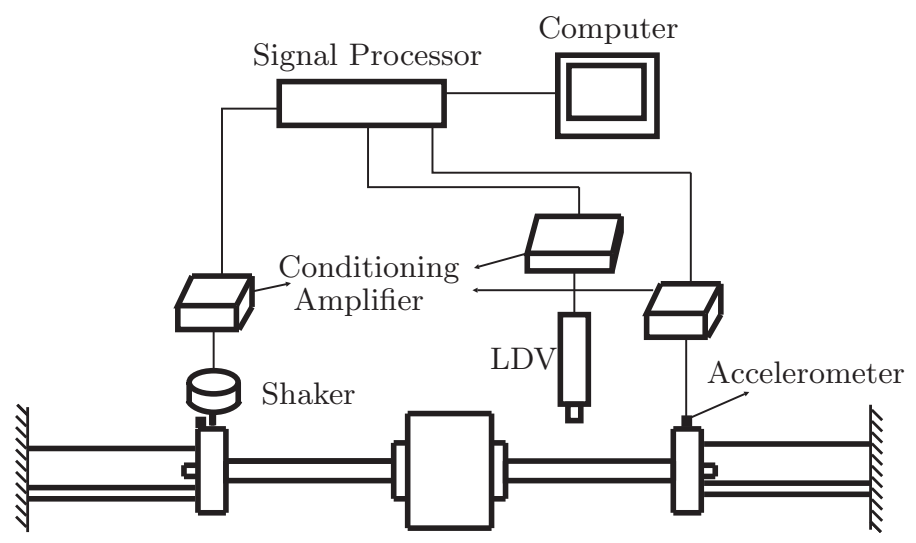

Figure 8.1: Measurement setup

\subsubsection{Experimental Procedure}

The experimental procedure and the aim of experiments at each step are illustrated in Fig. 8.2.

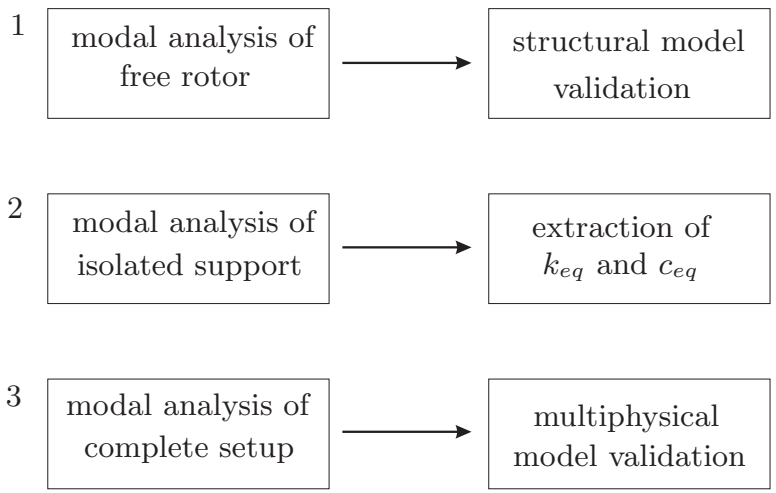

Figure 8.2: Experimental procedure 
At first a modal analysis of the rotor in free-free condition has been performed. This is accomplished by mounting the rotor in flexible cords. The experimental results have been compared with the theoretical results in order to validate the structural model. Then modal analysis of the isolated support has been realized in order to determine the dynamic characteristics of the supports. The equivalent stiffness $\left(k_{e q}\right)$ and damping $\left(c_{e q}\right)$ can be extracted from these results and these properties of the supports can be implemented in the structural rotor model. Finally, modal analysis of the complete system has been done at different rotation speeds to investigate the speed-dependent dynamic characteristics and the effect of the surrounding fluid in the gap between rotor and casing on the critical speeds. Spectrum measurements at different speeds have been done and spectrum maps have been plotted in order to determine the onset of instability. When plotting the spectrum maps, rotational speeds are varied in steps of $100 \mathrm{rpm}$ and the velocity of the rotor surface is measured. The experimental results and comparison with the theory are presented in detail in the following sections.

\subsection{Results}

\subsubsection{Modal Analysis of the Free Rotor}

As explained in the previous section, first the dynamic characteristics of the rotor are determined and compared with the theoretical results of the structural rotor model. In this way, the structural model is validated. The rotor is mounted by elastic cords as can be seen in Fig. 8.3.

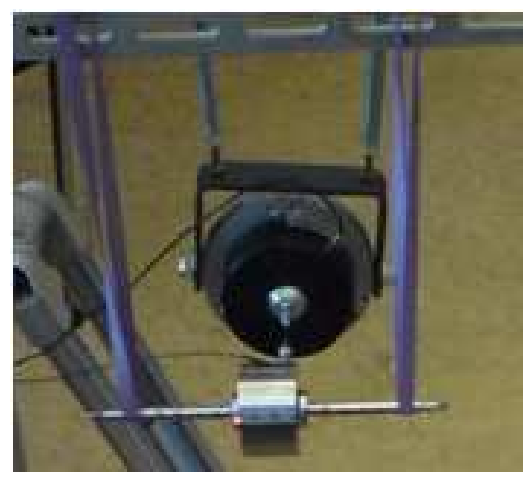

Figure 8.3: Modal analysis of the free rotor

The excitation is provided by a shaker and the responses are measured with the LDV. Being contactless, the added mass effect from sensors is avoided. The LDV is commonly used for vibration measurements of rotating machinery [65]. The theory, application and related problems are discussed by Bell et al. [11] in detail. 
Measurements are performed at different points and similar frequency response functions (FRF) are obtained. The FRF of the free rotor at halfspan is given in Fig. 8.4.

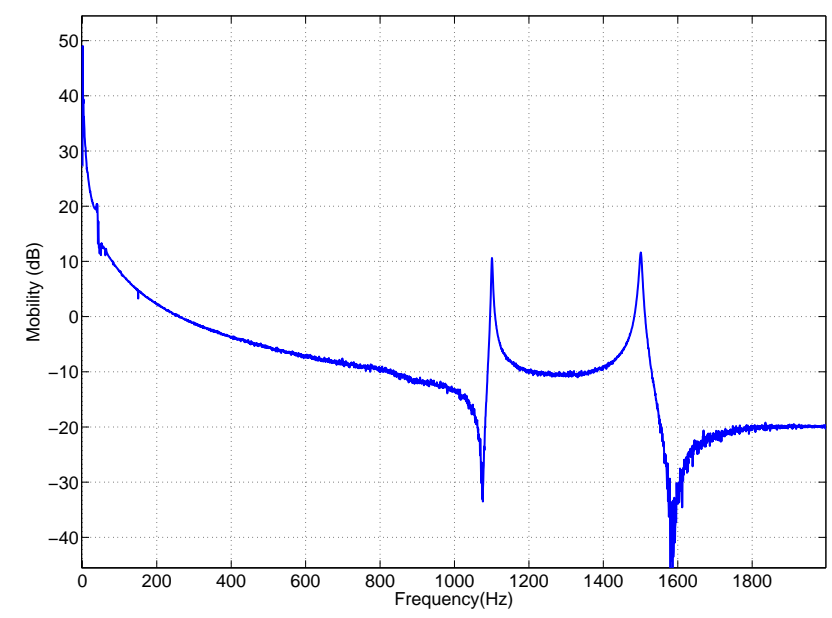

Figure 8.4: Frequency response function of the free rotor

\subsubsection{Modal Analysis of the Isolated Support}

The experimental setup has flexible supports each consisting of three thin beams, two brackets and a support disk in which the ball bearing has been mounted (Section 7.4.2 and Fig. 7.6). Experimental modal analysis of the isolated support is performed in order to determine the dynamic behavior and an equivalent stiffness and damping model for the support (Fig. 8.5). A shaker is used as an actuator and the experiments are done both with orthogonally placed accelerometers and an LDV. The stiffness of the support is adjusted by changing the length of the beams. Therefore the modal analysis is done for varying beam lengths and the results are presented in Fig. 8.6.

It is observed that the beam length has a significant effect on the support dynamics. As seen in Fig. 8.6, the natural frequency varies from $126 \mathrm{~Hz}$ for $60 \mathrm{~mm}$ to $84 \mathrm{~Hz}$ for $80 \mathrm{~mm}$.

\subsubsection{Modal Analysis of the Total System at Standstill}

The modal analysis of the complete system with different beam lengths has been performed at standstill to obtain the dynamic behavior of the complete system (Fig. 8.8). Random excitation is provided by the shaker mounted on the support. 


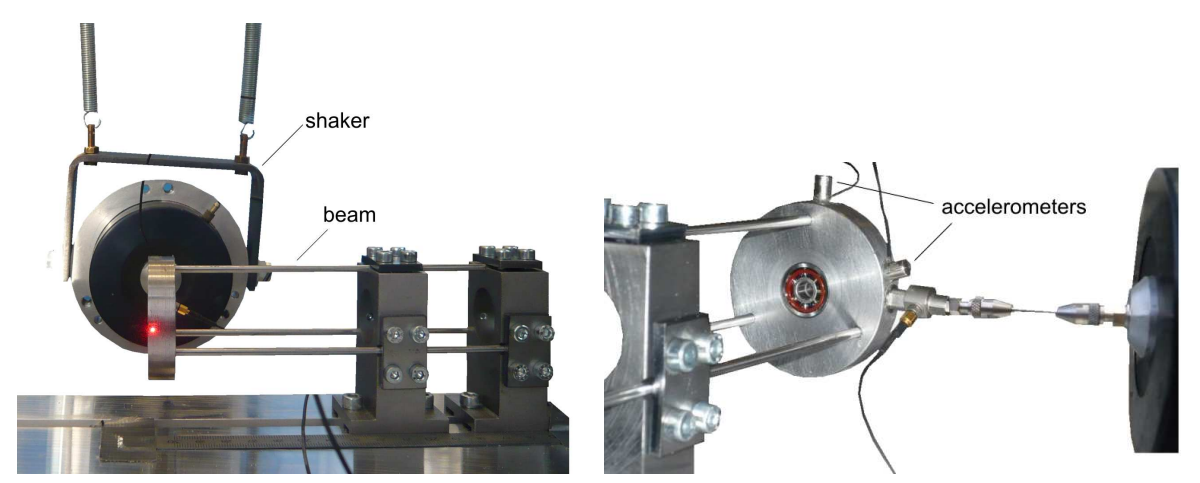

Figure 8.5: Modal analysis of the isolated support

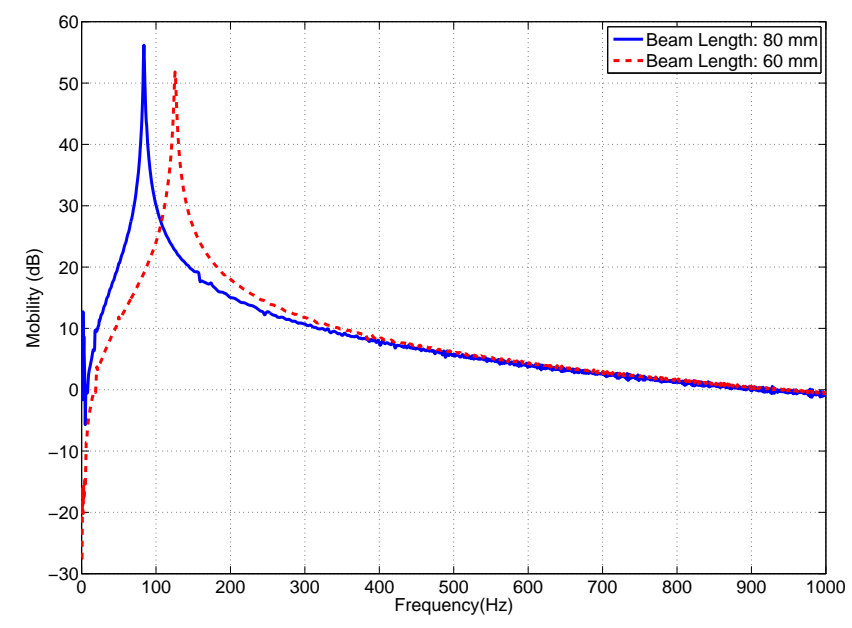

Figure 8.6: FRFs of the support with different beam lengths

The response is measured by the accelerometers mounted on the supports and the LDV directed towards the rotor surface. At first the motor is uncoupled and the supporting bracket moved to the support disk making the supports rigid. In this way only the flexibility of the ball bearings are effective and they can be determined (see Sec. 8.3.4). The related FRF is shown in Fig. 8.7. There is a small peak near to the second peak as seen in the figure. This may have resulted from slight differences between supports such as beam lengths or anisotropy of the bearings due to wear and corrosion.

Afterwards, the motor is mounted and the experiments are repeated at standstill for support beam lengths of $72 \mathrm{~mm}, 80 \mathrm{~mm}$ and $90 \mathrm{~mm}$, respectively. The FRF results for these three configurations are given in Fig. 8.9. 

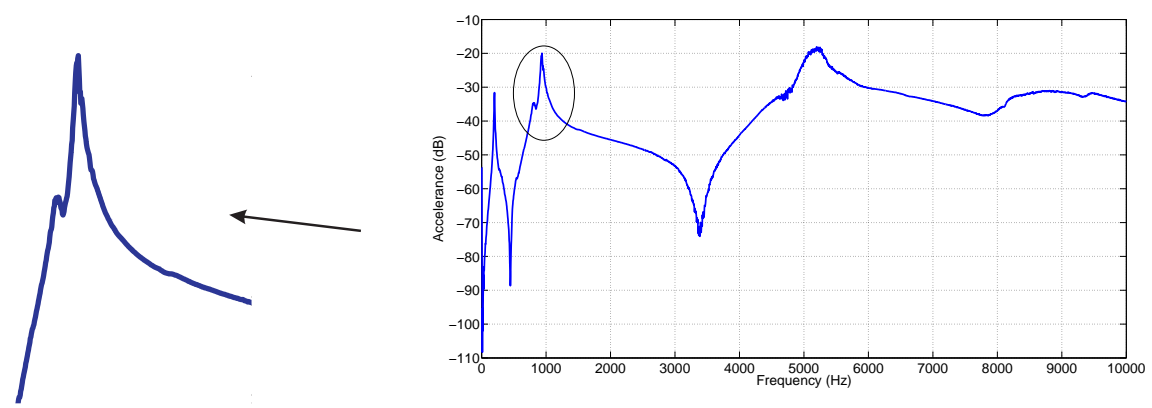

Figure 8.7: FRF of the rotor with rigid supports

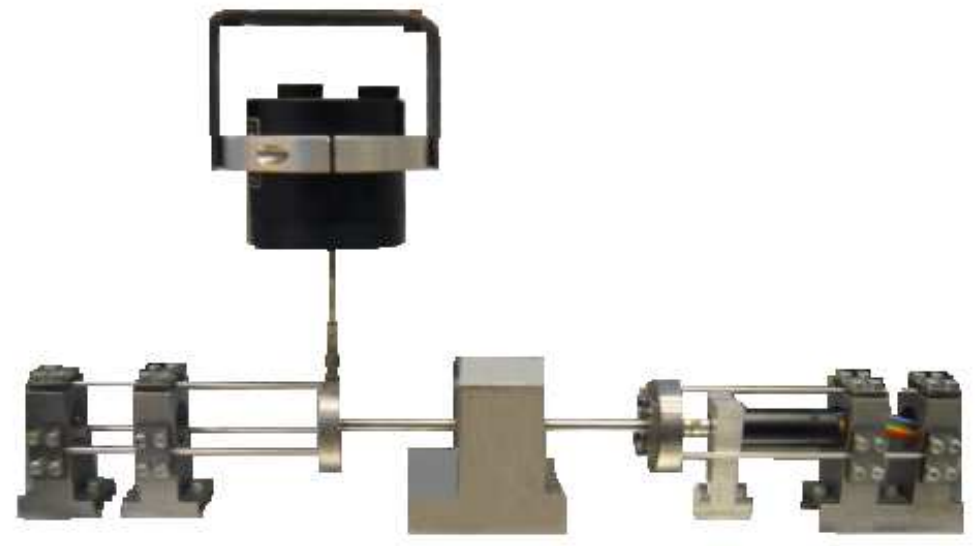

Figure 8.8: Experimental modal analysis of the complete system

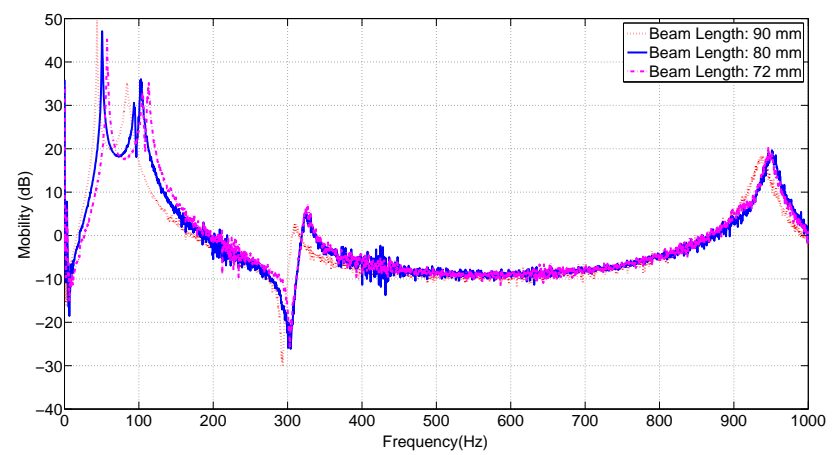

Figure 8.9: Modal analysis results with different beam lengths 
The natural frequencies of the rotor at different support beam lengths are summarized in Table 8.1.

Table 8.1: Summary of the natural frequencies for different configurations

\begin{tabular}{|c|c|c|c|}
\hline Beam Length: & $\mathbf{7 2} \mathbf{~ m m}$ & $\mathbf{8 0} \mathbf{~ m m}$ & $\mathbf{9 0} \mathbf{~ m m}$ \\
\hline \hline $1^{\text {st }}$ Rigid body & $57.2 \mathrm{~Hz}$ & $50.6 \mathrm{~Hz}$ & $43.7 \mathrm{~Hz}$ \\
$2^{\text {nd }}$ Rigid body & $113.4 \mathrm{~Hz}$ & $102.2 \mathrm{~Hz}$ & $84.0 \mathrm{~Hz}$ \\
$1^{\text {st }}$ Flexural & $327.2 \mathrm{~Hz}$ & $320.7 \mathrm{~Hz}$ & $311.6 \mathrm{~Hz}$ \\
\hline
\end{tabular}

When the rotor is much stiffer than the supports, some modes exist in which the deformation of the rotor is very small compared with that of the supports. These are known as rigid body modes. The higher order modes which involve the deformation of both rotor and supports are defined as flexural modes [32].

Changing the beam length results in a substantial change of the dynamics of the structure. Not only rigid body mode natural frequencies change, but also the natural frequency belonging to the first flexural mode of the whole setup changes by altering the beam length.

In order to observe the effect of coupling between the motor and rotor shaft on the dynamics of the rotor, modal analysis of the setup is performed with and without the coupling. The results for a support beam length of $72 \mathrm{~mm}$ are given in Table 8.2.

Table 8.2: Modal analysis results with and without coupling

\begin{tabular}{|c|c|c|}
\hline & with coupling & without coupling \\
\hline \hline $1^{\text {st }}$ Rigid Body Natural Frequency & $57.2 \mathrm{~Hz}$ & $56.9 \mathrm{~Hz}$ \\
$2^{\text {nd }}$ Rigid Body Natural Frequency & $113.4 \mathrm{~Hz}$ & $110.9 \mathrm{~Hz}$ \\
$1^{\text {st }}$ Flexural Natural Frequency & $327.2 \mathrm{~Hz}$ & $325.1 \mathrm{~Hz}$ \\
\hline
\end{tabular}

The coupling affects the dynamics of the structure only slightly. Therefore the coupling is considered to be flexible enough and is not included in the models.

\subsubsection{Modeling the rotor and flexible supports}

The structural FEM simulations of the free-free rotor are performed with a different number of elements (29 and 48) for the free rotor. The first two natural frequencies are given in Table 8.3 and compared with the experimental results. The results are almost the same for both small and large models, so a small model is appropriate and will be used. The theoretical model estimates the first natural frequency with 0.22 $\%$ difference and the second one with $0.87 \%$ when compared to experimental results. 
Table 8.3: First two natural frequencies: theoretical and experimental results

\begin{tabular}{|c|c|c|c|c|c|}
\hline Number of Elements & \multicolumn{2}{|c|}{ Small Model } & \multicolumn{2}{c|}{ Large Model } & Experiments \\
\hline \hline Rotation Speed & Standstill & $100000 \mathrm{rpm}$ & Standstill & $100000 \mathrm{rpm}$ & Standstill \\
\hline $1^{\text {st }}$ Natural frequency & $1097.4 \mathrm{~Hz}$ & $1103.6 \mathrm{~Hz}$ & $1097.5 \mathrm{~Hz}$ & $1103.6 \mathrm{~Hz}$ & $1100.6 \mathrm{~Hz}$ \\
$2^{\text {nd }}$ Natural frequency & $1487 \mathrm{~Hz}$ & $2391.1 \mathrm{~Hz}$ & $1487 \mathrm{~Hz}$ & $2391.2 \mathrm{~Hz}$ & $1500.5 \mathrm{~Hz}$ \\
\hline
\end{tabular}

Therefore, structural FEM is considered to be capable of modeling the dynamic behavior of the rotor.

Since the flexible supports have an important influence on the dynamics of the structure, they should be included in the rotordynamic structural model [15, 22, 72, 79, 81-85]. Accurate flexible support models demand large efforts and increase the computational time drastically, so simple models are deducted from experimental modal analysis, from static loading tests and by reduction of finite element models [16, 74, 81-83, 85]. Stephenson and Rouch [74] generated mass and stiffness matrices for the supporting structure from test data. These matrices are then combined with the matrices for the rotor system and the dynamic behavior is predicted. Vazquez et al. [81-85] used transfer functions at the bearing locations to model the support structure. These transfer functions are extracted from frequency response functions measured at the bearing locations and then combined with the rotordynamics model. Sinou et al. [72] determined the support characteristics by a static loading test. Then they implemented the obtained stiffness into the finite element model. Choi and Park [16] used support FRFs to extract an equivalent multi degree of freedom ( MDOF ) spring-mass model and applied this to the rotor of a double suction pump.

In our study, simple support models consisting of mass-spring-damper systems are developed because of their ease of implementation into the structural rotor model. At first the support is modeled as a mass, spring and damper and only translational degrees of freedom are taken into account. Bearing stiffness has been ignored since the equivalent stiffness and equivalent damping coefficient for the support are extracted from experimental modal analysis of the isolated support as shown in Fig. 8.6. An equivalent spring-damper system can be constructed from the modal analysis data by using the well-known peak amplitude method. The details of this method are explained by Ewins [27]. For each beam length, the stiffness is calculated by $k=\omega_{n}^{2} m$ where $m$ is the mass of the support disk and the damping ratio by $\zeta=\Delta \omega / \omega_{n}$ from which the support damping coefficient is found. Then these mass, stiffness and damping values representing the supports are implemented in the structural rotor model for the theoretical dynamic analysis of the total system. This first support model and the rotor are illustrated in Fig. 8.10. The theoretical and experimental results are compared in Table 8.4.

There is a significant difference between the theoretical and experimental results. Therefore this support model has to be enhanced. It has been observed that the 


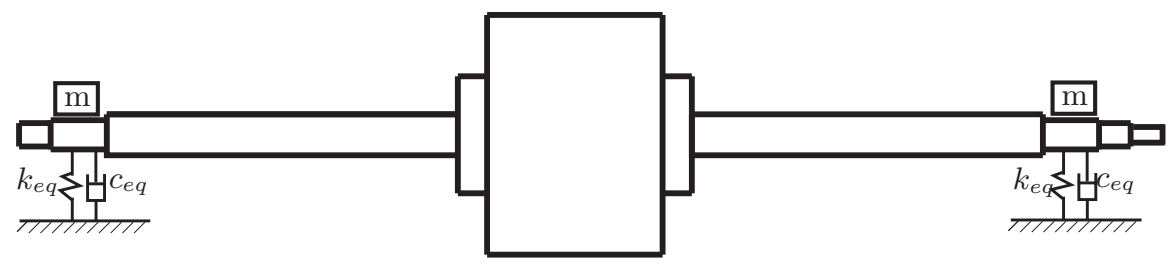

Figure 8.10: First support model

Table 8.4: Natural Frequencies with the first support model

\begin{tabular}{|c|c|}
\hline Experimental & Theoretical \\
\hline \hline $50.6 \mathrm{~Hz}$ & $51.4 \mathrm{~Hz}$ \\
$102.8 \mathrm{~Hz}$ & $80.1 \mathrm{~Hz}$ \\
$320.1 \mathrm{~Hz}$ & $263.1 \mathrm{~Hz}$ \\
$962.1 \mathrm{~Hz}$ & $877.0 \mathrm{~Hz}$ \\
\hline
\end{tabular}

support model consists of a translational spring and damper, and where the mass is directly added to the connection node, is not adequate enough to predict the dynamic behavior of the system.

This is why an additional node has been added to the support model, and the bearing rotational and translational stiffness have been taken into account. In addition, the rotational stiffness term $\left(k_{s r}\right)$ for the support beams and the inertia of the support disk have also been included in the support model. The bearing translational stiffness has been estimated from the supplier manual [34]. To determine the rotational stiffness of the bearing, the simulations for rigid supports (support beam length: $0 \mathrm{~mm}$ ) are performed with different bearing stiffnesses and compared with the experimental results (see section 8.3.3). In this way the support stiffness has been eliminated and the bearing stiffness can be independently examined. Then, appropriate rotational stiffness for the bearing has been determined. After determining the bearing stiffness the rotational $\left(k_{s r}\right)$ and translational $\left(k_{s}\right)$ stiffness of the supports should be determined. The previously explained ANSYS model of the supports (Fig. 7.7) is used to extract the rotational and translational stiffness of the supports statically. Known force and moment have been applied in the bearing positions, corresponding displacement and rotation has been obtained. The translational and rotational stiffness values are calculated by dividing the force and moment by displacement and rotation $\left(k_{s}=f / x, k_{s r}=M / \theta\right)$. The corresponding model is shown in Fig. 8.11.

After adding the extra node to the model and including rotational stiffness and inertia of the support disk the results have been improved. Table 8.5 illustrates the new results with this modeling approach.

The increase of the natural frequencies resulted from the disk mass, which is connected to the rotor with springs resembling the bearing instead of directly adding the mass. In 


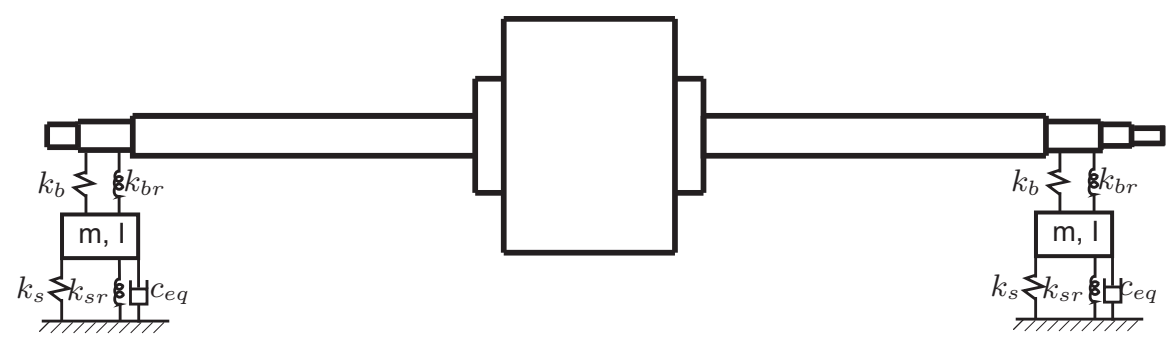

Figure 8.11: Support Model with Rotational DOF

Table 8.5: Natural Frequencies with the second support model

\begin{tabular}{|c|c|}
\hline Experimental & Theoretical \\
\hline \hline $50.6 \mathrm{~Hz}$ & $53.8 \mathrm{~Hz}$ \\
$102.8 \mathrm{~Hz}$ & $108.1 \mathrm{~Hz}$ \\
$320.1 \mathrm{~Hz}$ & $313.5 \mathrm{~Hz}$ \\
$962.1 \mathrm{~Hz}$ & $896.1 \mathrm{~Hz}$ \\
\hline
\end{tabular}

the previous modeling approach this mass was directly added to the rotor model. The first two natural frequencies are in fair agreement with simulation results. However, the estimation for the flexural mode natural frequency can still be improved.

Finally, the cross coupling between rotational and translational stiffness terms for the supports are also considered. This support model and the rotor are shown in Fig. 8.12. The same stiffness values are used for the bearings as in the previous model. However the support stiffness has been calculated with a different approach. Static loads (force and moment) are applied on the support disk and deformations (translational and angular displacement) are numerically obtained in order to calculate the equivalent stiffness matrix for the support.

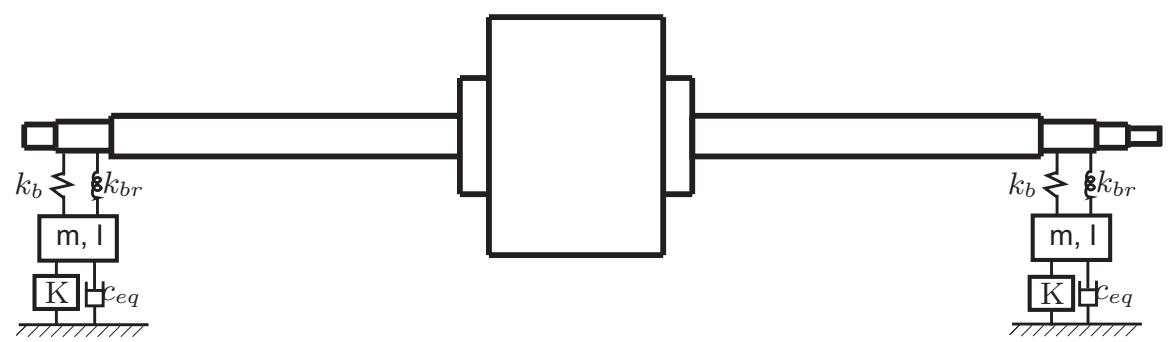

Figure 8.12: Final support model

A finite element model for the supports has been generated to extract the equivalent stiffness matrix for the supports using the commercial software package ANSYS. Static loading simulations are required to determine the parameters of the support model. 
In order to examine the capability of the model in representing the dynamic behavior of the support, a modal analysis of the model has first been performed and compared with the experimental results. Fig. 7.7 illustrates the FE model and Table 8.6 gives the natural frequencies for different beam lengths.

Table 8.6: Theoretical and experimental results for natural frequencies of the support

\begin{tabular}{|c|c|c|c|c|c|c|}
\hline & \multicolumn{3}{|c|}{ Theory } & \multicolumn{3}{c|}{ Experiment (Section 8.3.2) } \\
\hline \hline Beam Length & $70 \mathrm{~mm}$ & $80 \mathrm{~mm}$ & $90 \mathrm{~mm}$ & $70 \mathrm{~mm}$ & $80 \mathrm{~mm}$ & $90 \mathrm{~mm}$ \\
\hline $1^{\text {st }}$ Natural frequency & $108.8 \mathrm{~Hz}$ & $89.5 \mathrm{~Hz}$ & $75.4 \mathrm{~Hz}$ & $101.3 \mathrm{~Hz}$ & $83.8 \mathrm{~Hz}$ & $73.8 \mathrm{~Hz}$ \\
\hline
\end{tabular}

ANSYS simulation results agree well with the experimental ones. So this ANSYS model can be used to extract the simplified equivalent stiffness matrix with coupled terms for rotation and translation.

Next, static loads (force and moment) are applied on the support disk and deformations (translational and angular displacement) are obtained. The coupled stiffness matrix for the support is calculated by:

$$
\mathrm{BF}=\mathrm{q}
$$

where $\mathbf{B}$ is the compliance matrix, $\mathbf{q}$ is the deformation vector, $\mathbf{F}$ is the load vector and $\mathbf{K}$ is the stiffness matrix given as:

$$
\mathbf{q}=\left[\begin{array}{c}
x \\
\theta
\end{array}\right], \quad \mathbf{F}=\left[\begin{array}{c}
f \\
M
\end{array}\right], \quad \mathbf{K}=\mathbf{B}^{-1}=\left[\begin{array}{ll}
k_{1} & k_{2} \\
k_{3} & k_{4}
\end{array}\right]
$$

The simulations with this support model are performed and compared with the experimental results.

The experimental and theoretical results and the difference at standstill and 35000 rpm for a support beam length of $80 \mathrm{~mm}$ are presented in Table 8.7 for the first and final support model.

For the first support model, the stiffness is calculated from modal analysis data of the support and the rotational DOF are omitted. Therefore, the first natural frequency which is the rigid body translation mode is estimated with reasonable accuracy. However, there is a significant difference for the second rigid body mode natural frequency and the first flexural mode natural frequency because the rotational stiffness of the support is not taken into account. The final support model yields improvement in the prediction of dynamic behavior of the rotor. The better estimations for the third natural frequency are achieved. Therefore this support modeling approach with rotational DOF and cross-coupled terms are capable of representing the dynamic behavior of the flexible supports. As a result, this model is implemented in the structural model to represent the supports. 
Table 8.7: Dynamics of rotor with different support models

\begin{tabular}{|c|c|c|}
\hline Experiment-standstill & First support model & Final support model \\
\hline \hline $50.6 \mathrm{~Hz}$ & $51.4 \mathrm{~Hz}(1.6 \%)$ & $54.1 \mathrm{~Hz}(6.9 \%)$ \\
\hline $102.2 \mathrm{~Hz}$ & $80.1 \mathrm{~Hz}(21.6 \%)$ & $108.0 \mathrm{~Hz}(5.4 \%)$ \\
\hline $320.7 \mathrm{~Hz}$ & $263.0 \mathrm{~Hz}(17.8 \%)$ & $325.8 \mathrm{~Hz}(1.8 \%)$ \\
\hline \hline Experiment- 35 000 rpm & First support model & Final support model \\
\hline \hline $52.2 \mathrm{~Hz}$ & $51.2 \mathrm{~Hz}(1.9 \%)$ & $54.1 \mathrm{~Hz}(3.6 \%)$ \\
\hline $116.6 \mathrm{~Hz}$ & $95.7 \mathrm{~Hz}(17.7 \%)$ & $127.9 \mathrm{~Hz}(9.0 \%)$ \\
\hline $322.6 \mathrm{~Hz}$ & $263.0 \mathrm{~Hz}(18.3 \%)$ & $325.9 \mathrm{~Hz}(1.1 \%)$ \\
\hline
\end{tabular}

\subsection{Analyzing Multiphysical Effects}

After determining the equivalent support model the theoretical model becomes capable of representing the experimental setup. Then the multiphysical effects can be analyzed.

The multiphysical effects on the dynamics of the rotor have been analyzed by modal analysis and spectrum measurements with and without the casing. The change of natural frequencies at different speeds and onset of instability have been measured. For modal analysis, the excitation has been provided by the shaker mounted on the support disk. For spectrum measurements, rotation of the shaft is the only excitation source. The responses have been measured with two accelerometers mounted on the supports and an LDV directed towards the rotor. All experiments have been repeated for support beam lengths of $72 \mathrm{~mm}, 80 \mathrm{~mm}$ and $90 \mathrm{~mm}$ in the absence and presence of the casing. In this way the effect of the surrounding fluid on the dynamic behavior of the rotor has been analyzed for different support flexibility. The modal analysis results at $40000 \mathrm{rpm}$, have been shown in Fig. 8.13 and the natural frequencies have been given in Table 8.8 for a support beam length of $72 \mathrm{~mm}$.

Table 8.8: Experimental modal analysis with and without casing at $40000 \mathrm{rpm}$

\begin{tabular}{|c|c|c|}
\hline Natural frequency & with casing & without casing \\
\hline $1^{\text {st }}$ Rigid body mode & $58.1 \mathrm{~Hz}$ & $57.8 \mathrm{~Hz}$ \\
$2^{\text {nd }}$ Rigid body mode & $132.8 \mathrm{~Hz}$ & $133.1 \mathrm{~Hz}$ \\
$1^{\text {st }}$ Flexural mode & $337.8 \mathrm{~Hz}$ & $338.4 \mathrm{~Hz}$ \\
\hline
\end{tabular}

Similar frequency response functions have been obtained with and without casing. The surrounding air has a negligible effect on the natural frequencies of the system. The stability of the system has been studied by spectrum measurements. The rotor has been operated till the onset of instability and spectrum measurements have been done at every $100 \mathrm{rpm}$. 


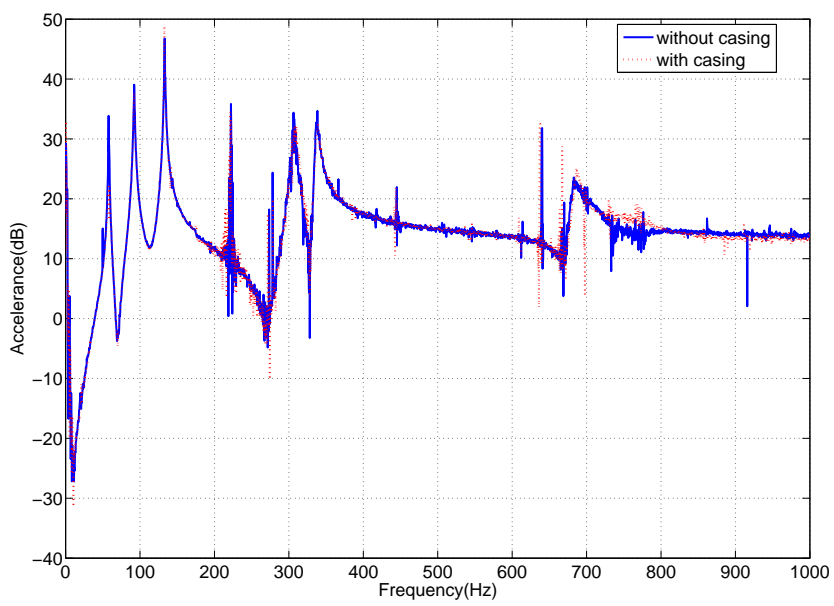

Figure 8.13: Modal analysis results with and without casing
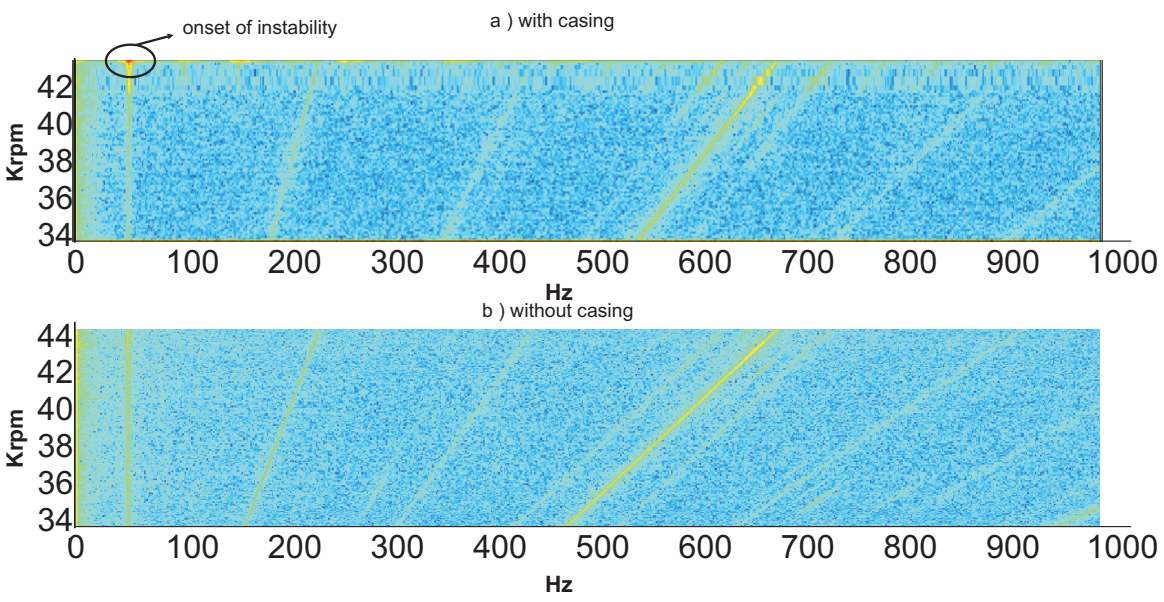

Figure 8.14: Spectrum maps-support beam length: $80 \mathrm{~mm}$

The spectrum maps with and without casing have been shown in Fig. 8.14. It was demonstrated that, depending on the support stiffness and damping, self-excited vibrations start to develop and instability occurs. The surrounding air between the casing and rotor has been observed to result in unstable operation and eventually catastrophic failure. The spectrum measurements at $42350 \mathrm{rpm}$ and $34300 \mathrm{rpm}$ with a support beam length of $80 \mathrm{~mm}$ have been shown in Fig. 8.15. The first mode becomes unstable in time and the amplitude in the spectrum at that frequency starts to increase. The amplitude at the first natural frequency has been plotted as a function 
of rotor speed in Fig. 8.16. The theoretical prediction of the onset of instability has been shown in Fig. 8.17. The decay rates of the first three modes have been plotted as a function of rotation speed. The decay rate has been the imaginary part of the complex frequency, which is the solution of the eigenvalue problem of the equation of motion of the rotor. As the decay rate becomes negative the system becomes unstable.

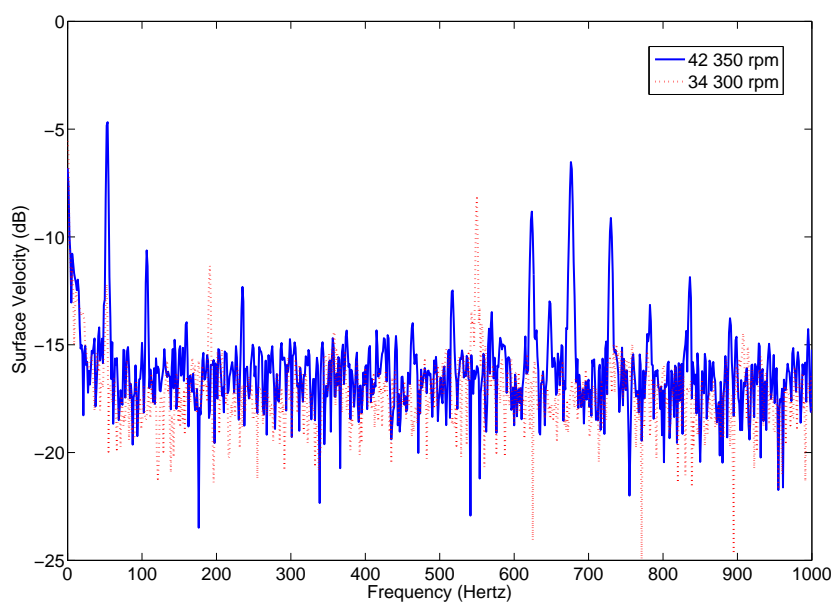

Figure 8.15: Spectrum measurements at different speeds

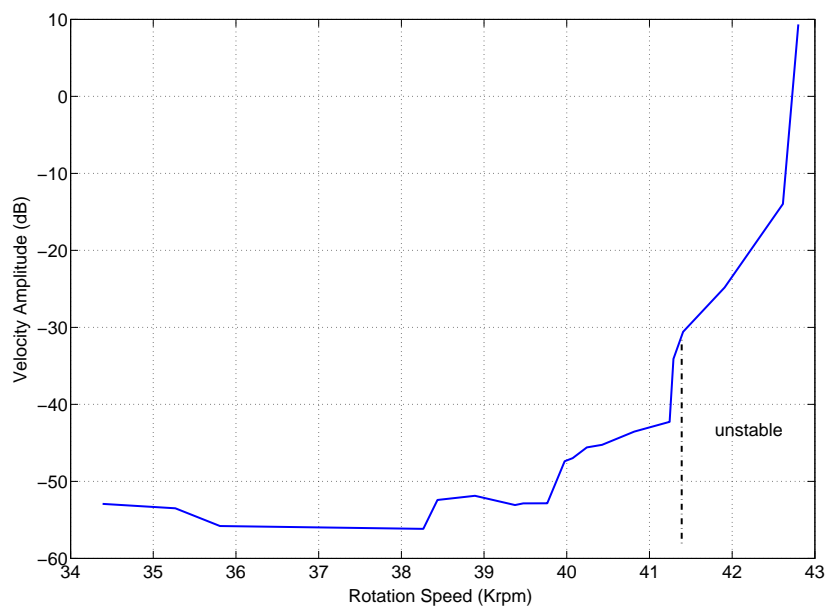

Figure 8.16: Amplitude of velocity spectrum at different rotor speeds 


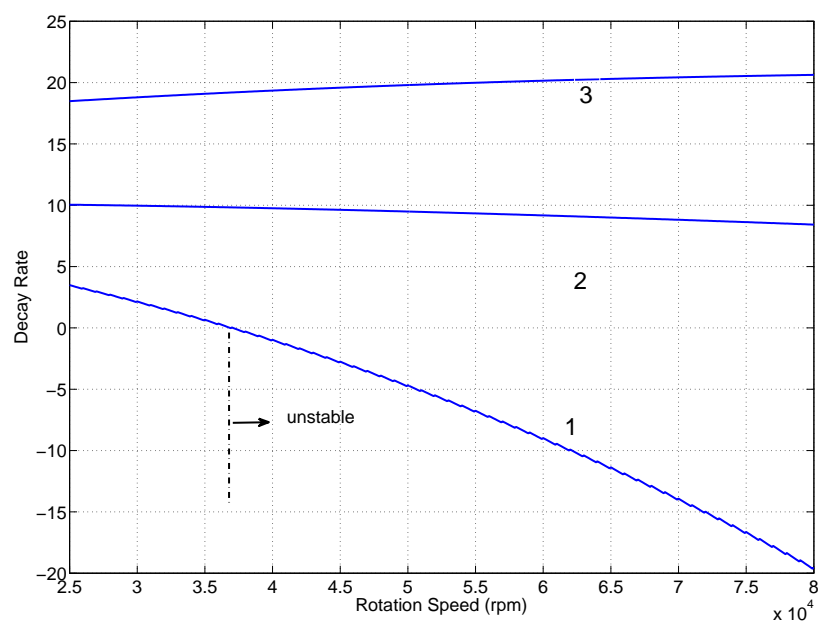

Figure 8.17: Theoretical prediction of onset of instability-support beam length: 80 $\mathrm{mm}$

Table 8.9: Experimental and theoretical results for natural frequency and stability

\begin{tabular}{|l|c|c|c|c|c|}
\hline \multicolumn{2}{|c|}{ Beam Length: 72 mm } & \multicolumn{2}{c|}{ Beam Length: 80 mm } & \multicolumn{2}{c|}{ Beam Length: 90 mm } \\
\hline \hline \multicolumn{2}{|c|}{ Rotation Speed: $40000 \mathrm{rpm}$} & \multicolumn{2}{|c|}{ Rotation Speed: $35000 \mathrm{rpm}$} & \multicolumn{2}{c|}{ Rotation Speed: 25 000 rpm } \\
\hline \multicolumn{2}{|c|}{ Natural Frequencies (Hz) } & Natural Frequencies (Hz) & Natural Frequencies (Hz) \\
\hline Experiments & Theory & Experiments & Theory & Experiments & Theory \\
\hline $58.1 \mathrm{~Hz}$ & $61.7 \mathrm{~Hz}$ & $51.8 \mathrm{~Hz}$ & $53.4 \mathrm{~Hz}$ & $44.0 \mathrm{~Hz}$ & $45.3 \mathrm{~Hz}$ \\
$132.8 \mathrm{~Hz}$ & $141.3 \mathrm{~Hz}$ & $116.3 \mathrm{~Hz}$ & $127.9 \mathrm{~Hz}$ & $100.3 \mathrm{~Hz}$ & $112.5 \mathrm{~Hz}$ \\
$337.8 \mathrm{~Hz}$ & $328.6 \mathrm{~Hz}$ & $322.2 \mathrm{~Hz}$ & $325.8 \mathrm{~Hz}$ & $315.3 \mathrm{~Hz}$ & $323.5 \mathrm{~Hz}$ \\
\hline \hline \multicolumn{2}{|c|}{ Onset of Instability } & \multicolumn{2}{|c|}{ Onset of Instability } & \multicolumn{2}{c|}{ Onset of Instability } \\
\hline Experiments & Theory & Experiments & Theory & Experiments & Theory \\
\hline $42250 \mathrm{rpm}$ & $40200 \mathrm{rpm}$ & $41800 \mathrm{rpm}$ & $37100 \mathrm{rpm}$ & $36250 \mathrm{rpm}$ & $30700 \mathrm{rpm}$ \\
\hline
\end{tabular}

The experimental and theoretical results with casing are tabulated and compared in Table 8.9 with different support beam lengths. A fair agreement between the theoretical and experimental results is obtained. The developed methodology (Chapter 6) identifies the onset of instability, which results from the rotating damping due to flow and estimates the natural frequencies in accordance with the experiments. The differences may result from accurate measurement of damping, the different clamping torques on the bolts connecting the support beams to the brackets, adjustment errors of the exact beam length and three-dimensional flow effects in the confinement. 
As the shaker has been removed the damping was observed to decrease significantly. The spectrum maps are plotted again for support beam lengths of $72 \mathrm{~mm}, 80 \mathrm{~mm}$ and $90 \mathrm{~mm}$. The spectrum map for $80 \mathrm{~mm}$ length is shown in Fig. 8.18. The numerical prediction of the onset of instability is shown in Fig. 8.19 for both friction models in laminar flow regime.

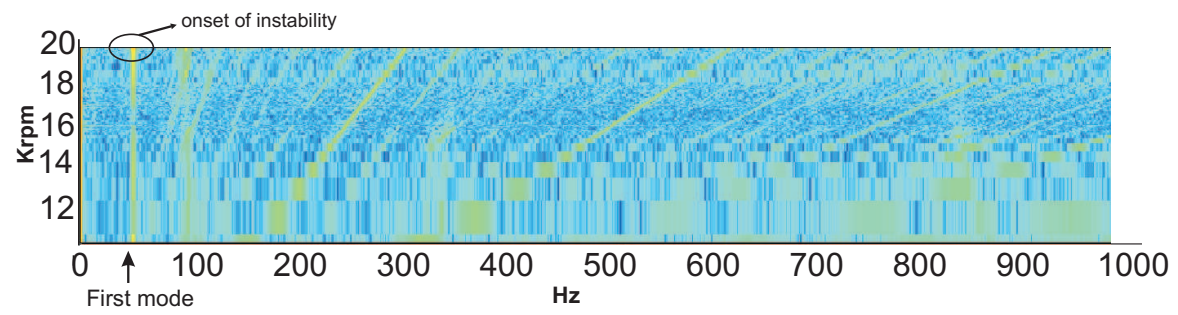

Figure 8.18: Spectrum map-support beam length: $80 \mathrm{~mm}$

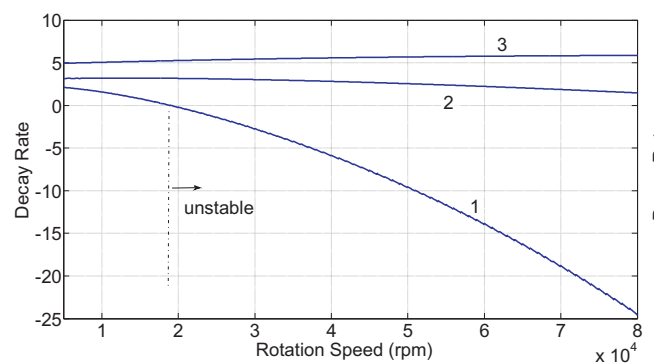

a) Empirical Friction Model (Bilgen-Boulos)

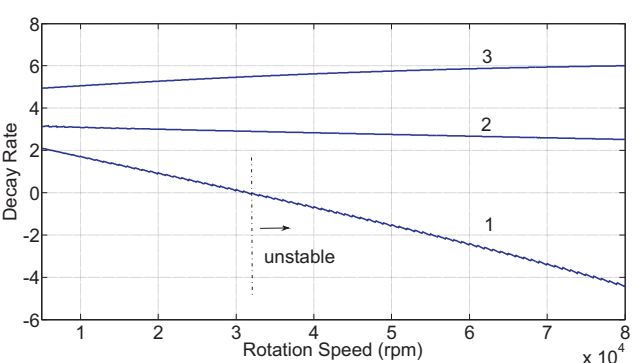

b) Analytical Friction Model (Brennen)

Figure 8.19: Onset of instability with different friction models-support beam length: $80 \mathrm{~mm}$

The decay rates of the first three modes have been plotted as a function of rotation speed. For the current setup the flow becomes turbulent at $24200 \mathrm{rpm}$. The model which uses the friction coefficient by Brennen predicts stable operation in laminar flow. On the other hand, the empirical friction model estimates instability in the laminar regime. Table 8.10 illustrates the stationary damping ratios for different beam lengths and experimental and numerical onset of instability for both friction models.

A reasonable agreement between the theoretical and experimental results is obtained for the empirical friction models given by Bilgen et al. [12]. However, the analytical friction coefficients given by Brennen fail to predict the onset of instability in the laminar regime. The observed onset of instability is at relatively high Reynolds numbers but still in the laminar regime. The flow is quite complex (vortices) and the empirically determined friction coefficient model must be used to estimate the unstable operation of the rotor. 
Table 8.10: Damping and onset of instability in the laminar regime

\begin{tabular}{|c|c|c|c|c|}
\hline $\begin{array}{c}\text { Support } \\
\text { Beam Length }\end{array}$ & $\begin{array}{c}\text { Damping } \\
(\mathbf{N s} / \mathbf{m})\end{array}$ & Experiments & $\begin{array}{c}\text { Empirical } \\
\text { Friction Model }\end{array}$ & $\begin{array}{c}\text { Analytical } \\
\text { Friction Model }\end{array}$ \\
\hline $72 \mathrm{~mm}$ & 2.1 & $23840 \mathrm{rpm}$ & $21900 \mathrm{rpm}$ & stable \\
\hline $80 \mathrm{~mm}$ & 1.86 & $17890 \mathrm{rpm}$ & $18900 \mathrm{rpm}$ & stable \\
\hline $90 \mathrm{~mm}$ & 1.80 & $15135 \mathrm{rpm}$ & $16800 \mathrm{rpm}$ & stable \\
\hline
\end{tabular}

\subsection{Validation of the Thermal Model}

The temperature measurements in the air gap between the rotor and the stator of the setup could be cumbersome, besides which, the temperature increase is calculated to be only a few degrees (see chapter 7 ). However in some cases the temperature increase could be higher. Therefore, validation of the thermal networks method (Chapter 5) is necessary and this could be done by comparing the calculated temperature increase with the one obtained from a more advanced numerical modeling approach.

The rotor and stator have been modeled by thermal networks at steady state as the initial step, the air in between has been described by a node (Chapter 5) and the temperature increase at this node has been calculated.

For the more advanced method, commercially available tools ANSYS Workbench and CFX have been used. The air gap is modeled by using CFX and the rotation speed and estimated steady state temperature of the rotor and stator surfaces are applied as boundary conditions. The heat transfer from the air and air gap temperatures is calculated. The rotor and stator are modeled in ANSYS; the heat transfer is imported from CFX. The rotor and stator temperatures are calculated.

Since only one-way coupling is possible between these packages, initial assumptions for the rotor and stator surface temperatures have been made; heat generation due to air friction, heat transfer coefficients and air temperature are calculated in CFX. The temperature in the gap and the convective heat transfer coefficients between the air-rotor and air-stator are calculated at each speed with initially assumed rotor and stator surface temperatures. The convective heat transfer coefficients are imported to ANSYS and the steady state temperatures of the rotor and stator surfaces are calculated. Then the updated boundary conditions (rotor-stator surface temperatures) are imported to CFX and the air temperature is recalculated. This procedure is continued till convergence of the results has been obtained. The procedure is shown in Fig. 8.20. The fluid film has been modeled in CFX as shown in Fig. 8.21. The modeled rotor and stator in ANSYS Workbench are shown in Fig. 8.22. The analysis has been run with different mesh sizes, and suitable mesh size has been determined as the convergence achieved. The rotation speed of the rotor outer surface as well as the temperatures of the rotor and stator surfaces have been applied as the boundary conditions. The total energy formulation, including the viscous terms, has been used for heat transfer equations since it is suitable for flows with a Mach 
number greater than 0.2. The $k-\epsilon$ turbulence model has been used since it is appropriate for internal flows and offers a good compromise between numerical effort and computational accuracy.

Simulations have been performed at each rotation speed and the air temperature profile has been obtained.

The simulations have been performed by using both thermal networks and CFX based CFD analysis for a rotor with a radius of $25 \mathrm{~mm}$, length of $30 \mathrm{~mm}$ and air gap of 0.5 mm. Table 8.11 compares the CFD analysis with the thermal networks method.

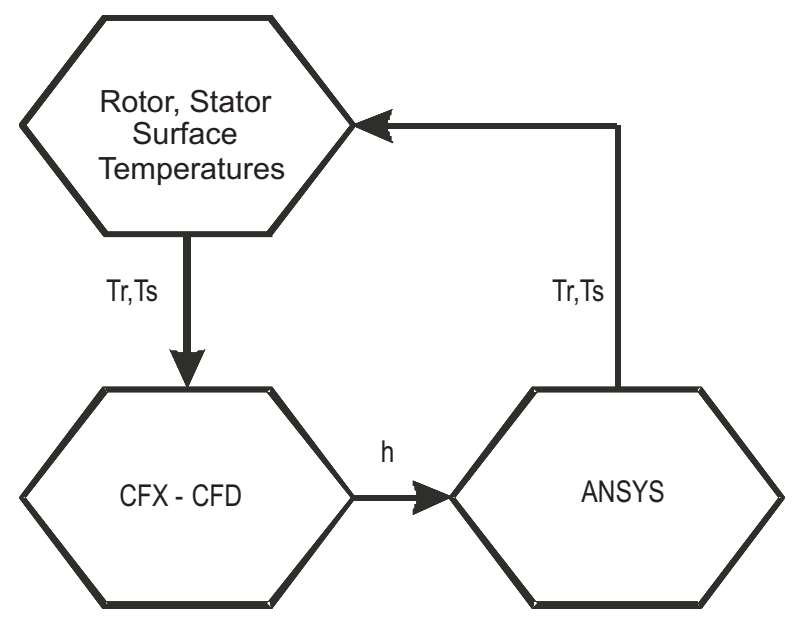

Figure 8.20: ANSYS-CFX Coupled Thermal Analysis Procedure

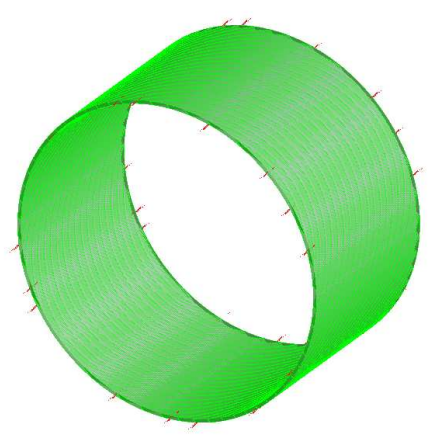

Figure 8.21: CFX Model for Air

The temperature profile in the air gap is computed in CFX, then the average of the air temperature profile is calculated and compared with the results obtained by using thermal networks (see Fig. 8.23). For the thermal networks, the air in the 


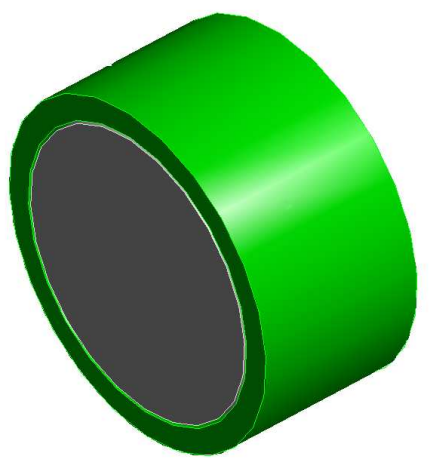

Figure 8.22: Rotor and Stator

Table 8.11: CFD vs Thermal Networks

\begin{tabular}{|c|c|}
\hline CFD & THERMAL NETWORKS \\
\hline \hline Many DOF & One node for modeling the air \\
\hline Local Temperature Distribution & Global Temperature distribution \\
\hline Much Computation time & Less computation time \\
\hline
\end{tabular}

gap is modeled as a node and the computation time to calculate the temperatures corresponding to the mid-rotor, stator and air was $0.06 \mathrm{~s}$. On the other hand, the CFD model constructed using ANSYS CFX involves 3072 elements, 6144 nodes and the computation time needed $214 \mathrm{~s}$.

There is fair agreement between both methods. The difference at higher rotational speeds could result from the high empirical friction coefficients used in thermal networks or detailed modeling in CFX. The thermal networks method gives a reasonable estimate of the air temperature. The thermal networks are simple to construct and can be easily coupled with other analysis methods. Thus, the thermal networks method seems to be appropriate to be implemented into fluid rotor interaction models to update temperature-dependent air properties for further analysis. The updated air temperature could be used to renew the air properties at the specific rotation speed for air-rotor coupled dynamic analysis.

\subsection{Conclusions}

The experimental results and advanced numerical modelling tools validate the developed multiphysical models. Modal analysis of the rotor in free-free condition verifies the structural model described in detail in Chapter 3. There is a good match 


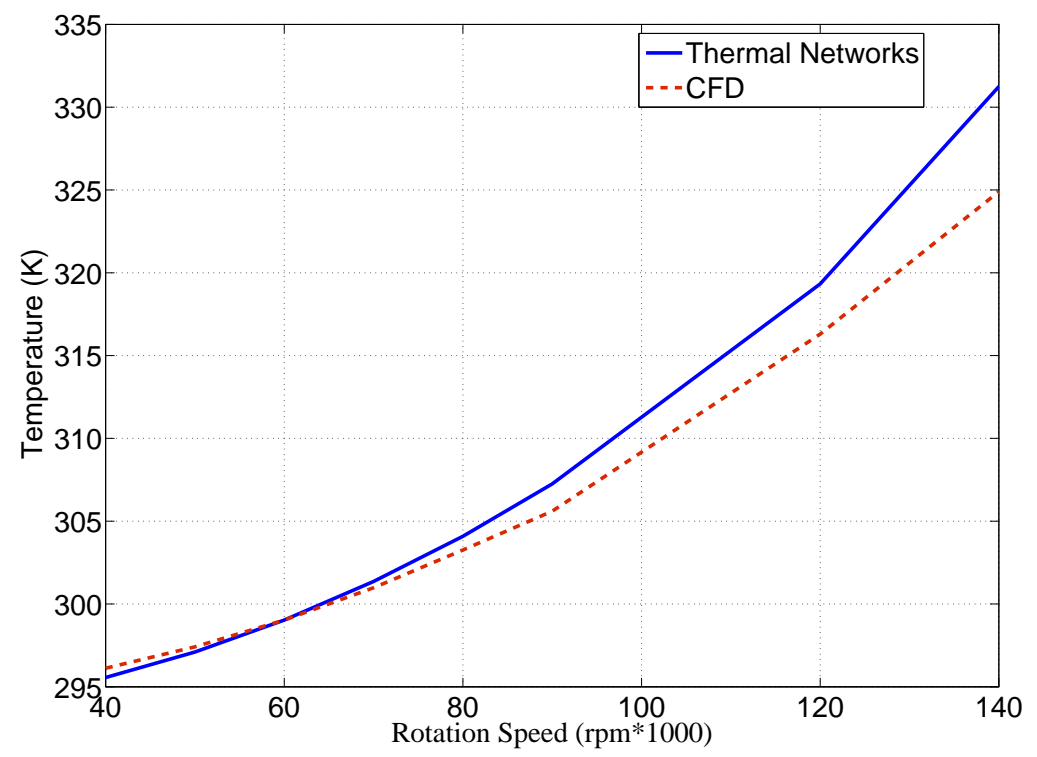

Figure 8.23: Thermal Network and CFD Results

between the theoretical and experimental results. The supports must be included to the structural model to simulate the experimental setup. Simple models for the supports as added springs and masses were not accurate enough to represent the dynamics of the structure. However, the equivalent model with coupled stiffness terms for rotational and translational degrees of freedom adequately simulates the dynamic behavior of the structure.

The modal analysis of the complete setup and spectrum maps with and without casing are performed to observe the influence of surrounding air. The surrounding air does not have an important effect on the natural frequencies and critical speeds; however, it significantly affects the stability of the system. The rotating damping, resulting from the surrounding air in the confinement between rotor and casing, causes instability depending on the support stiffness and damping. There is good agreement between the theoretical results and the experiments. More accurate identification of the support properties will probably result in even better estimates for the onset of instability.

The thermal model has been tested by comparing the air gap average temperature calculated with thermal networks (Chapter 5) and with CFD-FEM thermal analysis. The thermal networks method was observed to obtain the temperature increase in the gap with reasonable accuracy. This method is practical and can be easily used to update the air properties (density and viscosity) due to changing air temperature. 



\section{Chapter 9}

\section{Implementation of Viscoelastic Supports}

\subsection{Introduction}

In the previous chapters (Chapters 6-8), the theoretical and the experimental work revealed that the flow-induced effects result in rotating damping and consequently instability. Stationary damping is considered to be useful for extending the stable operation ranges. Simple ways to increase the stationary support damping are sought. Viscoelastic inserts are the cheapest, the easiest and the most widely applied solution for providing additional stationary damping and vibration isolation. This chapter presents the usage of viscoelastic pads in order to extend the stable operation range of the mini rotor in medium gap confinement.

There has been numerous work about characterization, modeling and application of viscoelastic pads for diminishing the vibration amplitude due to unbalance and enabling stable operation of rotors $[20,21,43,52,57-59,77]$. These works include parametric numerical studies $[20,21]$ to determine stability zones, identification of the material characteristics [90] or optimization of the support geometry [57]. These studies show that significant improvement could be achieved on the dynamic behavior of the rotors by using the viscoelastic supports.

As a consequence, it was decided to add viscoelastic pads into the experimental setup to provide more stationary damping and surpass the instability stemming from the surrounding air in the confinement. Four different materials with two different geometries were tested and radical change in the onset of instability was observed.

This chapter mainly presents the experimental results (modal analysis and spectrum maps) through implementing viscoelastic pads. Section 9.2 explains the support structure of viscoelastic pads with different material and geometry. The next section 
then gives the experimental results from the single support and the complete setup for different materials. Finally, section 9.4 discusses the results and draws conclusions.

\subsection{Viscoelastic Support Structure}

The aim of using the viscoelastic supports is to considerably increase the damping and slightly increase the stiffness. It is planned that the threshold of instability should reach a higher rotation speed, but the critical speeds should not be changed much to ensure that the setup does not operate in the neighborhood of a new critical speed. The materials with low shore have low stiffness [45]. Four different materials were ordered from a supplier with different shore values to observe the effect of different stiffness and damping. These materials are given in Table 9.1 [45]. More information about these materials can be found in the references by Lakes [47] and Van der Vegt [78].

Table 9.1: Viscoelastic Materials used in the setup

\begin{tabular}{|c|c|c|}
\hline Material & Shore & Density \\
\hline Polyurethane(PMC) & 30 & $1.1 \times 10^{3} \mathrm{~kg} / \mathrm{m}^{3}$ \\
\hline Neoprene & 40 & $1.3 \times 10^{3} \mathrm{~kg} / \mathrm{m}^{3}$ \\
\hline Pararubber & 60 & $1.4 \times 10^{3} \mathrm{~kg} / \mathrm{m}^{3}$ \\
\hline Styrene butadiene rubber(SBR) & 70 & $1.5 \times 10^{3} \mathrm{~kg} / \mathrm{m}^{3}$ \\
\hline
\end{tabular}

There are different locations in which the viscoelastic pads can be implemented. These locations are explained in Table 9.2.

Table 9.2: Possible Locations for the Pads

\begin{tabular}{|ccc|}
\hline Location & Description & Place in Fig.7.8 \\
\hline 1 & Between the bearing and the bearing holder & 3 \\
2 & Between the support \& aligning brackets and frame & 1,2 and 10,11 \\
3 & Between the extra support and the bearing holder & 3 \\
\hline
\end{tabular}

The first location is between the bearing and the bearing holder. In that case, the hole in the bearing holder needs to be enlarged and the viscoelastic pads or sections should be inserted in the hole between the bearing and bearing holder. However, the viscoelastic material cannot be manufactured with high tolerances. This results in a variable thickness of the viscoelastic material, which will cause alignment errors of the bearings (and the rotor). Besides, the strict tolerances for bearings will be lost and operation at high speeds would be difficult. 
The second location for the viscoelastic material is between the support brackets and the fixed frame. In this case alignment problems can occur as well, resulting in excessive vibration of the rotor.

The final location for viscoelastic material in the setup is between the bearing holder and an extra support. The viscoelastic pads in this location will directly damp the vibrations of the bearing holder disk. The implementation of the pads does not require changes in the setup and there is no restriction on the dimensions of the pads. An external bracket has to be designed for locating the pads. This enables easy mounting and replacement of different pads with different material properties and dimensions. As a result, this location is considered as the most suitable one. Four pads on each bearing holder are used. In this way isotropic stiffness and damping in both directions perpendicular to the rotor are obtained. The pad height is slightly larger $(0.1 \mathrm{~mm})$ than the gap between the bearing holder and the extra support. In this way the pads can be clamped and therefore there is no need to use glue. For the experiments, two different pad widths are used, 5 and $10 \mathrm{~mm}$ respectively. The pads are cut from the samples with $10 \mathrm{~mm}$ depth provided by the supplier. Hence; the pad height and depth are $10 \mathrm{~mm}$. The extra support bracket, the bearing holder and the pads are depicted in Fig. 9.1 and Fig. 9.2. The dimensions of the extra support is given in App. C.

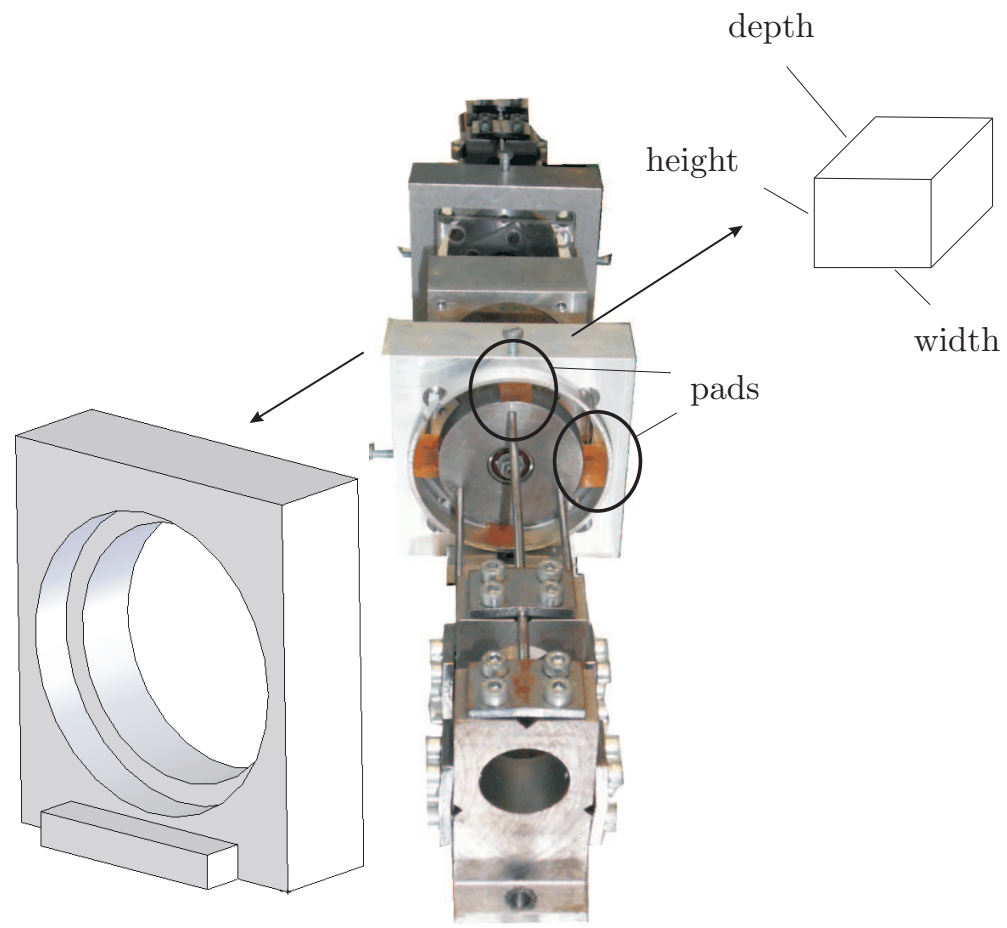

Figure 9.1: The extra support and pads 


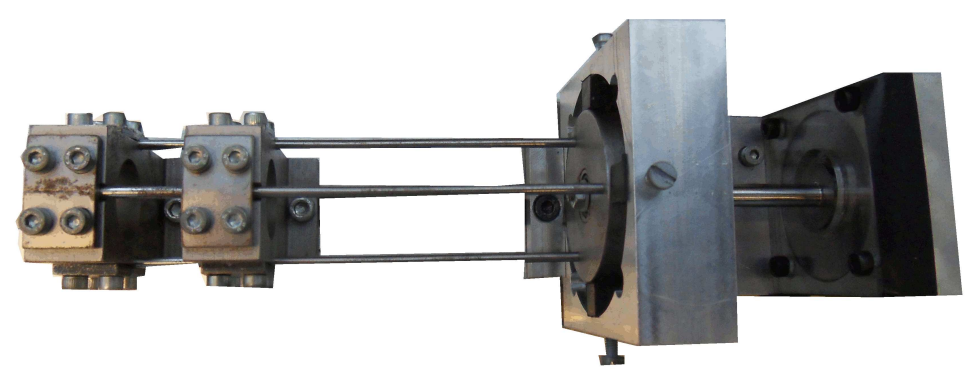

Figure 9.2: The experimental setup with pads

\subsection{Experiments}

\subsubsection{Modal Analysis of the Isolated Support}

Modal analysis of the isolated support with the viscoelastic pads is carried out to characterize the stiffness and damping for the different materials and two geometries. Stiffness and damping values are calculated from the FRFs by using the peak amplitude method (see Chapter 8).

\section{Pad width $5 \mathrm{~mm}$}

Firstly the experiments are performed for a pad width of $5 \mathrm{~mm}$ for different materials. The FRFs for the experiments on the support for different pad materials are shown in Fig. 9.3.

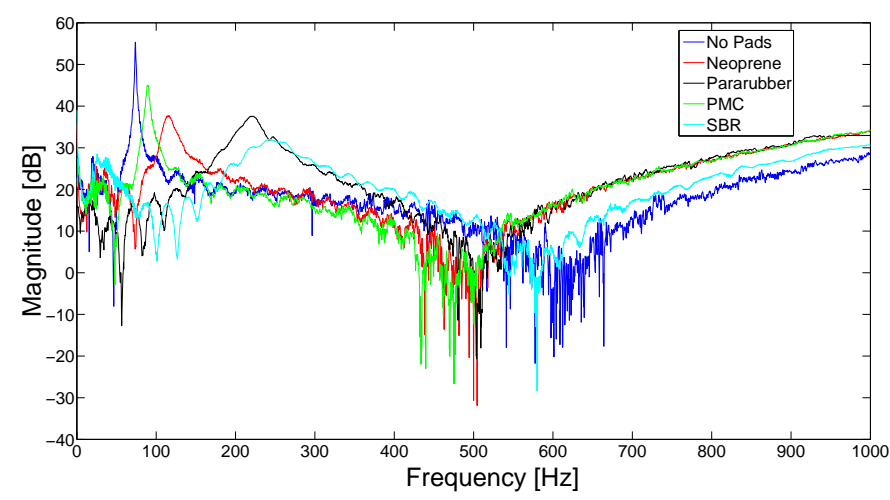

Figure 9.3: FRFs of the experiments on the support for different pad materials for pad width of $5 \mathrm{~mm}$ 
One peak frequency is observed with rubber pads as it was measured without pads (Chapter 8). Therefore the system can be considered as a single degree of freedom (SDOF) system. Among the materials used, PMC was observed to be the softest one as expected. It slightly changes the natural frequency and decreases the amplitude (adds some extra damping). The change in natural frequency is large with Neoprene, Pararubber and SBR. The calculated equivalent stiffness and damping values of the support structure are given in Table 9.3 for different materials [45].

Table 9.3: The stiffness and damping calculated from the experiments for pad width of $5 \mathrm{~mm}$

\begin{tabular}{|cccc|}
\hline Material & $\begin{array}{c}\text { Damping } \\
\mathbf{c}[\mathbf{N s} / \mathbf{m}]\end{array}$ & $\begin{array}{c}\text { Stiffness } \\
\mathbf{k}[\mathbf{N} / \mathbf{m}]\end{array}$ & $\begin{array}{c}\text { Natural frequency } \\
f_{0}[\mathbf{H z}]\end{array}$ \\
\hline Without Pads & 1.80 & $3.55 \times 10^{4}$ & 85.1 \\
PMC & 6.33 & $5.78 \times 10^{4}$ & 91.5 \\
Neoprene & 18.83 & $9.04 \times 10^{4}$ & 114.2 \\
Pararubber & 51.20 & $3.39 \times 10^{5}$ & 220.4 \\
SBR & 90.19 & $4.12 \times 10^{5}$ & 244.6 \\
\hline
\end{tabular}

\section{Pad width $10 \mathrm{~mm}$}

The modal analysis experiments are repeated also for the pads with a width of 10 mm. The FRFs resulting from the experiments are shown in Fig. 9.4.

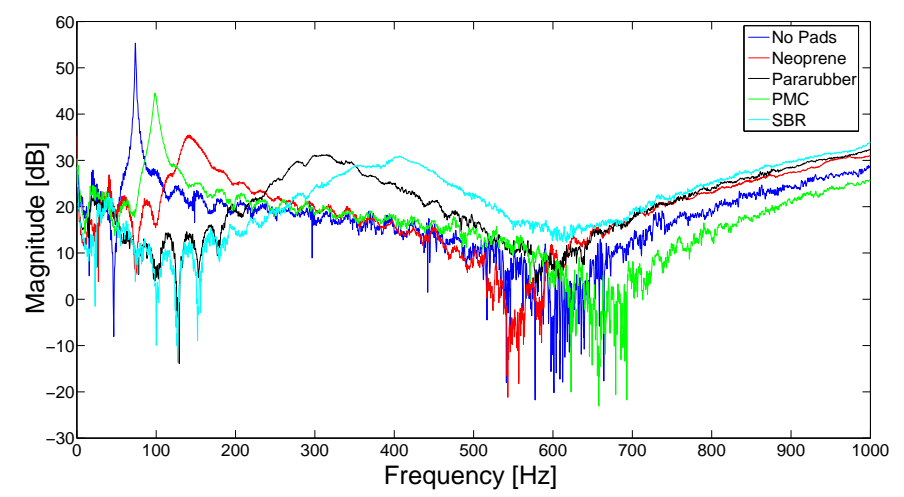

Figure 9.4: FRFs of the experiments on the support for different pad materials for pad width of $10 \mathrm{~mm}$

Again, the SDOF System behavior has been noticed. It is observed that both the 
stiffness and the damping increase for pads of an increasing width. The obtained stiffness and damping are given in Table 9.4.

Table 9.4: The stiffness and damping calculated from the experiments for pad width of $10 \mathrm{~mm}$

\begin{tabular}{|cccc|}
\hline Material & $\begin{array}{c}\text { Damping } \\
\mathbf{c}[\mathbf{N s} / \mathbf{m}]\end{array}$ & $\begin{array}{c}\text { Stiffness } \\
\mathbf{k}[\mathbf{N} / \mathbf{m}]\end{array}$ & $\begin{array}{c}\text { Natural frequency } \\
{[\mathbf{H z}]}\end{array}$ \\
\hline PMC & 12.95 & $6.76 \times 10^{4}$ & 98.9 \\
Neoprene & 31.70 & $1.40 \times 10^{5}$ & 142.3 \\
Pararubber & 69.10 & $6.91 \times 10^{5}$ & 316.0 \\
SBR & 160.0 & $1.01 \times 10^{6}$ & 380.0 \\
\hline
\end{tabular}

\subsubsection{Modal Analysis of the Complete Setup}

Modal Analysis of the setup is performed at standstill for different materials to investigate the change of natural frequencies. Experiments are performed for the two pad widths; $5 \mathrm{~mm}$ and $10 \mathrm{~mm}$. The results of the experiments are shown in Fig. 9.5 (for pad width $5 \mathrm{~mm}$ ) and Fig. 9.6 (for pad width $10 \mathrm{~mm}$ ).

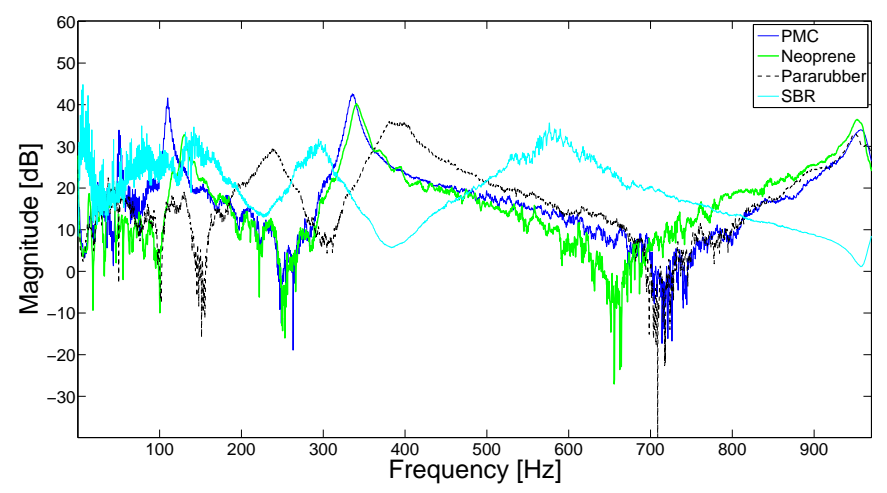

Figure 9.5: FRFs of the complete setup for different pad materials for pad width of $5 \mathrm{~mm}$

It can be seen that all pads have an influence on the natural frequencies. For PMC and Neoprene the natural frequency differs slightly, on the other hand for Pararubber and SBR the change is significant. For the $10 \mathrm{~mm}$ pad the change increases even more. Table 9.5 gives the natural frequencies at standstill for different materials and widths. In some measurements the peaks were not clear and are shown blank in the table. 


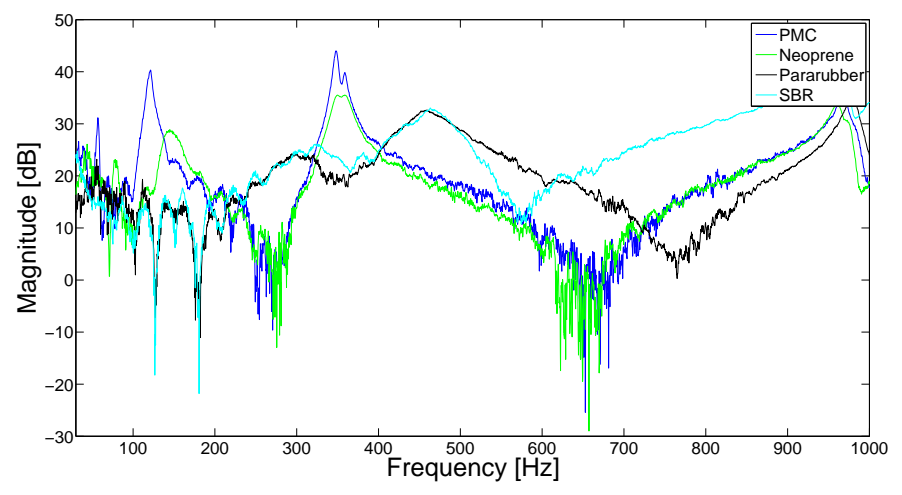

Figure 9.6: FRFs of the complete setup for different pad materials for pad width of $10 \mathrm{~mm}$

Table 9.5: Natural Frequencies of the setup with and without pads

\begin{tabular}{|ccccc|}
\hline $\begin{array}{c}\text { Pad } \\
\text { Material }\end{array}$ & $\begin{array}{c}\text { Pad } \\
\text { Width }\end{array}$ & $\begin{array}{c}\text { First natural } \\
\text { frequency [Hz] }\end{array}$ & $\begin{array}{c}\text { Second natural } \\
\text { frequency [Hz] }\end{array}$ & $\begin{array}{c}\text { Third natural } \\
\text { frequency [Hz] }\end{array}$ \\
\hline Without pads & & 43.7 & 84.0 & 311.6 \\
& & & & \\
PMC & $5 \mathrm{~mm}$ & 50.3 & 110.0 & 335.6 \\
Neoprene & $5 \mathrm{~mm}$ & - & 130.0 & 340.6 \\
Pararubber & $5 \mathrm{~mm}$ & 85.3 & 237.8 & 382.2 \\
SBR & $5 \mathrm{~mm}$ & 141.9 & 294.7 & 576.3 \\
& & & & \\
PMC & $10 \mathrm{~mm}$ & 56.9 & 121.3 & 348.1 \\
Neoprene & $10 \mathrm{~mm}$ & 78.1 & 145.0 & 365.0 \\
Pararubber & $10 \mathrm{~mm}$ & - & 295.9 & 458.4 \\
SBR & $10 \mathrm{~mm}$ & - & 320.9 & 463.4 \\
\hline
\end{tabular}

\subsubsection{Spectrum Maps of the Setup}

Finally, spectrum maps are plotted to observe the amplitude of vibrations in the presence of pads. The spectrum maps can be used to find the onset of instability if it exists in the operation range (see Chapter 8). Spectrum maps were made for all four materials again, for $5 \mathrm{~mm}$ and $10 \mathrm{~mm}$ pads. A spectrum map without the pads for a support beam of $90 \mathrm{~mm}$ is also given for reference in Fig. 9.7. It can be seen that the setup becomes unstable immediately after the start-up (at $15 \mathrm{krpm}$ ). The spectrum maps for pad dimensions of $5 \mathrm{~mm}$ and $10 \mathrm{~mm}$ are given below. 


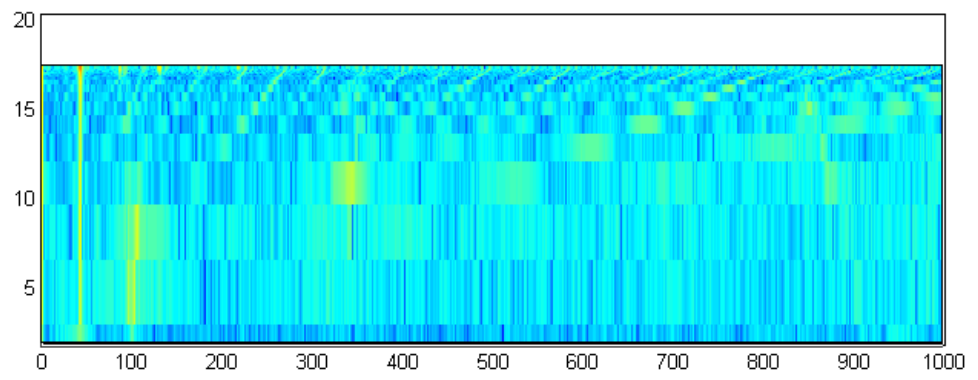

Figure 9.7: Spectrum map of the setup without pads, vertical axis: Krpm horizontal axis: $\mathrm{Hz}$

\section{pad width $=5 \mathrm{~mm}$}

Fig. 9.8 depicts a spectrum map of the setup with PMC pads of width $5 \mathrm{~mm}$. The peaks corresponding to the critical speed shown with the letter $\mathrm{c}$ disappear as the rotation speed increases. At $24900 \mathrm{rpm}$ the setup becomes unstable. The spectrum plot at $24900 \mathrm{rpm}$ is shown in Fig. 9.9. The amplitude of vibration corresponding to the first natural frequency (number 1) starts growing and becomes higher than the other frequencies.

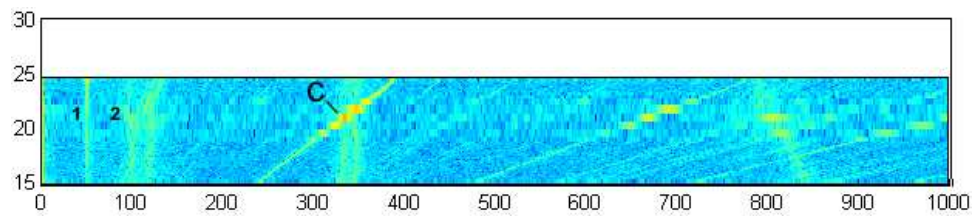

Figure 9.8: Spectrum maps of the setup with PMC pads of width $5 \mathrm{~mm}$

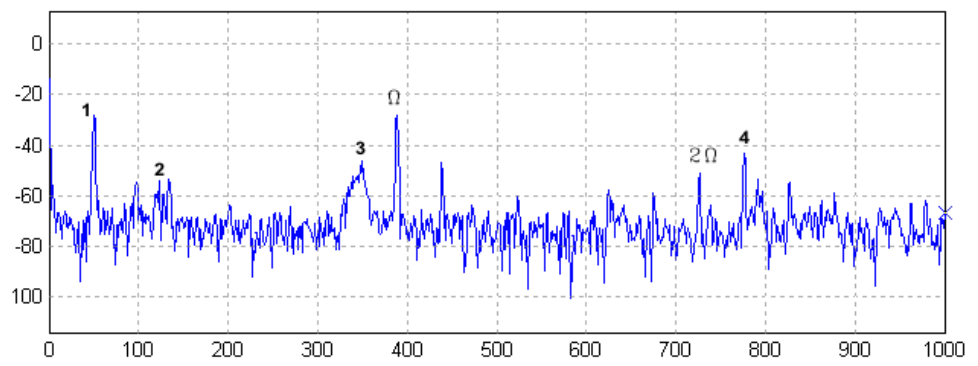

Figure 9.9: Spectrum plot at $24900 \mathrm{rpm}$ of the setup with PMC pads of $5 \mathrm{~mm}$, vertical axis: db horizontal axis: $\mathrm{Hz}$

The spectrum map of the setup with Neoprene is given in Fig. 9.10. It can be seen 
that the setup does not experience instability for speeds up to $50000 \mathrm{rpm}$, which is the maximum speed of the motor. There are two critical speeds in the spectrum map: $22000 \mathrm{rpm}$ and $43000 \mathrm{rpm}$. The amplitude of vibration due to synchronous excitation increases around these speeds, but as the rotation speeds increase the peaks disappear. Fig. 9.11 shows the spectrum map by using Pararubber pads. Like the

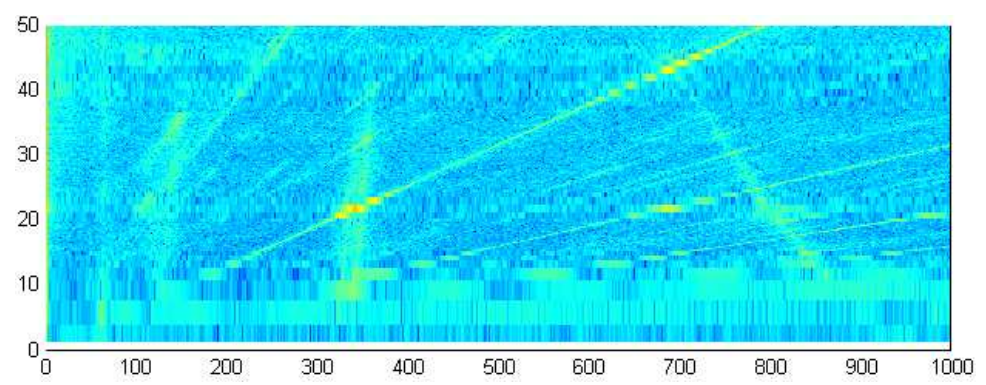

Figure 9.10: Spectrum maps of the setup with Neoprene pads of width $5 \mathrm{~mm}$

setup with Neoprene pads, the setup does not become unstable. In this case excessive vibrations were present around the final critical speed, therefore, the measurements were stopped at $42000 \mathrm{rpm}$. The critical speed at $22000 \mathrm{rpm}$ is visible here (c in the figure). Compared to the spectrum map in Fig. 9.10 it can be seen that there is more damping resulting in lower amplitudes, since the first and third natural frequencies are not visible.

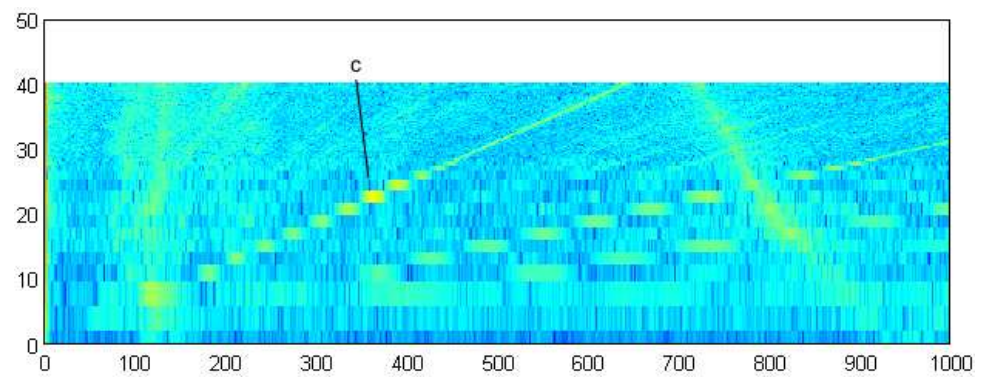

Figure 9.11: Spectrum maps of the setup with Pararubber pads of width $5 \mathrm{~mm}$

The spectrum map with SBR is shown in Fig. 9.12. Again, no instability has been observed. Also two critical speeds can be seen here, but with lower peaks than in the spectrum maps for the other materials. The first and third natural frequencies have completely disappeared here. It can be concluded that the second and fourth natural frequencies are less visible and thus more damped than with Pararubber (Fig. 9.12). 


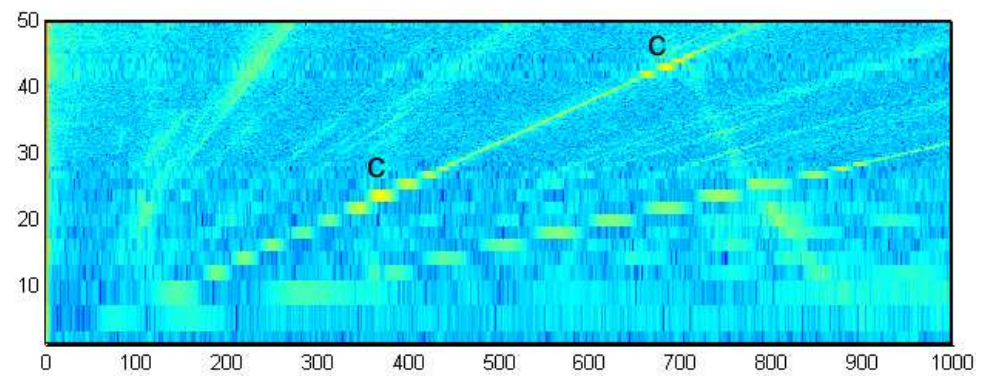

Figure 9.12: Spectrum maps of the setup with SBR pads of width $5 \mathrm{~mm}$

\section{pad width $=10 \mathrm{~mm}$}

The spectrum measurements are also repeated for pads of $10 \mathrm{~mm}$ width with the same materials. In Fig. 9.13 the spectrum map of the setup with PMC pads of width 10 $\mathrm{mm}$ is shown. It can be seen that instability occurs at $49900 \mathrm{rpm}$.

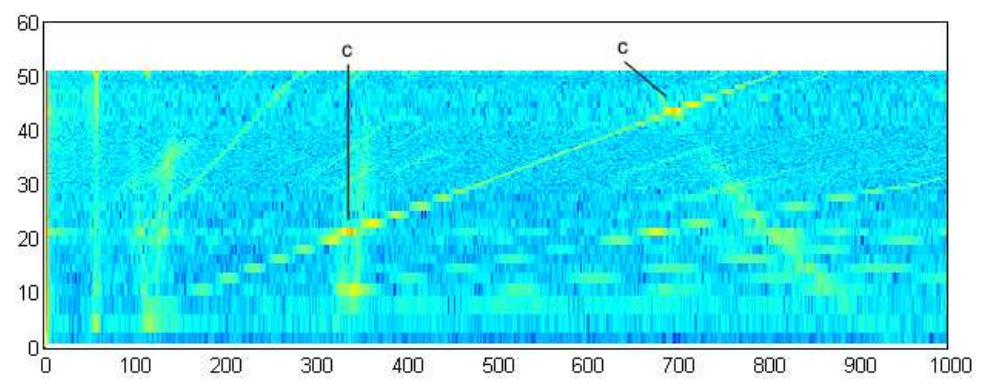

Figure 9.13: Spectrum maps of the setup with PMC pads of width $10 \mathrm{~mm}$

In addition the first, second and third natural frequencies are visible. The critical speeds exists around 20000 and 42 000. However, as the rotation speed increases the high amplitudes of vibration disappear. The spectrum measurements at 40000 and $49900 \mathrm{rpm}$ are given in Fig. 9.14. The natural frequencies are numbered on the upper plot. The amplitude of the first peak in the upper plot is significantly lower than in the lower plot. The fourth critical speed has been passed between $40000 \mathrm{rpm}$ and $49900 \mathrm{rpm}$, therefore that critical speed is not visible in the plots. Compared to the results with the ones obtained with $5 \mathrm{~mm}$ pads, the amplitude of peaks are less, which means more damping is present. As a result, the onset of instability also happens at a higher speed. The PMC pads of width $10 \mathrm{~mm}$ cause a higher stiffness and damping than the PMC pads of width $5 \mathrm{~mm}$. For the other materials instability has not been observed with a pad width of $10 \mathrm{~mm}$. 

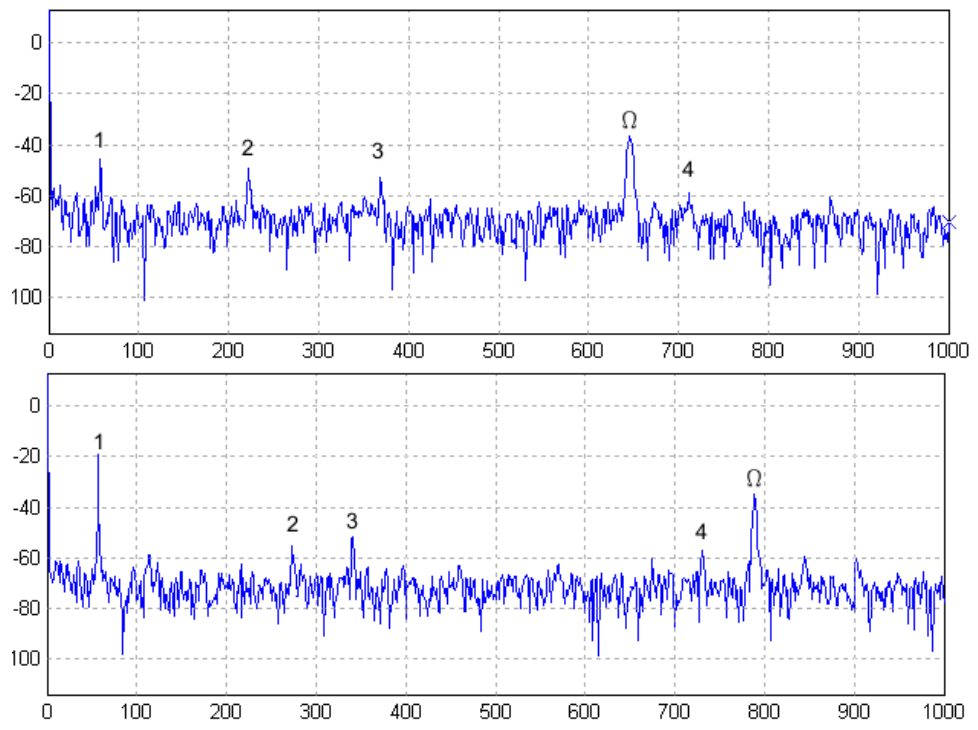

Figure 9.14: Spectrum plot at 40000 (above) and $49900 \mathrm{rpm}$ (below) of the setup

\subsection{Discussion and Conclusion}

Finally the theoretical and experimental results are compared. The damping ratios obtained from section 9.3.1 are added into the multiphysical model. As explained in chapter 8 , the translational stiffness obtained from the modal analysis of the isolated support does not yield accurate estimations. Therefore, a stiffness correction factor has been calculated by dividing the stiffness obtained from modal analysis of supports with pads to the one from without pads (Table 9.3 and Table 9.4). This correction factor is multiplied with the stiffness matrix, $K$ in the simulations. The simulation results are compared with the experiments in Table 9.6 and Table 9.7. Instability is only observed for PMC in the operation range (up to $50000 \mathrm{rpm}$ ). For the other materials only the simulation results are presented.

There is fair agreement between the theoretical and experimental results. The results can be improved by using more advanced models for viscoelastic material [33, 77].

In summary, four types of viscoelastic materials (PMC, Pararubber, Neoprene, SBR) are implemented in the experimental setup. The experiments reveal that the viscoelastic materials increase the stationary damping and stiffness and thereby extend the onset of instability. The PMC is observed to be the softest among the used materials. It does not have a strong effect on the critical speeds whereas the influence is high on the onset of instability. The damping value and stiffness correction factor are obtained from the modal analysis of the isolated support. These values are implemented into the theoretical model and the results are compared to the experiments. A more detailed analysis can provide more accurate models to obtain 
better prediction of the experimentally observed improved stability.

Table 9.6: Natural Frequencies ( $\mathrm{E}=$ Experiments, $\mathrm{S}=$ Simulation)

\begin{tabular}{|ccccccc|}
\hline Pad Material & $\mathrm{E}$ & $\mathrm{S}$ & $\mathrm{E}$ & $\mathrm{S}$ & $\mathrm{E}$ & $\mathrm{S}$ \\
\hline PMC(5 mm) & 50.3 & 57.7 & 110.0 & 112.8 & 335.6 & 327.4 \\
Neoprene(5 mm) & - & 71.2 & 130.0 & 130.9 & 340.6 & 332.8 \\
Pararubber $(5 \mathbf{~ m m})$ & 85.3 & 124.5 & 237.8 & 224.5 & 382.2 & 369.5 \\
SBR(5 mm) & 141.9 & 132.9 & 294.7 & 243.5 & 576.3 & 378.9 \\
& & & & & & \\
PMC(10 mm) & 56.9 & 62.9 & 121.3 & 118.4 & 348.1 & 328.8 \\
Neoprene(10 mm) & 78.1 & 86.66 & 145.0 & 154.07 & 365.0 & 339.52 \\
Pararubber(10 mm) & - & 154.3 & 295.9 & 311.31 & 458.4 & 423.36 \\
SBR $(10 \mathbf{~ m m})$ & - & 168.3 & 320.9 & 369.3 & 463.4 & 466.3 \\
\hline
\end{tabular}

Table 9.7: Onset of Instability (rpm)

\begin{tabular}{|ccc|}
\hline Pad Material & Experiment & Simulation \\
\hline PMC (5) mm & $24900 \mathrm{rpm}$ & 34300 \\
Neoprene (5) mm & - & 70700 \\
Pararubber (5) mm & - & 126500 \\
SBR (5) mm & - & 164700 \\
& & \\
PMC (10) $\mathbf{~ m m}$ & $49900 \mathrm{rpm}$ & 53900 \\
Neoprene (10) mm & - & 100600 \\
Pararubber (10) mm & - & 118900 \\
SBR(10) $\mathbf{~ m m ~}$ & - & 142900 \\
\hline
\end{tabular}




\section{Chapter 10}

\section{Conclusions and Recommendations}

\subsection{Conclusions}

The aim of this research was to obtain insight into the multiphysical aspects that are significant for high-speed small-scale rotating machinery. For this purpose an analysis tool has been developed to investigate the dynamic behavior under these multiphysical effects. Furthermore, experiments have been carried out to evaluate the developed analysis approach. The modeling approach was intended to enable the design of rotors that can operate at higher rotation speeds without encountering critical speeds and onset of instability.

Firstly, a literature survey has been carried out to investigate the developments in high-speed minirotating machinery. It is observed that most of the studies involve the design and manufacturing of microrotating machinery and modeling studies mainly concentrate on the non-conventional bearings. However in many applications there is a casing around the rotor. The air in the confinement between the casing and the rotor has a significant effect on the dynamic behavior of the rotor. The existing literature lacks coupled thermal, fluid and structural analysis for dynamic behavior. As a consequence, it was decided to model the multiphysical flow effects on the rotordynamics of small-scale machines with medium gap.

An analysis approach has been developed to model the individual physical domains and to investigate their coupled influence on the dynamics of mini rotors. Flowinduced forces have been described for laminar and turbulent flow regimes in terms of added mass, damping and stiffness and a method to include these elements into the structural model has been provided (Chapter 4 and Chapter 6). In addition, a thermal model based on thermal networks has been developed to take the changing fluid properties due to temperature into account (Chapter 5). 
Afterwards, the different physical models have been coupled to each other and an analysis for the dynamic behavior of an arbitrary rotor has been performed. The analysis reveals that the flow in moderate air gaps of minirotating machinery results in stability problems due to the rotating air in the gap generating rotating damping.

An experimental setup has been built to verify the developed modeling approach. The design criteria have been determined and the design of an experimental setup has been realized. Flexible supports with changing stiffness have been designed in order to provide low support stiffness (which is common in minirotating machinery) and to examine the effect of the support stiffness on the dynamics of the rotor. Modal analysis of individual components and the complete setup have been performed to identify the dynamic characteristics. Modeling approaches for flexible supports have been sought to obtain equivalent stiffness and damping to be combined with the structural model. Different support models have been implemented into the theoretical model and the simulation results have been compared with the experimental modal analysis of the complete setup. In this way the support model yielding good estimations has been determined. It has been observed that rotational DOFs, rotational stiffness and inertia must be included in the extracted models to obtain good estimates. Spectrum maps have been plotted for determining the onset of instability. The experimental results have been compared with the theoretical models covering both the laminar and turbulent flow regimes. Good agreement has been obtained between theory and experiments. The developed methodology has been shown to be useful to model the dynamic behavior under multiphysical effects.

The thermal model was difficult to be verified by experiments. A more detailed thermal analysis was done instead, and this was compared with the results from the thermal networks model used in the multiphysical modeling. Thermal analysis of a simple cylindrical rotor and stator system has been performed by using thermal networks and CFD-FEM. The simulations were performed and fair agreement was obtained between the results using both methods. Consequently, the thermal networks method seems to be appropriate to be implemented into fluid rotor interaction models to update temperature-dependent air properties for further analysis.

In conclusion, a methodology has been developed to add the flow-induced forces on high-speed minirotating machinery with medium gap for both laminar and turbulent regimes into a structural FE model including the thermal effects. The results from the developed methodology were compared with the experimental results carried out on a specially designed setup. Good agreement between theory and experiments has been observed. The developed method can be used to obtain the desired rotordynamic behavior of minirotating machinery which includes medium gaps.

As is well known in the literature, stationary/rotating damping ratio determines the stable operation of the rotor. Increase of stationary damping broadens the stable operation range. Therefore, simple ways to surpass the observed stability problems by increasing the stationary damping were investigated. Different types of pads were inserted in the supports. The onset of instability is observed to change drastically by using viscoelastic inserts. As a consequence, viscoelastic inserts were observed to be 
the cheapest and the simplest solution to increase the stationary damping and extend the stable operation range.

\subsection{Recommendations}

Some recommendations to extend the modeling approach and the design of the experiments follow from the presented research:

- More advanced modeling of the multiphysics is significant in simulating rotordynamic behavior. In the current study simple modeling approaches (linearized fluid forces and thermal networks) with one-way coupling between the physical domains are used for initial estimations. It is recommended to apply more advanced numerical techniques to examine flow forces and temperature increase. Besides, methods for full coupling between physical domains may result in further improvements in the model.

- In order to prepare a model to simulate the experimental setup the support structure should be included. In the present research, equivalent support models consisting of springs and dampers are extracted from static loading simulations and modal analysis. It is suggested to investigate methods for detailed FE modeling or identification of supports to improve the accuracy of the model.

- The viscoelastic pads have a significant effect on stability and critical speeds. A correction factor is calculated using experimental data for the pads in the present work. However, viscoelastic models coupled with the multiphysical models may increase the accuracy of the predictions. Furthermore, it is recommended to investigate optimization of the pad shapes to obtain the desired rotordynamic properties (critical speeds and onset of instability).

- In the present research an experimental setup has been designed. As an improvement to the current experimental setup, the drive system and bearings that operate at higher speeds can be investigated. In this way the validity of the models can be examined experimentally at higher speeds. 



\section{Nomenclature}

\section{Roman}

\begin{tabular}{ll}
$A$ & Area of the cross section \\
$A_{c}$ & The surface area in contact with air \\
$\mathbf{B}$ & Compliance matrix \\
$\mathbf{C}$ & Damping matrix \\
$\mathbf{C}_{r}$ & Rotating damping matrix \\
$\mathbf{C}_{n}$ & Non-rotating damping matrix \\
$c$ & Damping of the fluid in the gap \\
$c_{e q}$ & Equivalent damping \\
$c_{f}$ & Friction coefficient \\
$c_{f r}$ & Friction coefficient for the rotor \\
$c_{f s}$ & Friction coefficient for the stator \\
$c_{i}$ & Damping of the fluid in the gap per unit length \\
$c_{p}$ & Specific heat at constant pressure \\
$c_{3 d}$ & Correction factor for three-dimensional flow effects \\
$D_{d}$ & Disk diameter \\
$D_{s}$ & Shaft diameter \\
$E$ & Young's modulus \\
$\mathbf{F}$ & Load vector \\
$f$ & Applied force in x and y direction \\
$f_{n}$ & Non-rotating force vector \\
$f_{x}$ & Flow-induced forces in x direction \\
$f_{y}$ & Flow-induced forces in y direction \\
$f_{r}$ & Force vector resulting from unbalance \\
$\mathbf{G}$ & Gyroscopic matrix \\
$G$ & Shear modulus \\
$H$ & Nominal clearance \\
$h$ & Convective heat transfer coefficient \\
$h_{a}$ & Convective heat transfer coefficient for ambient \\
$h_{r}$ & Convective heat transfer coefficient for the gap \\
$h_{g}$ & Annular gap depth \\
$J$ & Inertia \\
& \\
\hline &
\end{tabular}


I Inertia of the support disk

$I_{y} \quad$ Inertia of the structural element

K Stiffness matrix

$\mathbf{K}_{e} \quad$ Stiffness element matrix

$\widetilde{K}_{z} \quad$ Shear stress factor

$k \quad$ Translational Stiffness

$k_{a} \quad$ Axial thermal conductivity

$k_{b} \quad$ Translational stiffness of the bearing

$k_{b r} \quad$ Rotational stiffness of the bearing

$k_{\text {cond }} \quad$ Thermal conductivity

$k_{e q} \quad$ Equivalent stiffness

$k_{i} \quad i^{\text {th }}$ element of the stiffness matrix

$k_{s} \quad$ Translational Support Stiffness

$k_{s r} \quad$ Rotational Support Stiffness

$k_{r} \quad$ Radial thermal conductivity

$k_{\text {ro }} \quad$ Thermal conductivity of rotor

$k_{\text {st }} \quad$ Thermal conductivity of stator

$k_{1} \quad$ Roughness coefficient

$L \quad$ Length of the rotor confined in fluid

Total shaft length

Element length

Mass matrix

$\mathbf{M}$

M

Applied moment in $\mathrm{x}$ and $\mathrm{y}$ direction

$M_{a 2 d} \quad$ Added mass for 2-D flow

$M_{a 3 d} \quad$ Added mass for 3-D flow

$\mathbf{M}_{e} \quad$ The mass element matrix

$\mathbf{M}_{t}$

$\mathbf{M}_{r}$

Mass matrix related with translational inertia

Mass matrix related with rotational inertia

Nu Nusselt number

$m \quad$ Mass

Added mass

$m_{a}$

q

Vector of nodal displacements

Rotor radius

Stator outer radius

$\left[\mathrm{W} /\left(\mathrm{K} \mathrm{m}^{2}\right)\right]$
$[\mathrm{N} / \mathrm{m}]$

$[\mathrm{N} \mathrm{m} / \mathrm{rad}]$

$\left[\mathrm{W} /\left(\mathrm{K} m^{2}\right)\right]$

$[\mathrm{N} / \mathrm{m}]$

$\left[\frac{N}{m}, \frac{N m}{r a d}\right]$

$[\mathrm{N} / \mathrm{m}]$

$[\mathrm{N} \mathrm{m} / \mathrm{rad}]$

$\left[\mathrm{W} /\left(\mathrm{K} \mathrm{m}^{2}\right)\right]$

$\left[\mathrm{W} /\left(\mathrm{K} m^{2}\right)\right]$

$\left[\mathrm{W} /\left(\mathrm{K} m^{2}\right)\right.$ ]

$\left[\mathrm{kg}, \mathrm{kg} \mathrm{m}^{2}\right]$

$[\mathrm{N} \mathrm{m}]$

$\left[\mathrm{kg}, \mathrm{kg} \mathrm{m}^{2}\right]$

$\left[\mathrm{kg}, \mathrm{kg} \mathrm{m}^{2}\right]$

$\left[\mathrm{kg}, \mathrm{kg} \mathrm{m}^{2}\right]$

$\left[\mathrm{kg}, \mathrm{kg} \mathrm{m}^{2}\right]$

$\left[\mathrm{kg}, \mathrm{kg} \mathrm{m}^{2}\right]$

Stator inner radius

$[\mathrm{m}, \mathrm{rad}]$

[m]

[m]

[m]

Vector of power generation

[W]

Prandtl number

$P_{f} \quad$ Heat dissipation due to air friction

$[\mathrm{W} / \mathrm{K}]$

Thermal conductance matrix

$[\mathrm{K} / \mathrm{W}]$

$R_{\text {conv }} \quad$ The convective thermal resistance

$[\mathrm{K} / \mathrm{W}]$

$R_{i}$

$i^{\text {th }}$ Thermal Resistance in network

$[\mathrm{K} / \mathrm{W}]$

Axial Thermal Resistance

$[\mathrm{K} / \mathrm{W}]$

$R_{i r}$

Radial Thermal Resistance

$[\mathrm{K} / \mathrm{W}]$

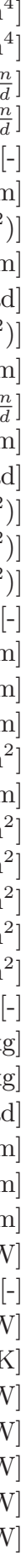




$\begin{array}{llr}R_{\text {irs }} & \text { Radial Thermal Resistance for symmetric cylindrical } & {[\mathrm{K} / \mathrm{W}]} \\ R_{e} & \text { section } & {[-]} \\ R e_{r} & \text { Couette Reynolds number } & {[-]} \\ R e^{*} & \text { Tip Reynolds number } & {[-]} \\ \mathbf{T} & \text { Modified Reynolds number } & {[\mathrm{K}]} \\ T_{\text {air }} & \text { Vector of nodal temperatures } & {[\mathrm{K}]} \\ T_{r} & \text { Mean temperature of the air gap } & {[\mathrm{K}]} \\ T_{s} & \text { Mean temperature of the rotor } & {[\mathrm{K}]} \\ T_{i} & \text { Mean temperature of the stator } & {[\mathrm{K}]} \\ T_{m} & \text { Temperature of the } i^{\text {th }} \text { node } & {[\mathrm{K}]} \\ T a & \text { Mean temperature of the component } & {[-]} \\ u_{x_{i}} & \text { Taylor number } & {[\mathrm{m}]} \\ u_{y_{i}} & \text { Displacement of } i^{\text {th }} \text { node in x direction } & {[\mathrm{m}]} \\ x & \text { Displacement of } i^{\text {th node in y direction }} & {[\mathrm{m}]} \\ u & \text { Translational deformation } & {[\mathrm{m} / \mathrm{s}]} \\ v & \text { gap averaged tangential velocity } & {[\mathrm{m} / \mathrm{s}]}\end{array}$

\section{Greek}

$\delta$

$\epsilon$

$\theta$

$\lambda$

$\mu$

$\kappa$

$\Phi$

$\phi_{x_{i}}$

$\phi_{y_{i}}$

$\rho$

$\sigma$

$\bar{\sigma}$

$\tau$

$\tau_{r}$

$\tau_{s}$

$\chi$

$\Omega$

$\omega$

$\omega_{1}$

$\bar{\omega}$

$\Delta \omega$

$\omega_{n}$

$\zeta$
Reduced gap ratio

eccentricity

Rotational deformation

Complex frequency

Dynamic viscosity

Rotational Stiffness

Non dimensional variable

Rotation of $i^{\text {th }}$ node in $\mathrm{x}$ direction

Rotation of $i^{\text {th }}$ node in y direction

Density

Decay rate

Reduced decay rate

Shear stress

Shear stress on the rotor

Shear stress on the stator

Shear factor

Rotation speed

Natural frequency

First rigid body mode natural frequency

Reduced natural frequency

Frequency difference between half power points

Natural frequency

Damping ratio m]

[m]

$[\mathrm{m}]$ $\mathrm{m} / \mathrm{s}]$ $\mathrm{m} / \mathrm{s}]$ 


\section{Abbreviations}

CFD Computational fluid dynamics

DOF Degree(s) of freedom

FE Finite element

FEM Finite element method

FRF Frequency response function

$\mathrm{krpm} \quad$ thousand rotations per minute

rpm

rotation per minute

SBR Styrene butadiene rubber

SDOF Single degree of freedom 


\section{Appendix A}

\section{Element Matrices for Structural Model}

According to Genta [32] the consistent stiffness and gyroscopic matrices for a beam element, Figure 3.1, are given as:

$$
\begin{aligned}
& \boldsymbol{K}=\frac{E I_{y}}{l^{3}(1+\Phi)}\left[\begin{array}{cccc}
12 & 6 l & -12 & 6 l \\
& (4+\Phi) l^{2} & -6 l & (2-\Phi) l^{2} \\
& & 12 & -6 l \\
& \text { symm. } & & (4+\Phi) l^{2}
\end{array}\right] \\
& \boldsymbol{M}_{\boldsymbol{T}}=\frac{\rho A l}{420(1+\Phi)^{2}}\left[\begin{array}{cccc}
m_{1} & l m_{2} & m_{3} & -l m_{4} \\
& l^{2} m_{5} & l m_{4} & -l^{2} m_{6} \\
& & m_{1} & -l m_{2} \\
& \text { symm. } & & l^{2} m_{5}
\end{array}\right] \\
& \boldsymbol{M}_{\boldsymbol{R}}=\frac{\rho I_{y}}{30 l(1+\Phi)^{2}}\left[\begin{array}{cccc}
m_{7} & l m_{8} & -m_{7} & l m_{8} \\
& l^{2} m_{9} & -l m_{8} & -l^{2} m_{10} \\
& & m_{7} & -l m_{8} \\
& \text { symm. } & & l^{2} m_{9}
\end{array}\right]
\end{aligned}
$$

where $\Phi=\frac{12 E I_{y} \chi}{G A l^{2}}$ and $m_{1} \ldots m_{10}$ are:

$$
\begin{array}{ll}
m_{1}=156+294 \Phi+140 \Phi^{2}, & m_{2}=22+38.5 \Phi+17.5 \Phi^{2}, \\
m_{3}=54+126 \Phi+70 \Phi^{2}, & m_{4}=13+31.5 \Phi+17.5 \Phi^{2}, \\
m_{5}=4+7 \Phi+3.5 \Phi^{2}, & m_{6}=3+7 \Phi+3.5 \Phi^{2}, \\
m_{7}=36, & m_{8}=3-15 \Phi, \\
m_{9}=4+5 \Phi+10 \Phi^{2}, & m_{10}=1+5 \Phi-5 \Phi^{2} .
\end{array}
$$


The consistent mass and gyroscopic matrices are:

$$
M=M_{T}+M_{R}, \quad G=2 M_{R}
$$




\section{Appendix B}

\section{Thermal Network}

If the face temperatures $T_{3}$ and $T_{4}$ are equal for the cylinder given in Fig. 5.1, only half of the cylinder can be modeled [54] considering only half heat generation. Then the thermal networks in Fig. 5.1 reduce to the form:

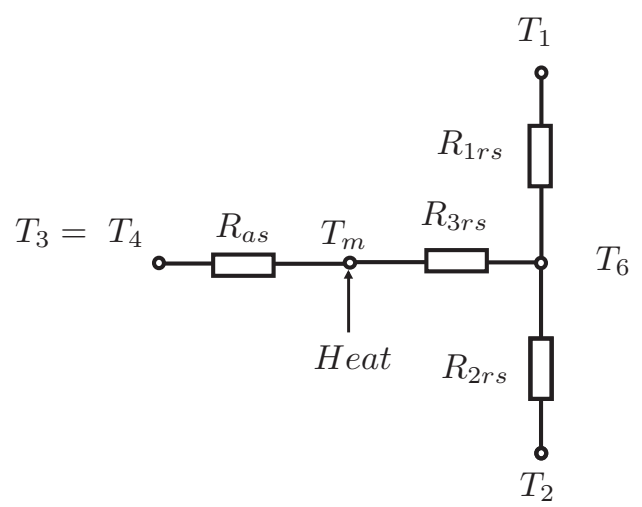

Figure B.1: Thermal network for a symmetric cylindrical section [54] 
where the resistances in Fig. 5.1 change as [54]:

$$
\begin{aligned}
R_{a s} & =R_{1 a}+2 R_{3 a}=\frac{L}{6 \pi k_{a}\left(r_{1}^{2}-r_{2}^{2}\right)} \\
R_{1 r s} & =\frac{1}{2 \pi k_{r} L}\left[1-\frac{2 r_{2}^{2} \ln \left(\frac{r_{1}}{r_{2}}\right)}{\left(r_{1}^{2}-r_{2}^{2}\right)}\right] \\
R_{2 r s} & =\frac{1}{2 \pi k_{r} L}\left[\frac{2 r_{1}^{2} \ln \left(\frac{r_{1}}{r_{2}}\right)}{\left(r_{1}^{2}-r_{2}^{2}\right)}-1\right] \\
R_{3 r s} & =\frac{-1}{4 \pi\left(r_{1}^{2}-r_{2}^{2}\right) k_{r} L}\left[r_{1}^{2}+r_{2}^{2}-\frac{4 r_{1}^{2} r_{2}^{2} \ln \left(\frac{r_{1}}{r_{2}}\right)}{\left(r_{1}^{2}-r_{2}^{2}\right)}\right]
\end{aligned}
$$

The resistances are multiplied by two since half of the cylinder is modeled. In the present work the above network is used to model the stator. The rotor is modeled as a solid rod (see Fig. 5.2). The complete network is illustrated below:

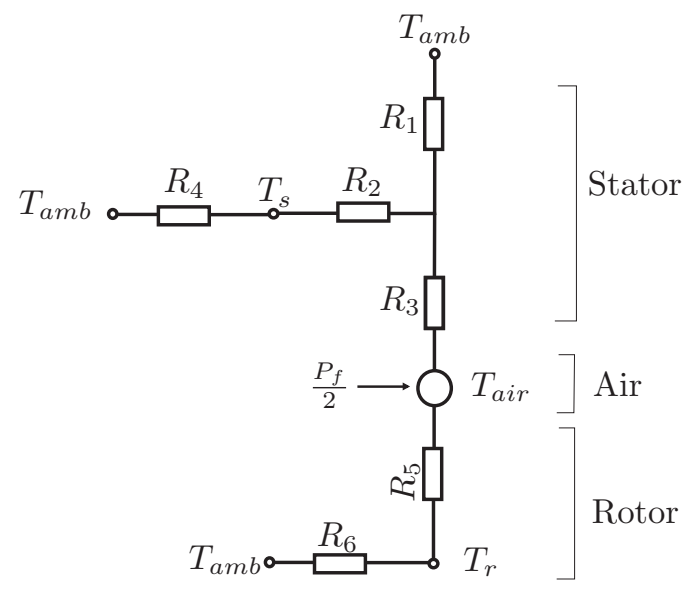

where $T_{r}$ is the mean temperature of the rotor, $T_{s}$ is the mean temperature of the stator and $T_{a i r}$ is the mean temperature of the air in the gap between the rotor and stator, $T_{a m b}$ is the ambient temperature. The resistances in the network are given as: 


$$
\begin{aligned}
R_{1} & =\frac{1}{2 \pi k_{s t} L}\left[1-\frac{2 r_{2}^{2} \ln \left(\frac{r_{1}}{r_{2}}\right)}{\left(r_{1}^{2}-r_{2}^{2}\right)}\right] \\
R_{2} & =\frac{-1}{4 \pi\left(r_{1}^{2}-r_{2}^{2}\right) k_{s t} L}\left[r_{1}^{2}+r_{2}^{2}-\frac{4 r_{1}^{2} r_{2}^{2} \ln \left(\frac{r_{1}}{r_{2}}\right)}{\left(r_{1}^{2}-r_{2}^{2}\right)}\right] \\
R_{3} & =\frac{1}{2 \pi k_{s t} L}\left[\frac{2 r_{1}^{2} \ln \left(\frac{r_{1}}{r_{2}}\right)}{\left(r_{1}^{2}-r_{2}^{2}\right)}-1\right]+\frac{1}{h_{a} \pi r_{2} L} \\
R_{4} & =\frac{L}{6 \pi k_{s t}\left(r_{1}^{2}-r_{2}^{2}\right)} \\
R_{5} & =\frac{1}{4 \pi k_{r o} L}+\frac{1}{h_{a} \pi r L} \\
R_{6} & =\frac{L}{6 \pi r^{2} k_{r o}}+\frac{1}{h_{r} \pi r^{2}}
\end{aligned}
$$

where $r_{1}$ is the stator outer radius, $r_{2}$ is the stator inner radius, $r$ is the radius of the rotor. The convective heat transfer coefficient for rotor-air gap and stator-air gap are assumed to be equal and given as $h_{a}$. The axial convective heat transfer coefficient between rotor and ambient is given as $h_{r}$. The conductivities in axial and radial directions are assumed to be the same and given as $k_{r o}$ for the rotor and $k_{s t}$ for the stator.

The heat transfer equations for each node in the network are written and formed in matrix form (see Eq. 5.17). Then the temperatures $T_{a i r}, T_{s}$ and $T_{r}$ are obtained. 



\section{Appendix $\mathrm{C}$}

\section{Dimensions of the Extra Bracket}
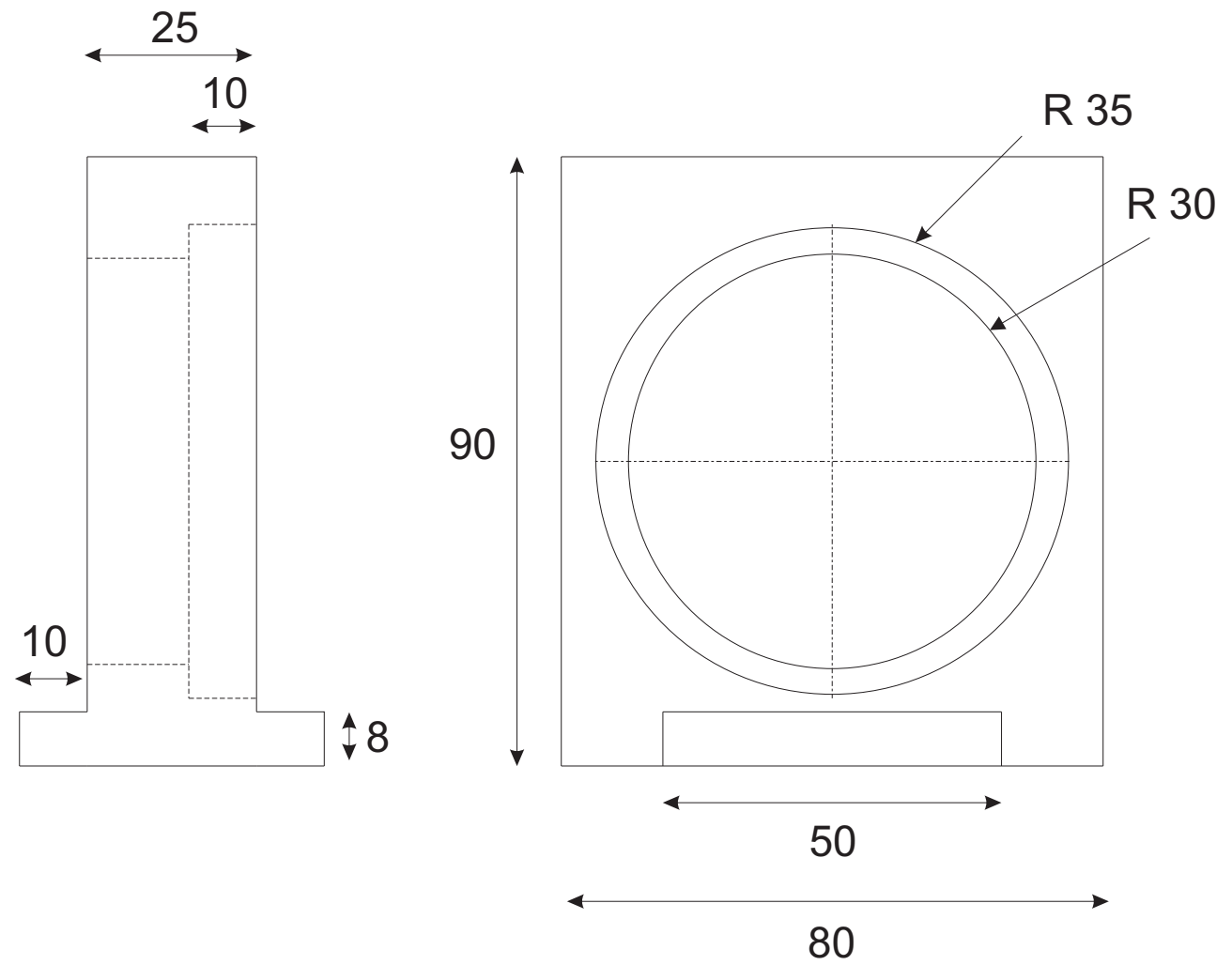

Figure C.1: The dimensions of the extra support in $\mathrm{mm}$ 



\section{Research Deliverables}

\section{Journal Papers}

E. Dikmen, P. van der Hoogt, A. de Boer, and R. Aarts. Influence of multiphysical effects on the dynamics of high speed mini rotors, part 1: Theory. Journal of Vibration and Acoustics, 132, 2010.

E. Dikmen, P. van der Hoogt, A. de Boer, and R. Aarts. Influence of multiphysical effects on the dynamics of high speed mini rotors, part 2: Results. Journal of Vibration and Acoustics, 132, 2010.

E. Dikmen, P. van der Hoogt, A. de Boer, B. Jonker and R. Aarts. Design of an Experimental Setup for Testing Multiphysical Effects on High Speed Mini Rotors, Journal of Mechanical Design, (accepted).

E. Dikmen, P. van der Hoogt, A. de Boer, B. Jonker and R. Aarts. Flow Induced Instability on High Speed Mini Rotors in Laminar Flow., Journal of Vibration and Acoustics, (in review).

\section{Conference Papers}

E. Dikmen, P. van der Hoogt, and R. Aarts. Modeling of high speed micro rotors in moderate flow confinement. International Conference on Noise and Vibration Engineering, ISMA, 2008.

E. Dikmen, P. van der Hoogt, A. de Boer, and R. Aarts. Thermal modeling of a mini rotor-stator system. ASME 2009 International Mechanical Engineering Congress, Exposition, 2009.

E. Dikmen, P. van der Hoogt, A. de Boer, and R. Aarts. A Flexible Rotor on Flexible Supports: Modeling and Experiments. ASME 2009 International Mechanical Engineering Congress, Exposition, 2009. 



\section{Bibliography}

[1] O. Aglen and A. Andersson. Thermal analysis of a high-speed generator. In IEEE IAS, pages 547-554, 2003.

[2] L. San Andrés. Modern lubrication theory-lecture notes. Texas A \& M University, 2008 .

[3] J. Antunes, F. Axisa, and T. Grunenwald. Dynamics of rotors immersed in eccentric annular flow: Part [1]: Theory. Journal of Fluids and Structures, 10:897-918, 1996.

[4] J. Antunes, F. Axisa, and F. Hareux. Flexural vibrations of rotors immersed in dense fluids part 2: Experiments. Journal of Fluids and Structures, 6:23-38, 1992.

[5] J. Antunes, J. Mendes, and M. Moreira. A theoretical model for nonlinear planar motions of rotors under fluid confinement. Journal of Fluids and Structures, 13:103-126, 1999.

[6] J. Archer. Consistent matrix formulations for structural analysis using finite element techniques. AIAA Journal, 3:1910-1918, 1965.

[7] M. Athavale, R.C. Hendricks, and B. M. Steinetz. Numerical simulation of flow in a whirling annular seal and comparison with experiments. Technical report, National Aeronautics and Space Administration, 1995.

[8] M. Athavale and A. Przekwas. A CFD code for analysis of fluid dynamic forces in seals. Technical report, CFD Research Corporation, 1995.

[9] F. Axisa and J. Antunes. Flexural vibrations of rotors immersed in dense fluids, part 1: theory. Journal of Fluids and Structures, 6:3-21, 1992.

[10] K.M. Becker and J. Kaye. Measurements of diabatic flow in an annulus with an inner rotating cylinder. Journal of Heat Transfer, 2:97-105, 1962.

[11] J. R. Bell and S. J. Rothberg. Rotational vibration measurements using laser doppler vibrometry: Comprehensive theory and practical application. Journal of Sound and Vibration, 238:673-690, 2000. 
[12] E. Bilgen and R. Boulos. Functional dependence of torque coefficient of coaxial cylinders on gap width and reynolds numbers. Journal of Fluids Engineering, 95:122-126, 1973.

[13] B. Bolund, H. Bernhoff, and M. Leijon. Flywheel energy and power storage systems. Renewable and Sustainable Energy Reviews, 11:235-258, 2007.

[14] C. Brennen. Hydrodynamics of pumps. Concepts ETI, 1994.

[15] D. Childs. Turbomachinery rotordynamics: phenomena, modeling, and analysis. John Wiley and Sons, 1993.

[16] B. L. Choi and J. M. Park. An improved rotor model with equivalent dynamic effects of the support structure. Journal of Sound and Vibration, 244:569-581, 2001 .

[17] Y. Chun, W. Keyin, and W. Xiaonian. Coupled-field thermal analysis of highspeed permanent magnetic generator applied in micro-turbine generator. In Eighth International Conference on Electrical Machines and Systems, pages 2458-2461, 2005.

[18] E. Dikmen, P. van der Hoogt, A. de Boer, and R. Aarts. Thermal modeling of a mini rotor-stator system. In ASME 2009 International Mechanical Engineering Congress, Exposition, 2009.

[19] E. Dikmen, P. van der Hoogt, A. de Boer, and R. Aarts. Influence of multiphysical effects on the dynamics of high speed mini rotors, part 2: Results. Journal of Vibration and Acoustics, 132, 2010.

[20] J. K. Dutt and B. C. Nakra. Stability of rotor systems with viscoelastic supports. Journal of Sound and Vibration, 153:89-96, 1992.

[21] J. K. Dutt and B. C. Nakra. Stability characteristics of rotating systems with journal bearings on viscoelastic support. Mech. Mach. Theory, 31:771-779, 1996.

[22] F. F. Ehrich. Handbook of Rotordynamics. McGraw-Hill, 1992.

[23] F. F. Ehrich and S. A. Jacobson. Development of high-speed gas bearings for high-power density microdevices. Journal of Engineering for Gas Turbines and Power, 125:141-148, 2003.

[24] A. Epstein. Millimeter-scale, micro electro-mechanical systems gas turbine engines. Journal of Engineering for Gas Turbines and Power, 126:205-226, 2004.

[25] A. Epstein, C.J. Teo, and Z. S. Spakovszky. Hydrostatic gas journal bearings for micro-turbomachinery. Journal of Vibration and Acoustics, 127:157-164, 2005.

[26] A.H. Epstein, S. Senturia, G. Anathasuresh, A. Ayon, K. Breuer, K.S. Chen, F.E. Ehrich, G. Gauba, R. Ghodssi, C. Groshenry, S. Jacobson, J.H. Lang, C.C. Lin, A. Mehra, J.M. Miranda, S. Nagle, D.J. Orr, E. Piekos E., M.A. Schmidt, 
G. Shirley, M.S. Spearing, C.S. Tan, Y.S. Tzeng, and I.A. Waitz. Power mems and microengines. In International Conference on Solid State Sensors and Actuators, pages 754-756, 1997.

[27] D. Ewins. Modal Testing. Research Studies Press, 2000.

[28] R. W. Fox, P. J. Pritchard, and A.T. McDonald. Introduction to Fluid Mechanics. John Wiley \& Sons, 2009.

[29] L. G. Fréchette, S.A. Jacobson, K.S. Breuer, F. Ehrich, R. Ghodssi, R. Khanna, C.H. Wong, X. Zhang, M.A. Schmidt, and A. Epstein. Highspeed microfabricated silicon turbomachinery and fluid film bearings. Journal of Microelectromechanical Systems, 14:141-152, 2005.

[30] R.J. Fritz. The effects of an annular fluid on the vibrations of a long rotor, part 1: Theory. Journal of Basic Engineering, 92:923-929, 1970.

[31] G. Genta. Consistent matrices in rotor dynamics. Meccanica, 20:235-248, 1985.

[32] G. Genta. Dynamics of Rotating Systems. Springer, 2005.

[33] N. Gil-Negrete, J. Vinolas, and L. Kari. A simplified methodology to predict the dynamic stiffness of carbon-black filled rubber isolators using a finite element code. Journal of Sound and Vibration, 296:757-776, 2006.

[34] GMN@. GMN Ball Bearings, 2008.

[35] T. Grunenwald. Comportement vibratoires d'arbres de machines tournantes dans un espace annulaire de fluide de confinement de modéré. PhD thesis, Paris University, 1994.

[36] T. Grunenwald, F. Axisa, and J. Antunes. Rotor vibration under fluid confinement: Analysis of dissipative phenomena and stability. In Eighth World Congress on the Theory of Machines and Mechanisms, pages 21-26, 1991.

[37] T. Grunenwald, F. Axisa, G. Bennett, and J. Antunes. Dynamics of rotors immersed in eccentric annular flow: Part [2]: Experiments. Journal of Fluids and Structures, 10:919-944, 1996.

[38] R.C. Hendricks, A. Przekwas, L.T. Tam, A. Muszynska, M. J. Braun, and R. J. Mullen. Numerical modeling of multidimensional flow in seals and bearings used in rotating machinery. Technical report, National Aeronautics and Space Administration, 1988.

[39] G. G. Hirs. A bulk-flow theory for turbulence in lubricant films. ASME Journal of Lubrication Technology, 95:137-146, 1973.

[40] K. Isomura, S. Tanaka, S. Togo, and M. Esashi. Development of high-speed micro-gas bearings for three-dimensional micro-turbo machines. Journal of Micromechanics and Microengineering, 15:222-227, 2005. 
[41] K. Isomura, S. Tanaka, S. Togo, H. Kanebako, M. Murayama, M. Saji, F. Sato, and M. Esashi. Development of micromachine gas turbine for portable power generation. JSME International Journal Series B, 43:459-464, 2004.

[42] H. Jeffcott. The lateral vibration of loaded shafts in the neighborhood of a whirling speed-the effect of want of balance. Phil. Mag., 37:304-314, 1919.

[43] R. G. Kirk and E. J. Gunter. Stability and transient motion of a plain journal mounted in flexible damped supports. Journal of Engineering for Industry, 98:576-592, 1976.

[44] F. Kreith. Convection heat transfer in rotating systems. Advances in Heat Transfer, 5:129-246, 1968.

[45] W. Kuindersma. Dynamics of viscoelastically damped high speed micro rotors. Master's thesis, University of Twente, 2010.

[46] G. Kylander. Thermal modeling of small cage induction motors. PhD thesis, Chalmers University of Technology, 1995.

[47] R. S. Lakes. Viscoelastic Solids. CRC Press, 1998.

[48] E. Lee. A micro hts renewable energy/attitude control system for micro/nano satellites. IEEE Transactions on applied superconductivity, 3:2263-2266, 2003.

[49] E. Lee. Microsatellite combined attitude/energy systems magazine. IEEE A $\&$ E Systems, 19:27-32, 2004.

[50] Y. Lee, D. Park, C. Kim, and R. Keun. Rotordynamic characteristics of a micro turbo generator supported by air foil bearings. Journal of Micromechanics and Microengineering, 17:297-303, 2007.

[51] R.M. Lin and W.J. Wang. Millimeter-scale, micro electro-mechanical systems gas turbine engines. Mechanical Systems and Signal Processing, 20:1015-1043, 2006 .

[52] J. W. Lund. The stability of an elastic rotor in journal bearing with flexible damped supports. Journal of Applied Mechanics, 32:911-922, 1965.

[53] MATLAB®. Release 7.6 (R2008a), MATLAB Documentation, 2008.

[54] P.H. Mellor, D. Roberts, and D.R. Turner. Lumped parameter thermal model for electrical machines of tefc design. IEE Proceedings-B, 138:205-218, 1991.

[55] G. Meng, M. W. Zhang, H. Huang, H.G. Li, and D. Chen. Micro-rotor dynamics for micro-electro-mechanical systems (MEMS). Chaos, Solitons and Fractals, 40:538-562, 2009.

[56] A. Muszynska. Rotordynamics. CRC Taylor \& Francis, 2005. 
[57] B. C. Nakra. Vibration control in machines and structures using viscoelastic damping. Journal of Sound and Vibration, 221:449-465, 1998.

[58] B. C. Nakra and K. Tonder. The influence of viscoelastically supported bearings on the dynamic response of a rotor. In EUROTRIB, pages 446-451, 1989.

[59] S. W. Park. Analytical modeling of viscoelastic dampers for structural and vibration control. International Journal of Solids and Structures, 38:8065-8092, 2001 .

[60] J. Peirs. Micro power generation based on micro gas turbines: a challenge. In MST News, pages 37-39, 2005.

[61] J. Peirs, D. Reynaerts, and F. Verplaetsen. Development of an axial microturbine for a portable gas turbine generator. Journal of Micromechanics and Microengineering, 13:190-195, 2003.

[62] J. Peirs, D. Reynaerts, and F. Verplaetsen. A microturbine for electric power generation. Sensors and Actuators A, 113:86-93, 2004.

[63] J. Peirs, D. Reynaerts, F. Verplaetsen, F. Norman, and S. Levefer. Development of a micro gas turbine for electric power generation. In MicroMechanics Europe Workshop, pages 215-218, 2003.

[64] I.J. Perez and J.G. Kassakian. A stationary thermal model for smooth air-gap rotating electric machines. Electric Machines and Electromechanics, 3:285-303, 1979.

[65] S. J. Rothberg and N. A. Halliwell. Vibration measurements on rotating machinery using laser doppler velocimetry. Journal of Vibration and Acoustics, 116:326-331, 1994.

[66] J. Saari. Thermal modeling of high-speed induction machines. Acta Polytechnica Scandinavica, 1995.

[67] J. Saari. Friction losses and heat transfer in high-speed electrical machines: A literature review. Technical report, Helsinki University of Technology, 1996.

[68] J. Saari. Thermal analysis of high-speed induction machines. PhD thesis, Helsinki University of Technology, 1998.

[69] L. San Andrés. Hybrid flexure pivot-tilting pad gas bearings: Analysis and experimental validation. Journal of Tribology, 128:551-558, 2006.

[70] L. San Andrés and O. Deborah. Comparison of rotordynamic analysis predictions with the test response of simple gas hybrid bearings for oil free turbomachinery. Journal of Engineering for Gas Turbines and Power, 128:634-643, 2006.

[71] S. Senturia. Simulation and design of microsystems: a 10 year perspective. Sensors and Actuators A, 67:1-7, 1998. 
[72] J. J. Sinou, C. Villa, and F. Thouverez. Experimental and numerical investigations of a flexible rotor on flexible bearing supports. International Journal of Rotating Machinery, 3:179-189, 2005.

[73] T. Staubli and M. Bissig. Numerically calculated rotor dynamic coefficients of a pump rotor side space. In International Symposium on Stability Control of Rotating Machinery, 2001.

[74] R. W. Stephenson and K.E. Rouch. Generating matrices of the foundation structure of a rotor system from test data. Journal of Sound and Vibration, 3:467-484, 1992.

[75] T.H. Sung, J.S. Lee S.C. Han, and N.H. Jeong. Designs and analyses of flywheel energy storage systems using high-tc superconductor bearings. Cryogenics, 42:357-362, 2002.

[76] T. Theodorsen and A. Regier. Experiments of drag of revolving disks, cylinders, and streamline rods at high speeds. Technical report, National Advisory Committee for Aeronautics (NACA), 1944.

[77] H. Tillema. Noise reduction of rotating machinery by viscoelastic bearing supports. PhD thesis, University of Twente, 2003.

[78] A. K. Van der Vegt. Polymeren-Van keten tot kunststof. Delft University Press, 2003.

[79] J. M. Vance. Rotordynamics of Turbomachinery. John Wiley \& Sons, 1988.

[80] R. Varatharajoo and S. Fasoulas. Methodology for the development of combined energy and attitude control systems for satellites. Aerospace Science and Technology, 6:303-311, 2002.

[81] J. Vazquez. Using Transfer Functions to Model Flexible Supports and Casings of Rotating Machinery. PhD thesis, University of Virginia, 1999.

[82] J. A. Vazquez and L. E. Barrett. Transfer function representation of flexible supports and casings of rotating machinery. In 17th IMAC Conference, 1999.

[83] J. A. Vazquez, L. E. Barrett, and R. D. Flack. A flexible rotor on flexible bearing supports: Stability and unbalance response. Journal of Vibration and Acoustics, 123:137-144, 2001.

[84] J. A. Vazquez, L. E. Barrett, and R. D. Flack. Including the effects of flexible bearing supports in rotating machinery. International Journal of Rotating Machinery, 7:223-236, 2001.

[85] J. A. Vazquez, L. E. Barrett, and R. D. Flack. Flexible bearing supports, using experimental data. Journal of Engineering for Gas Turbines and Power, 124:369$374,2002$. 
[86] P. Vleugels, T. Waumans, and J. Peirs. High-speed bearings for micro gas turbines: stability analysis of foil bearings. Journal of Micromechanics and Microengineering, 16:282-289, 2006.

[87] F. Wendt. Turbulente stromungen zwischen zwei rotierenden koaxialen zylindern. Ingenieur Archiv, 4:577-595, 1933.

[88] C.H. Wong, X. Zhang, and A. Epstein. A self-acting gas thrust bearing for highspeed microrotors. Journal of Micromechanics and Microengineering, 13:158$164,2004$.

[89] Y. Yamada. Resistance of a flow through an annulus with an inner rotating cylinder. Bulletin of JSME, 5:302-310, 1962.

[90] J. Zhang and C. M. Richards. Dynamic analysis and parameter identification of a single mass elastomeric isolation system using a Maxwell-Voigt model. Journal of Vibration and Acoustics, 128:713-721, 2006.

[91] C. Zwyssig and J.W. Kolar. Design considerations and experimental results of a $100 \mathrm{w}, 500000 \mathrm{rpm}$ electrical generator. Journal of Micromechanics and Microengineering, 16:297-302, 2006.

[92] C. Zwyssig, J.W. Kolar, and S.D. Round. Analytical and experimental investigation of a low torque, ultra-high speed drive system. In IEEE IAS, pages 1507-1513, 2006.

[93] C. Zwyssig, J.W. Kolar, W. Thaler, and M. Vohrer. Design of a $100 \mathrm{w}, 500$ $000 \mathrm{rpm}$ permanent-magnet generator for mesoscale gas turbines. In IEEE IAS, pages 253-260, 2005. 